Discussion Paper No. 12-055

\title{
The EU Decarbonisation Roadmap 2050 What Way to Walk?
}

Michael Hübler and Andreas Löschel

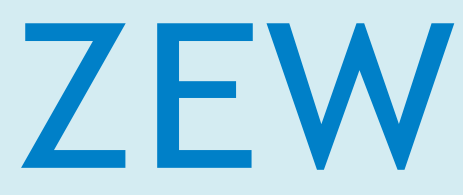

Zentrum für Europäische Wirtschaftsforschung $\mathrm{GmbH}$ Centre for European Economic Research 
Discussion Paper No. 12-055

\title{
The EU Decarbonisation Roadmap 2050 What Way to Walk?
}

\author{
Michael Hübler and Andreas Löschel
}

Download this ZEW Discussion Paper from our ftp server:

http://ftp.zew.de/pub/zew-docs/dp/dp12055.pdf

Die Discussion Papers dienen einer möglichst schnellen Verbreitung von neueren Forschungsarbeiten des ZEW. Die Beiträge liegen in alleiniger Verantwortung der Autoren und stellen nicht notwendigerweise die Meinung des ZEW dar.

Discussion Papers are intended to make results of ZEW research promptly available to other economists in order to encourage discussion and suggestions for revisions. The authors are solely responsible for the contents which do not necessarily represent the opinion of the ZEW. 


\section{Non-technical Summary}

The objective of this study is the economic analysis of the Decarbonisation Roadmap 2050, recently published by the EU Commission. The Decarbonisation Roadmap is the latest strategy to make the decarbonisation of the EU reality. It aims at a reduction in greenhouse gas emissions of more than $80 \%$ in 2050 vis-à-vis 1990 and an expansion of renewable energies to $50 \%$ or more in electricity generation in 2050. Since there is a lack in detailed economic analysis of this latest EU climate strategy so far, our study aims at shedding more light on it at the sectoral and the macro level. Compared to the EU Roadmap simulations, we examine especially welfare effects, carbon leakage and terms of trade on the macro level, and output, investment, emissions and competitiveness on the sectoral level.

For this purpose, our study significantly extends the Computable General Equilibrium (CGE) model PACE (Policy Analysis based on Computable Equilibrium) developed at ZEW Mannheim: The model combines an extended sectoral disaggregation (beyond GTAP 7, Global Trade Analysis Project) with a bottom-up representation of technologies for electricity generation. It represents current EU climate policies as well as Copenhagen Pledges for 2020 in a new reference scenario and extends the time horizon of the model from 2020 to 2050. The recursive-dynamic model is recalibrated in dynamic terms using data from the European Commission and the U.S. Energy Information Administration. We study one Reference scenario and six policy scenarios implementing the Roadmap emissions targets (Fragmented Action; Fragmented Action with sustained free allocation of allowances; Fragmented Action with extended future use of the Clean Development Mechanism, CDM; Global Action, Global Action with equalisation of the $\mathrm{CO} 2$ price within the EU; Global Action with global equalisation of the $\mathrm{CO} 2$ price) and discuss and compare the results. Herein, we contribute to the literature on EU climate policy analyses with the help of CGE models and to the literature of longterm integrated assessment studies as well.

The simulation of the Fragmented Action scenario yields the following key results: The costs for the EU-27 induced by the Decarbonisation Roadmap could stay below $0.3 \%$ until 2020 and below $2 \%$ until 2035 in terms of consumption losses (or welfare effects). They might increase to $3 \%$ thereafter and possibly increase significantly in later periods in the absence of breakthrough technologies. The international carbon leakage rate might reach up to $20 \%$, presumably mainly through the fossil fuel price channel. Moreover, the changes in the output value of industry sectors could substantially differ in a range of around $+1 \%$ to $-15 \%$ in the 2040 s.

The simulations of the other policy scenarios show that an extensive future use of CDM would have strong positive welfare effects on the EU and could widely disburden the EU from the additional costs of the Decarbonisation Roadmap. (Herein, we understand CDM in the sense of 'where'flexibility, this means the reduction of emissions where it is cheapest, such as in developing countries, not in the sense of a project-based mechanism associated with technology transfer.) CDM would not solve the global climate problem, though. A sustained allocation of free allowances (benchmarking) to leakage sectors, on the contrary, would slightly increase overall costs. Global climate action would improve the terms of trade in favour of the EU. Without international emissions trading, it would have limited positive welfare effects on the EU, though. However, the equalisation of the $\mathrm{CO}_{2}$ price across EU ETS and non-ETS sectors would significantly reduce the mitigation costs (under global action). Additionally allowing for international emissions trading (under global action) 
might disburden the EU from the additional costs of the Roadmap until 2040; and in the 2040s the mitigation costs for the EU could fall to less than $1.5 \%$.

At the sectoral level, CDM could increase the output of all EU sectors compared to pure fragmented action, sustained free allocation of allowances could increase the output of most ETS sectors, and global climate action without international emissions trading would have diverse sectoral effects. When the carbon price were equalised across sectors and across regions via international emissions trading, global climate action would benefit most EU sectors. Climate policy induced changes in investment, emissions and competitiveness could have even more diverse sectoral patterns than the output effects under the different climate policy scenarios mentioned above.

We also discuss a number of uncertainties and limitations that numerical economic analyses in general face. Some of the most important uncertainties are future economic growth (against the backdrop of the current economic turbulences in the EU and the USA and political upheavals in middle-East and North African countries), technical progress (in general and regarding energy efficiency and energy generation technologies in particular) and elasticities of substitution and price elasticities (that govern, for example, the possibility to replace fossil fuel inputs in production and in electricity generation). These uncertainties strongly increase when extending the time horizon of the analysis. In this sense, our estimations for the final periods with high emissions cuts are subject to the highest uncertainties.

We conclude that the successful implementation of the EU Decarbonisation Roadmap probably requires a wise and joint consideration of technology, policy design and sectoral aspects. These three aspects are closely interlinked. For example, technological solutions are necessary to achieve ambitious emissions targets at acceptable costs from a global perspective. An appropriate climate policy design is necessary to transfer the benefits from climate policy to the EU macro level and further to the sectoral level. Sector- or firm-specific strategies in correspondence with macro policies can be helpful for avoiding structural and technological lock-in effects and reducing costs in energyintensive sectors. However, the avoidance of severe climate change damages requires global action. In this sense, as a feasible option, climate policy could make use of CDM in (smaller) countries that are not part of the climate coalition, while the main emitters were within the climate coalition; and climate policy would make use of international emissions trading as well as emissions trading across all sectors within the EU and elsewhere to avoid the additional costs of the EU Decarbonisation Roadmap to a large extent. 


\section{Das Wichtigste in Kürze}

Das Ziel dieser Studie besteht in der ökonomischen Analyse der Dekarbonisierungsstratie 2050 („Roadmap for moving to a low-carbon economy in 2050“) hinsichtlich ihrer Auswirkungen auf die europäische Union (EU-27) - auf der makro- und mikroökonomischen Ebene. Das zugrunde liegende Strategiepapier wurde in 2011 von der EU-Kommission veröffentlicht. Es strebt eine Reduktion der Treibhausgasemissionen von mehr als $80 \%$ in 2050 gegenüber 1990 sowie eine Ausdehnung des Anteils erneuerbarer Energien in der Elektrizitätsgewinnung auf 50\% oder mehr in 2050 an. Verglichen zum Strategiepapier der EU Kommission untersuchen wir unter Anderem Wohlfahrtseffekte, Carbon Leakage (Emissionsanstieg im Ausland durch Emissionsvermeidung in der EU) und Veränderungen der Terms of Trade (Handelsbedingungen) auf der Makroebene sowie Produktion, Investitionen, Emissionen und Wettbewerbsfähigkeit auf der Sektorebene.

Zu diesem Zweck erweitern wir in dieser Studie das Allgemeine Gleichgewichtsmodell (Computable General Equilibrium, CGE, Model) PACE (Policy Analysis based on Computable Equilibrium), das am ZEW Mannheim entwickelt und vielfach erfolgreich eingesetzt wurde. Die verwendete Modellversion verbindet eine hohe sektorale Auflösung (besser als GTAP 7, Global Trade Analysis Project) mit einer technologiebasierten Darstellung des Elektrizitätssektors. Der Zeithorizont des Modells wurde für diese Studie von 2020 auf 2050 erweitert. Die bestehende EU-Klimapolitik bis 2020 und die Kopenhagenziele für 2020 sind dabei im Referenzszenario implementiert. Wir untersuchen in unseren Modellsimulationen sechs Politikszenarien, welche die Dekarbonisierungsstragie umsetzen, mit dem Referenzszenario.

Die Simulation des Szenarios mit fragmentierter Klimapolitik (,EU-Alleingang') liefert die folgenden Ergebnisse: Die Kosten der Dekarbonisierungsstrategie für die EU-27 können bis 2020 unter $0.3 \%$ und bis 2035 unter 2\% des Konsumwerts liegen. Sie könnten danach auf 3\% steigen und gegen 2050 weiter ansteigen, falls keine bahnbrechenden Technologien zum Einsatz kommen. Die Rate des internationalen Carbon Leakage beträgt circa 20\%. Dies wird hauptsächlich dadurch verursacht, dass der Ölpreis aufgrund der EU-Klimapolitik sinkt, so dass andernorts mehr Öl verbraucht wird. Des Weiteren unterscheiden sich die Produktionseinbußen der EU-Industriesektoren deutlich $(-15 \%$ bis $+1 \%$ in 2040).

Die Simulationen der anderen Szenarien zeigen auf der Makroebene, dass sich eine weitreichende zukünftige Nutzung des CDM (Clean Development Mechanism) klar positiv auf die EU auswirkt und die zusätzlichen Kosten der Dekarbonisierungsstrategie sogar wettgemacht werden könnten. Allerdings löst CDM nicht das Klimaproblem, da lediglich die Emissionsvermeidungen dorthin verlagert werden, wo sie billiger zu erreichen sind. Eine über 2027 hinausgehende freie Vergabe von Emissionsrechten an bestimmte energieintensive EU-Produzenten würde dagegen die gesamtwirtschaftlichen Kosten leicht erhöhen. Globale Klimapolitik würde die Terms of Trade für die EU verbessern. Ohne internationalen Emissionshandel wäre die Kostenreduktion für die EU jedoch gering. Die Erweiterung des Emissionshandels auf alle EU-Sektoren sowie die Einführung von internationalem Emissionshandel führen im Rahmen der globalen Klimapolitik zu deutlichen Kostenreduktionen. Erst gegen 2050 würde der internationale $\mathrm{CO}_{2}$-Preis durch die weltweiten ambitionierten Klimaziele ansteigen, so dass die EU nicht mehr die zusätzlichen Kosten der Dekarbonisierungsstrategie durch den Zukauf billiger Zertifikate vermeiden kann. 
Auf sektoraler Ebene würde CDM allen EU-Sektoren zugutekommen. Die freie Vergabe von Emissionsrechten über 2027 hinaus käme den meisten Sektoren im EU-Emissionshandelssystem zugute. Globale Klimapolitik ohne internationalen Emissionshandel würde sich jedoch unterschiedlich auf die EU-Sektoren auswirken. Die Angleichung des CO2-Preises über alle Sektoren und Länder käme den meisten EU-Sektoren zugute. Die durch die Dekarbonisierungsstrategie hervorgerufenen Veränderungen von Investitionen, Emissionen und der Wettbewerbsfähigkeit würden sich noch stärker zwischen den EU-Sektoren unterscheiden als die Produktionsveränderungen.

Wir schlussfolgern, dass eine erfolgreiche Umsetzung der Dekarbonisierungsstrategie bis 2050 eine geschickte, gemeinsame Berücksichtigung von Technologieoptionen (Energieeffizienz und Dekarbonisierung), Politikdesign und sektoralen Charakteristika erfordert. Dabei spielt das Politikdesign (das heißt die Art und Weise, wie ein bestimmtes Klimaziel umgesetzt wird) eine entscheidende Rolle dafür, dass Kostenersparnisse auf EU-Ebene und weiter auf sektoraler Ebene verwirklicht werden können. Da die sektoralen Effekte stark unterschiedlich ausfallen, erscheint es sinnvoll, stärker als bisher über sektorale Auswirkungen von Klimapolitik und sektorale Maßnahmen zu deren Umsetzung nachzudenken. Globale Klimaschutzmaßnahmen erscheinen letztendlich notwendig, um ambitionierte Klimaziele zu erreichen. CDM könnte darüber hinaus im Hinblick auf (kleinere) Länder, die nicht offiziell an der globalen Klimapolitik teilnehmen, zu Kostenreduktionen führen. 


\title{
The EU Decarbonisation Roadmap 2050
}

\author{
What Way to Walk?
}

Michael Hübler and Andreas Löschel

May 2012

\begin{abstract}
:
We carry out a detailed CGE (Computable General Equilibrium) analysis of the EU Decarbonisation Roadmap 2050 on a macroeconomic and on a sectoral level. Herein, we study a Reference scenario that implements existing EU policies as well as 3 unilateral and 3 global climate action scenarios. We identify global climate action with international emissions trading and the ful I equalization of $\mathrm{CO} 2$ prices across all (EU) sectors as a reasonable policy option to avoid additional costs of the Decarbonisation Roadmap to a large extent. This policy option may include CDM (Clean Development Mechanism in the sense of 'where'-flexibility) in an extended form if there are countries without emissions caps. Moreover, we identify diverse sectoral effects in terms of output, investment, emissions and international competitiveness. We conclude that the successful realization of the EU Decarbonisation Roadmap probably requires a wise and joint consideration of technology, policy design and sectoral aspects.
\end{abstract}

Keywords: EU, Decarbonisation Roadmap, Copenhagen Pledges, post Kyoto, energy-intensive sectors, competitiveness, leakage

JEL Classifications: C68, F18, Q43, Q54

Highlights:

- We extend the CGE model PACE until 2050 and include energy technologies.

- We assess the newest EU Decarbonisation Roadmap in six policy scenarios.

- Global action with ETS, and CDM from non-participants, create low(est) costs.

- Mitigation costs can strongly increase at $\mathrm{CO} 2$ reductions around $80 \%$.

- The policy effects vary strongly across EU sectors. 


\section{Introduction}

In 2011 the European Commission presented the 'Roadmap for moving to a low-carbon economy in 2050' (EU, 2011). This Roadmap aims at a reduction of greenhouse gas emissions in the EU-27 by at least $80 \%$ in 2050 vis-à-vis emissions in 1990. Such an effort appears necessary in order to avoid a temperature increase of more than $2^{\circ} \mathrm{C}$ which would create severe climate change hazards. Such an emissions reduction requires the restructuring of the energy system: The share of renewable energies in EU electricity generation is expected to rise from about 15\% in 2005 to $50 \%$ or more in 2050. Renewable energies plus nuclear power and fossil-based energies in combination with carbon capture and storage (CCS) might even cover almost 100\% of electricity generation in 2050 (EU, 2011).

Our study is to our knowledge the first research article on the EU Decarbonisation Roadmap. It is the policy contribution of this study to assess the sectoral effects and the overall costs of decarbonisation given certain policy scenarios. In this respect, this study contributes to the academic literature on EU policy modelling (such as Klepper and Peterson, 2006; Böhringer et al., 2009) by studying the most recent EU climate policy proposal based on an established state-of-the-art CGE (Computable General Equilibrium) model. Herein, this study makes significant technical contributions: First, it provides a high sectoral disaggregation beyond GTAP (Global Trade Analysis Project). This allows us to identify detailed sectoral results that are crucial for the actual implementation of emissions reductions on the industry level. - Many macroeconomic studies, CGE and in particular Integrated Assessment studies with a focus on modelling energy technologies, abstain from modelling sectoral effects. And the original publication by the EU Commission (EU 2011) provides only some selected sectoral results. - Second, we combine the high sectoral resolution with a simplified bottom-up representation of energy sources. This allows us to include renewable targets, the (restricted) use of nuclear power and the reduction of fossil fuel use in electricity generation. The explicit inclusion of renewable energies is important for implementing the 20-20-20 targets as well as the EU Decarbonisation Roadmap 2050 that include an expansion of renewables explicitly. The expansion of renewables can help reduce mitigation costs and is for instance a pillar of the German plan for restructuring the energy system. - Most CGE models abstract from a bottom-up approach. Third, it extends the time horizon of the PACE model from 2020 to 2050 and calibrates a new reference scenario that includes existing EU policies. The extension to 2050 is necessary for the analysis of the EU Roadmap reaching an $80 \%$ reduction in 2050. - Most EU climate policy studies have so far examined the year 2020 which is the target year of the EU 20-20-20 policy. In other words, the new 'EU Roadmap to a Low Carbon Economy' has extended the time horizon of 'official' policy targets applicable to numerical analysis to 2050. - Due to these contributions, our paper refers 
to the Integrated Assessment literature of long-term analyses including different energy technologies (such as the ADAM project, Edenhofer et al., 2010; Leimbach et al., 2010). - Fourth, it focusses on the comparison of different policy designs implementing the same emissions targets. It reveals significant differences in the economic outcomes between the different designs. - The original EU Roadmap 2050 (EU 2011) publication examines different technological and Fragmented versus Global Action assumptions but it does not contrast the various sub-scenarios (extended free allocation of allowances, extended CDM, national or international emissions trading) that we examine. - Against this backdrop, our quantitative results are supposed to be novel and relevant for decision makers in policy and industry as well as for the public.

The newest climate policy developments during and after the COP17 in Durban question the decarbonisation path until 2020 to some extent since countries like the USA and Canada are reluctant to agree on or to keep binding targets. Nonetheless, Durban has given new hope that a global long-term decarbonisation strategy starting in 2020 will be realized. Such a long-term strategy is the focus of our policy assessment. Durban has also confirmed that the EU is going to stay a frontrunner in climate policy and that the Copenhagen Pledges for 2020 will hold. Accordingly, we take both aspects into account in our assessment.

\section{Model}

The quantitative assessment of the EU Decarbonisation Roadmap is carried out with PACE, a multisector, multi-region computable general equilibrium (CGE) model of global production, consumption, trade and energy use. PACE is established in economic research and policy consulting. The following description provides a model overview. A technical description of the CGE model structure is provided by Böhringer and Lange (2005). A recent description including the bottom-up representation of the energy system is provided by Böhringer et al. (2009); for further details see Böhringer and Löschel (2006) and Böhringer and Rutherford (2008).

\subsection{Methodology}

PACE (Policy Analysis based on Computable Equilibrium) is implemented in MPSGE (Mathematical Programming System for General Equilibrium Analysis; Rutherford, 1999), a subsystem of GAMS (General Algebraic Modeling System; Brooke et al. 2010), using PATH (Dirkse and Ferris 1995) for solving the MCP (mixed complementarity problem). 
The model runs until 2050 in five-year steps. (We will only report the results for 2010, 2020, $\ldots$ in order to reduce the amount of reported data. The results for $2015,2025, \ldots$ are available upon request.) It is recursive dynamic, this means it solves for a sequence of market equilibria. These equilibria are endogenously connected via investment. Investment in one period increases the capital stock of the next period. However, capital accumulation is not due to inter-temporal optimization. Capital accumulation follows the Solow-Swan model: The representative consumer saves a certain fraction of income. All savings are invested so that they augment the capital stock which is available in the next period. The resulting capital accumulation is a driver of economic growth besides population growth and technical progress which are both exogenous. In the Business as Usual scenario without climate policy, each period is calibrated to external data that includes technical progress and population growth. While capital accumulation is determined by the Business as Usual calibration, it reacts to policy shocks together with production and consumption. One can expect that the introduction of climate policy reduces production and investment and thus the growth path.

The model consists of a set of numerous equations (in-equalities) that describe the world economy. For each period, there exists a set of prices and quantities that solves the equations. Two classes of conditions characterize the perfectly competitive equilibrium of a general equilibrium model like PACE: zero-profit conditions and market clearing conditions. The validity of these conditions follows directly from the assumptions of profit maximization of firms, utility maximization of consumers, constant returns to scale in production, and homotheticity of consumer preferences. The latter class of conditions determines the price of each output good as the unit cost to produce this good. This cost equals the marginal cost as well as the average cost of production. The key model equations are described in Appendix M.

Each region consists of a microeconomic consumer and a microeconomic producer for each production sector. The consumer chooses a bundle of consumption goods that maximizes her utility given her preferences and her budget. The budget is determined by her income received from selling the primary production factors (labour, capital and fossil-fuels) that she owns. We also assume that each region can obtain a certain amount of emission permits in each period. Final demand of the representative consumer is modelled as a constant elasticity of substitution (CES) composite good which combines an energy aggregate with a non-energy aggregate (analogue to the production structure described below). Substitution patterns within the non-energy aggregate are reflected by a Cobb-Douglas function. The energy aggregate consists of several energy goods combined with a constant elasticity of substitution. 
The producer chooses a bundle of production goods that maximizes his profits given his set of production possibilities. The production possibilities are determined by his technology, which efficiently transfers a certain amount of input goods and production factors into a certain amount of one output good. Herein, the production factors capital and labour are perfectly mobile across sectors within regions while the production factor natural resources is sector-specific. Land is attributed to the production factor capital. The main production function has the following principal CES structure - illustrated in Figure M1 in Appendix M - in each sector: At the top level, non-energy inputs are employed with an aggregate of energy, capital and labour. At the second level, a CES function describes the substitution possibilities between the energy aggregate and the aggregate of labour and capital. At the third level, capital and labour are combined with a constant elasticity of substitution. Moreover, at the third level, the energy aggregate consists of electricity and a fossil fuel input. The latter input is further split into coal, gas and oil associated with different elasticities of substitution and with emission permits in fixed proportions (in the presence of a carbon pricing scheme). The CES specification allows producers to substitute fossil fuel inputs by other inputs as a reaction to an increasing carbon price. The extent of substitution, however, is limited by the choice of the cost minimizing input bundle given the elasticities of substitution. Moreover, each good used in intermediate and final demand corresponds to a CES aggregate of a domestically produced variety and a CES import aggregate of the same variety imported from the other regions (Armington, 1969). The model does not impose a restriction on the trade balance, this means trade surpluses or deficits can change over time or between policy scenarios without economic repercussions.

The tax system includes all types of taxes (production taxes or subsidies, intermediate good taxes, input factor taxes, consumption taxes as well as tariffs). The government collects tax revenues and redistributes them to the representative consumer in a lump-sum way. The use of fossil energy in production requires producers to pay for the released carbon corresponding to the physical carbon content of each fossil fuel input in the presence of a carbon pricing scheme and of auctioning allowances. In case of free allocation of allowances (for example in combination with a benchmarking scheme), producers have to pay in the same way in the first step. In the second step, producers receive a subsidy which compensates them for the bill paid in the first step (compare Jensen and Rasmussen, 2000; Edwards and Hutton, 2001). As a result of this subsidy, the producer expands output which raises the demand for fossil and other inputs. This can in turn drive up the carbon price. The model allows for free trading of allowances without transaction costs across sectors within the EU emissions trading scheme (ETS). The other sectors need to reduce emissions, too, so that the total emissions target of the EU is kept. This is achieved via another emissions trading mechanism in the model, and via a carbon tax in reality. 
Importantly, the model does not take any costs due to climate damages into account. Such costs would include reduced productivity due to yield losses in agriculture, due to heat stress and diseases of workers, for instance. They would also include destruction of capital due to flooding at coasts and large rivers, due to storms and avalanches, and other disasters. The avoidance of these costs of climate change creates a benefit that is not captured in the model. Therefore, in our scenario analysis, different policy scenarios will result in different global emissions and thus regional climate damages, which are not included our numerical policy valuation.

\subsection{Data}

The base year data for 2004 are taken from the GTAP 7 data base (Global Trade Analysis Project; Badri and Walmsley, 2008). Data for the future economic development until 2050 are taken from IEO (2008/2010). IEO (2008/2010) provides very detailed regional data on total and fuel-specific primary energy consumption and carbon emissions given assumptions on the development of GDP, fossil fuel prices and other factors. The data take population growth and technical progress into account. $^{1}$

Substitution elasticities in international trade (so-called Armington elasticities) are based on empirical estimates reported in the GTAP database. The values of sectoral Armington elasticities are reported in Table M1 in Appendix M. Certain CES elasticities of substitution between production factors (capital, labour, energy inputs, non-energy inputs) are taken from Okagawa and Ban (2008) based on recent sectoral panel data estimates for the period 1995 to $2004 .^{2}$ The values of the sector dependent elasticities corresponding to the production structure in Figure M1 are also reported in Table M1. A higher elasticity number denotes a better possibility to substitute inputs for each other due to price changes. An elasticity number of zero denotes a Leontief relationship without substitution possibilities; this means all inputs are used in fixed proportions.

\subsection{Aggregation}

The model version applied here partitions the world into 13 regions:

\footnotetext{
${ }^{1}$ Technical progress involves crucial uncertainties in all existing numerical models.

${ }^{2}$ Negative estimates in the original dataset are replaced. - Despite using such estimates, the choice of elasticities - such as the elasticities of substitution in the production function and the elasticities of electricity supply for different energy sources - involves crucial uncertainties in all existing numerical models.
} 
- EUR European Union 27

- USA United States of America

- CAN Canada

- MeX Mexico

- ANZ Australia and New Zealand

- BRA Brazil

- RUS Russia

- CHN China

- IND India

- JPN Japan

- SIM South Korea, Indonesia and Malaysia

- RAX Rest of Annex-I (Switzerland, Norway, Iceland, Ukraine, Belarus etc.)

- ROW Rest of the World (mainly developing countries)

It distinguishes 24 production sectors that include seven disaggregated energy intensive sectors (FER, ORG, INO, CEM, BRT, ISP and ALU) ${ }^{3}$ beyond the sectors in the GTAP 7 data base as an extended feature based on Löschel et al. (2009):

- CRU Crude oil

- OIL Refined oil and coal products

- GAS Natural gas

- COL Coal

- MIN Mining and construction

- FAW Food, agriculture and wood

- PPP Paper, pulp and printing

- FER Fertilizers

- ORG Organic chemicals

- INO Inorganic chemicals

- OCR Other chemicals

- CEM Cement

- BRT Bricks and tiles

- ISM Manufacturing of iron and steel

- ISP Further processing of iron and steel

- ALU Aluminium

- ONF Other non-ferrous metals

- ONM Other non-metallic minerals

- $\mathrm{MCH}$ Machinery and other manufacturing

- ELE Electricity and heat

- TRN Transport

- TWL Textiles, wearing, apparel and leather

- SER Services

- CGD Investment good composite

The additional energy intensive sectors are added to the GTAP 7 database by means of the Splitcom routines (Horridge, 2005). Based on additionally collected data from diverse sources (Eurostat, 20094;

\footnotetext{
${ }^{3}$ ONF, ONM, ISM and PPP are other energy intensive sectors.

${ }^{4}$ Eurostat Structural Business Statistics (SBS) for production values and purchases of energy products, and Eurostat External Trade for import and export values.
} 
UN, 2009a, b), Splitcom disaggregates all relevant values of the underlying GTAP 7 database - such as production, trade, primary and intermediate inputs and final use - at the sectoral level for all model regions and balances the extended GTAP 7 database with the newly added sectors. The sector split is performed by using information on the relative size of the disaggregated sectors in production, international trade, energy consumption (electricity and fuel use) and final consumption. It is a particular problem of the simultaneous application of the data sources for the sectoral disaggregation that these databases are built upon alternative industrial classification systems. Hence, the sectoral disaggregation is carried out by establishing a concordance scheme linking the GTAP 7 sectors and the sectors in the respective classification schemes. Based on these additional data, the production shares, the energy consumption shares as well as the export and import shares are calculated for all relevant subsectors and sectors for all model regions. For the EU-27, all required data are available. Production and trade data are also available for almost all model regions outside the EU-27. For other (small) non-EU regions for which there are no data available, the respective sectoral structure is estimated in a reasonable way based on geographic proximity.

As another advanced feature beyond GTAP 7, the model distinguishes five energy sources (energy technologies) for electricity generation in the EU, based on Böhringer and Rutherford (2008):

- COL Coal 31

- GAS Natural gas 20

- OIL Refined oil and coal ${ }^{5} \quad 3$

- NUC Nuclear 31

- REN Renewable energies 15

The numbers indicate the percentage shares in total electricity generation for the benchmark year 2004/2005 in the EU-27 in accordance with EU (2007). Renewables encompass those energies that were in use in 2005 such as solar-thermal, photovoltaic, biomass - given the state of technology in this year. This means, our model does not take technological progress and breakthrough technologies into account. The energy sources are associated with a fixed factor via a certain elasticity of substitution which rises from 0.1 in 2005 to one in 2050. This represents an increasing possibility of expanding energy technologies in the long-run while there are stronger limitations in the short-run. Energy technologies are represented by Leontief production functions that can be active or inactive depending on their profitability. Each technology uses general and electricityspecific intermediate inputs and, if necessary, fossil fuels as inputs and produces electricity as the output. Herein, the inputs create costs as in any other sectoral production function. And every energy technology is calibrated to benchmark year data like other sectoral production functions. As a

\footnotetext{
${ }^{5}$ Rarely used for electricity generation.
} 
result, we gain an endogenous development of the energy mix over time. Herein, nuclear power is an exception since the elasticity is reduced so that the output of nuclear power (in absolute numbers) rises only by $20 \%$ between 2005 and 2045 . Alternatively, target shares of energy technologies, e.g. in form of 'green quotas' can be set.

\section{Scenarios}

This section describes the new, detailed scenarios (also see Table S1): (1) The calibration of the new Reference scenario that implements current policies, and the design of the policy scenarios based on EU (2009a, 2011): (2) Fragmented Action, i.e. bilateral ambitious EU climate policy efforts, (3) Fragmented Action Free, i.e. the extended free allocation of allowances to EU ETS sectors, (4) Fragmented Action CDM, i.e. the extended future use of the Clean Development Mechanism, (5) Global Action, i.e. global ambitious climate action, (6) Global Action National, i.e. the equalization of CO2 prices across EU ETS and non-ETS sectors, and (7) Global Action International, i.e. the equalization of $\mathrm{CO} 2$ price across all regions and all sectors.

Emissions targets and other economic indicators as summarized in Table 1 are given by EU (2011) for each time period. They stem from other exemplary (cost minimizing) scenario simulations and do not represent optimal time paths in the sense of (socially) optimal growth. Monetary values are always expressed in $€$ (2005-Euros). The choice of our policy scenarios under scrutiny has two reasons:

First, the three main scenario categories, Reference, Fragmented Action, and Global Action, follow the scenario setup in EU (2011). The distinction between Fragmented and Global Action is in particular relevant because currently the EU is a front runner in climate policy and it is sometimes argued that such a 'fragmented' approach does not have any significant impact on global warming. We ought to strive for a 'global' approach instead. Others argue that giving a good example and being a technological leader in 'green' technologies is nonetheless desirable or inevitable. Although the latter two aspects cannot be captured in our model, it appears helpful for providing policy advice to compare 'fragmented' and 'global' policies with regard to their economic impacts.

Second, from an economic perspective, it appears insightful to quantify the expected efficiency gains stemming from a Clean Development Mechanism and emissions trading across all EU sectors and across countries world-wide. Moreover, from an energy-intensive industry perspective, it appears interesting to quantify the effects of an extended free allocation of allowances. The following tables for the different scenarios will be explained in the subsequent subsections. 


\begin{tabular}{|c|c|c|c|}
\hline & $\begin{array}{c}\text { Emissions } \\
\text { target (2020) } \\
2050 \text { vis-à-vis } \\
1990[\%]\end{array}$ & Policy characteristics in the EU-27 & Policy characteristics abroad \\
\hline 1 Reference & $(-21)-40$ & $\begin{array}{l}\text { Currently implemented \& } \\
\text { agreed policies }\end{array}$ & $\begin{array}{l}\text { Copenhagen Pledges } \\
\text { for } 2020 \text { \& kept constant } \\
\text { thereafter }\end{array}$ \\
\hline $\begin{array}{l}2 \text { Fragmented } \\
\text { Action }\end{array}$ & $(-25)-80$ & EU Roadmap & $\begin{array}{l}\text { Copenhagen Pledges as } \\
\text { above }\end{array}$ \\
\hline $\begin{array}{l}3 \text { Fragmented } \\
\text { Action Free }\end{array}$ & $(-25)-80$ & $\begin{array}{l}\text { EU Roadmap with extended } \\
\text { allocation of free allowances }\end{array}$ & $\begin{array}{l}\text { Copenhagen Pledges as } \\
\text { above }\end{array}$ \\
\hline $\begin{array}{l}4 \text { Fragmented } \\
\text { Action CDM }\end{array}$ & $(-25)-80$ & $\begin{array}{l}\text { EU Roadmap with extended \& } \\
\text { optimistic CDM use }\end{array}$ & $\begin{array}{l}\text { Copenhagen Pledges as } \\
\text { above }\end{array}$ \\
\hline 5 Global Action & $(-25)-80$ & EU Roadmap & $\begin{array}{l}\text { Copenh. Pled. intensified } \\
\text { for all regions } \& \text { up to } \\
80 \% \text { by } 2050 \text { in Annex-I }\end{array}$ \\
\hline $\begin{array}{l}6 \text { Global Action } \\
\text { National }\end{array}$ & $(-25)-80$ & $\begin{array}{l}\text { EU Roadmap \& equalization of } \\
\text { CO2 prices ETS \& non-ETS }\end{array}$ & $\begin{array}{l}\text { Copenhagen Pledges } \\
\text { intensified as above }\end{array}$ \\
\hline $\begin{array}{l}7 \text { Global Action } \\
\text { International }\end{array}$ & $(-25)-80$ & $\begin{array}{l}\text { EU Roadmap \& full inter- } \\
\text { national emissions trading }\end{array}$ & $\begin{array}{l}\text { Copenhagen Pledges } \\
\text { intensified as above }\end{array}$ \\
\hline
\end{tabular}

Table S1: Overview of policy scenarios 


\begin{tabular}{|c|c|c|c|c|c|c|c|c|c|}
\hline & $\begin{array}{l}\text { World } \\
\text { GDP } \\
\text { growth } \\
\text { rate [\%] } \\
\text { en./cal. }\end{array}$ & $\begin{array}{l}\text { EU GDP } \\
\text { growth } \\
\text { rate [\%] } \\
\text { en./cal. }\end{array}$ & $\begin{array}{l}\text { EU coal } \\
\text { consum. } \\
\text { [Mtoe] } \\
\text { en./cal. }\end{array}$ & $\begin{array}{c}\text { EU gas } \\
\text { consum. } \\
\text { [Mtoe] } \\
\text { en./cal. }\end{array}$ & $\begin{array}{c}\text { EU oil } \\
\text { consum. } \\
\text { [Mtoe] } \\
\text { en./cal. }\end{array}$ & $\begin{array}{l}\text { EU elec. } \\
\text { gener. } \\
\text { [TWh] } \\
\text { en./cal. }\end{array}$ & $\begin{array}{l}\text { EU ener- } \\
\text { gy per } \\
\text { GDP int. } \\
\text { [toe/M€] } \\
\text { end. }\end{array}$ & $\begin{array}{c}\text { World } \\
\text { rel. oil } \\
\text { price } \\
{[\%]} \\
\text { en./cal. }\end{array}$ & $\begin{array}{c}\text { EU rel. } \\
\text { electr. } \\
\text { price [\%] } \\
\text { end. }\end{array}$ \\
\hline 2005 & 1.3 & 0.5 & 302 & 355 & 734 & 3033 & 157 & 100 & 100 \\
\hline 2010 & 2.8 & 2.2 & 275 & 384 & 671 & 2993 & 123 & 127 & 109 \\
\hline 2020 & 2.5 & 2.1 & 215 & 339 & 650 & 3194 & 90 & 142 & 108 \\
\hline 2030 & 2.1 & 1.7 & 196 & 367 & 548 & 3559 & 68 & 175 & 108 \\
\hline 2040 & 2.0 & 1.5 & 148 & 330 & 519 & 3529 & 52 & 195 & 108 \\
\hline 2050 & & & 124 & 308 & 507 & 3517 & 42 & 212 & 118 \\
\hline & $\begin{array}{c}\text { EU } \\
\text { renew. } \\
\text { share in } \\
\text { elec. [\%] } \\
\text { en./cal. }\end{array}$ & $\begin{array}{l}\text { World } \\
\text { CO2 em. } \\
\text { vs. } 1990 \\
{[\%]} \\
\text { end. }\end{array}$ & $\begin{array}{c}\text { EU } \\
\text { CO2 em. } \\
\text { vs. } 1990 \\
\text { [\%] } \\
\text { exog. }\end{array}$ & $\begin{array}{c}\text { EU ETS } \\
\text { share in } \\
\text { emis. } \\
\text { [\%] } \\
\text { exog. }\end{array}$ & $\begin{array}{c}\text { EU CO2 } \\
\text { per GDP } \\
\text { intens. } \\
{[\mathrm{g} / €]} \\
\text { en./cal. }\end{array}$ & $\begin{array}{c}\text { EU CO2 } \\
\text { per GDP } \\
\text { growth } \\
\text { rate[\%] } \\
\text { end. }\end{array}$ & $\begin{array}{l}\text { EU ETS } \\
\text { CO2 } \\
\text { price } \\
{[€ / t]} \\
\text { end. }\end{array}$ & $\begin{array}{c}\mathrm{EU} \\
\text { terms of } \\
\text { trade [\% } \\
\left.\mathrm{BAU}_{2005}\right] \\
\text { end. }\end{array}$ & $\begin{array}{c}\text { EU } \\
\text { welfare } \\
\text { (consum.) } \\
\text { [\% BAU] } \\
\text { end. }\end{array}$ \\
\hline 2005 & 15 & 27 & -7 & 56 & 371 & -1.6 & 5 & 100.3 & -0.72 \\
\hline 2010 & 18 & 27 & -12 & 53 & 342 & -2.8 & 9 & 99.9 & -0.26 \\
\hline 2020 & 25 & 44 & -21 & 53 & 247 & -2.3 & 32 & 100.3 & -0.82 \\
\hline 2030 & 28 & 63 & -28 & 55 & 184 & -3.0 & 33 & 100.3 & -1.53 \\
\hline 2040 & 32 & 79 & -36 & 50 & 139 & -2.1 & 51 & 100.4 & -1.42 \\
\hline 2050 & 36 & 97 & -40 & 45 & 113 & & 60 & 100.6 & -1.08 \\
\hline
\end{tabular}

Table 1: Macroeconomic indicators of the Reference scenario ${ }^{6}$

\begin{tabular}{|c|c|c|c|c|c|c|c|c|c|}
\hline & $\begin{array}{l}\text { World } \\
\text { CO2 em. } \\
{\left[\%{ }^{\prime} 90\right]}\end{array}$ & $\begin{array}{l}\text { CO2 } \\
\text { emis. } \\
{[\% ` 90]}\end{array}$ & $\begin{array}{c}\text { CO2/GDP } \\
\text { intensity } \\
{[\mathrm{g} / €]}\end{array}$ & $\begin{array}{l}\text { Renew. } \\
\text { share in } \\
\text { ele. [\%] }\end{array}$ & $\begin{array}{l}\text { Rel. ele. } \\
\text { price } \\
\text { [\%] }\end{array}$ & $\begin{array}{c}\text { ETS CO2 } \\
\text { price } \\
{[€ / t]}\end{array}$ & $\begin{array}{l}\text { Leakage } \\
\text { rate [\% } \\
\text { REF] }\end{array}$ & $\begin{array}{c}\text { Terms o. } \\
\text { trade }[\% \\
\left.\mathrm{BAU}_{05}\right]\end{array}$ & $\begin{array}{l}\text { Welfare } \\
\text { change } \\
{[\% \text { REF] }}\end{array}$ \\
\hline 2005 & 27 & -7 & 371 & 15 & 100 & 5 & 0.0 & 100.3 & 0.00 \\
\hline 2010 & 27 & -12 & 342 & 18 & 105 & 9 & 0.0 & 99.9 & 0.00 \\
\hline 2020 & 43 & -25 & 235 & 26 & 120 & 38 & 17.8 & 100.4 & -0.30 \\
\hline 2030 & 61 & -40 & 154 & 31 & 126 & 50 & 19.9 & 100.6 & -1.24 \\
\hline 2040 & 75 & -62 & 84 & 40 & 147 & 94 & 19.2 & 101.2 & -3.29 \\
\hline 2050 & 90 & -80 & 39 & 51 & 158 & 144 & 19.6 & 102.1 & -5.98 \\
\hline
\end{tabular}

Table 2: Macroeconomic indicators for the EU-27 under the Fragmented Action scenario

\footnotetext{
${ }^{6}$ The results for the years 2015, 2025, 2035 and 2045 are available for all scenarios upon request.
} 


\begin{tabular}{|c|c|c|c|c|c|c|c|c|c|}
\hline & $\begin{array}{l}\text { World } \\
\text { CO2 em. } \\
{[\% \text { '90] }}\end{array}$ & $\begin{array}{l}\text { CO2 } \\
\text { emis. } \\
\text { [\% ‘90] }\end{array}$ & $\begin{array}{c}\text { CO2/GDP } \\
\text { intensity } \\
{[\mathrm{g} / €]}\end{array}$ & $\begin{array}{l}\text { Renew. } \\
\text { share in } \\
\text { ele. [\%] }\end{array}$ & $\begin{array}{c}\text { Rel. ele. } \\
\text { price } \\
{[\%]}\end{array}$ & $\begin{array}{c}\text { ETS CO2 } \\
\text { price } \\
{[€ / t]}\end{array}$ & $\begin{array}{c}\text { Leakage } \\
\text { rate [\% } \\
\text { REF] }\end{array}$ & $\begin{array}{c}\text { Term. of } \\
\text { trade [\% } \\
\left.\mathrm{BAU}_{05}\right]\end{array}$ & $\begin{array}{l}\text { Welfare } \\
\text { change } \\
{[\% \text { REF] }}\end{array}$ \\
\hline 2005 & 27 & -7 & 371 & 15 & 100 & 5 & 0.0 & 100.3 & 0.00 \\
\hline 2010 & 27 & -12 & 342 & 18 & 105 & 9 & 0.0 & 99.9 & 0.00 \\
\hline 2020 & 43 & -25 & 235 & 24 & 120 & 38 & 17.8 & 100.4 & -0.30 \\
\hline 2030 & 61 & -40 & 154 & 29 & 130 & 60 & 17.3 & 100.4 & -1.28 \\
\hline 2040 & 75 & -62 & 84 & 35 & 155 & 111 & 16.6 & 100.9 & -3.50 \\
\hline 2050 & 90 & -80 & 39 & 43 & 167 & 192 & 16.0 & 101.4 & -6.55 \\
\hline
\end{tabular}

Table 3: Macroeconomic indicators for the EU-27 under the Fragmented Action Free scenario

\begin{tabular}{|c|c|c|c|c|c|c|c|c|c|}
\hline & $\begin{array}{c}\text { World } \\
\text { CO2 em. } \\
\text { [\% ' } 90]\end{array}$ & $\begin{array}{c}\text { Rel. CO2 } \\
\text { emissions } \\
\text { [\% ' } 90]\end{array}$ & $\begin{array}{c}\text { CO2/GDP } \\
\text { intensity } \\
{[\mathrm{g} / €]}\end{array}$ & $\begin{array}{l}\text { Renew. } \\
\text { share in } \\
\text { ele. [\%] }\end{array}$ & $\begin{array}{c}\text { Rel. ele. } \\
\text { price } \\
{[\%]}\end{array}$ & $\begin{array}{c}\text { ETS CO2 } \\
\text { price } \\
{[€ / t]}\end{array}$ & $\begin{array}{c}\text { Leakage } \\
\text { rate [\% } \\
\text { REF] }\end{array}$ & $\begin{array}{l}\text { Term. of } \\
\text { trade [\% } \\
\left.\mathrm{BAU}_{2005}\right]\end{array}$ & $\begin{array}{c}\text { Welfare } \\
\text { change } \\
{[\%]}\end{array}$ \\
\hline 2005 & 27 & -3 & 387 & 15 & 100 & 2 & 14.4 & 100.3 & 0.19 \\
\hline 2010 & 28 & -8 & 358 & 18 & 104 & 4 & 18.0 & 99.8 & 0.13 \\
\hline 2020 & 45 & -16 & 263 & 24 & 110 & 16 & 17.3 & 100.3 & 0.06 \\
\hline 2030 & 65 & -16 & 215 & 27 & 115 & 22 & 19.9 & 100.0 & 0.97 \\
\hline 2040 & 80 & -28 & 158 & 30 & 123 & 37 & 18.8 & 100.2 & 0.47 \\
\hline 2050 & 97 & -39 & 117 & 33 & 127 & 48 & - & 100.6 & -0.17 \\
\hline
\end{tabular}

Table 4: Macroeconomic indicators for the EU-27 under the Fragmented Action CDM scenario

\begin{tabular}{|c|c|c|c|c|c|c|c|c|}
\hline & $\begin{array}{l}\text { World } \\
\text { CO2 em. } \\
\text { [\% '90] }\end{array}$ & $\begin{array}{c}\text { CO2 } \\
\text { emis. } \\
{[\% \text { '90] }}\end{array}$ & $\begin{array}{c}\text { CO2/GDP } \\
\text { intensity } \\
{[\mathrm{g} / €]}\end{array}$ & $\begin{array}{l}\text { Renew. } \\
\text { share in } \\
\text { elec. [\%] }\end{array}$ & $\begin{array}{l}\text { Rel. ele. } \\
\text { price } \\
\text { [\%] }\end{array}$ & $\begin{array}{c}\text { ETS CO2 } \\
\text { price } \\
{[€ / t]}\end{array}$ & $\begin{array}{l}\text { Term. of } \\
\text { trade [\% } \\
\left.\mathrm{BAU}_{2005}\right]\end{array}$ & $\begin{array}{l}\text { Welfare } \\
\text { change } \\
{[\% \text { REF] }}\end{array}$ \\
\hline 2005 & 27 & -7 & 371 & 15 & 100 & 5 & 100.3 & 0.00 \\
\hline 2010 & 27 & -12 & 342 & 18 & 105 & 9 & 99.9 & 0.00 \\
\hline 2020 & 43 & -25 & 235 & 26 & 120 & 38 & 100.4 & -0.30 \\
\hline 2030 & 36 & -40 & 154 & 31 & 126 & 54 & 100.7 & -1.20 \\
\hline 2040 & -7 & -62 & 84 & 39 & 146 & 110 & 102.0 & -3.17 \\
\hline 2050 & -52 & -79 & 40 & 51 & 163 & 164 & 104.3 & -5.80 \\
\hline
\end{tabular}

Table 5: Macroeconomic indicators for the EU-27 under the Global Action scenario 


\begin{tabular}{|c|c|c|c|c|c|c|c|c|}
\hline & $\begin{array}{c}\text { World } \\
\text { CO2 em. } \\
\text { [\% '90] }\end{array}$ & $\begin{array}{c}\text { CO2 } \\
\text { emis. } \\
{[\% ` 90]}\end{array}$ & $\begin{array}{c}\text { CO2/GDP } \\
\text { intensity } \\
{[\mathrm{g} / €]}\end{array}$ & $\begin{array}{l}\text { Renew. } \\
\text { share in } \\
\text { elec. [\%] }\end{array}$ & $\begin{array}{l}\text { Rel. ele. } \\
\text { price } \\
{[\%]}\end{array}$ & $\begin{array}{c}\text { ETS CO2 } \\
\text { price } \\
{[€ / t]}\end{array}$ & $\begin{array}{l}\text { Term. of } \\
\text { trade [\% } \\
\left.\mathrm{BAU}_{2005}\right]\end{array}$ & $\begin{array}{c}\text { Welfare } \\
\text { change } \\
{[\%]}\end{array}$ \\
\hline 2005 & 27 & -7 & 370 & 16 & 100 & 25 & 100.3 & 0.38 \\
\hline 2010 & 27 & -12 & 340 & 18 & 100 & 17 & 99.8 & 0.09 \\
\hline 2020 & 44 & -25 & 230 & 28 & 120 & 54 & 100.5 & 0.06 \\
\hline 2030 & 36 & -40 & 150 & 39 & 140 & 99 & 100.4 & 0.04 \\
\hline 2040 & -7 & -62 & 80 & 56 & 171 & 227 & 101.7 & -1.25 \\
\hline 2050 & -51 & -79 & 40 & 59 & 161 & 794 & 104.0 & -3.45 \\
\hline
\end{tabular}

Table 6: Macroeconomic indicators for the EU-27 under the Global Action National scenario

\begin{tabular}{|c|c|c|c|c|c|c|c|c|}
\hline & $\begin{array}{l}\text { World } \\
\text { CO2 em. } \\
{[\% \text { '90] }}\end{array}$ & $\begin{array}{c}\text { CO2 } \\
\text { emis. } \\
{[\% \text { '90] }}\end{array}$ & $\begin{array}{c}\text { CO2/GDP } \\
\text { intensity } \\
{[\mathrm{g} / €]}\end{array}$ & $\begin{array}{l}\text { Renew. } \\
\text { share in } \\
\text { elec. [\%] }\end{array}$ & $\begin{array}{l}\text { Rel. ele. } \\
\text { price } \\
\text { [\%] }\end{array}$ & $\begin{array}{c}\text { ETS CO2 } \\
\text { price } \\
{[€ / \mathrm{t}]}\end{array}$ & $\begin{array}{l}\text { Terms of } \\
\text { trade [\% } \\
\left.\mathrm{BAU}_{2005}\right]\end{array}$ & $\begin{array}{c}\text { Welfare } \\
\text { change } \\
{[\%]}\end{array}$ \\
\hline 2005 & 27 & -7 & 370 & 15 & 100 & 5 & 100.3 & 0.00 \\
\hline 2010 & 27 & -12 & 340 & 18 & 105 & 9 & 99.9 & 0.00 \\
\hline 2020 & 43 & -25 & 240 & 26 & 120 & 38 & 100.4 & -0.30 \\
\hline 2030 & 37 & -1 & 250 & 31 & 109 & 11 & 99.7 & 1.35 \\
\hline 2040 & -7 & -27 & 160 & 39 & 129 & 73 & 100.7 & 0.06 \\
\hline 2050 & -52 & -67 & 60 & 51 & 176 & 362 & 103.5 & -2.73 \\
\hline
\end{tabular}

Table 7: Macroeconomic indicators for the EU-27 under the Global Action International scenario

\subsection{Reference}

The Reference scenario includes existing EU policies, in particular a 20\% reduction of greenhouse gas emissions until 2020 vis-à-vis 1990 levels and an expansion of renewable energies to a share of $20 \%$ in energy consumption and an improvement in energy efficiency. (Herein, the EU 20-20-20 strategy ${ }^{7}$ also aims at a $20 \%$ improvement in energy efficiency vis-à-vis a projected value in 2020. - Reference is in accordance with a $1.74 \%$ p.a. reduction in EU ETS emissions.) Other taxes and subsidies existing in the $\mathrm{EU}$ and the other regions in 2004/2005 are included as well. Moreover, the Reference scenario

\footnotetext{
${ }^{7}$ http://ec.europa.eu/clima/policies/package/index en.htm (accessed 08/2011).
} 
includes the Copenhagen Pledges ${ }^{8}$ for 2020 and assumes that these pledges are kept constant after 2020 - except for the EU-27 which reduces emissions in accordance with the Reference scenario in EU (2011). The Copenhagen Pledges lead to the following rounded emissions changes for the non-EU model regions in 2020 vis-à-vis 1990 in \%: ${ }^{9}$

- USA $\quad-0.5$

- CAN 3.0

- ANZ 5.5

- RUS -15.0

- JPN -25.0

- RAX -17.5

Since we allow for intersectoral permit trade but not for international permit trade, $\mathrm{CO} 2$ prices differ across the model regions that have implemented an emissions pricing scheme and are equal within model regions in all scenarios. Herein, we do not distinguish between ETS and non-ETS sectors except in the EU-27. We rather assume that the emissions targets hold for the whole economies.

In the EU-27, ETS sectors exposed to a significant risk of carbon leakage receive $100 \%$ of benchmark allowances for free. Following the calculations by Graichen et al. (2010), p. 88, the average benchmark shares of free allowances in all allowances for these sectors in $\%$ are: ${ }^{10}$

- OIL 86

- PPP 77

- fer 74

- ORG 63

- INO 63

- CEM 92

- BRT 70

- ISM 91

- ALU 80

These calculations assume that the emissions of the ten most efficient per cent of installations are relevant for determining the amount of free allowances. ${ }^{11}$ This policy is kept until the model year 2025. It is supposed to be removed after 2027 in reality, i.e. there will be no free allowances from model year 2030 on in the Reference scenario. In the other ETS sectors, except the energy sector (ISP, ONM, ONF) the average benchmark share of free allowances in all allowances is assumed to be

\footnotetext{
${ }^{8}$ http://unfccc.int/meetings/cop 15/copenhagen accord/items/5264.php (accessed 08/2011).

${ }^{9}$ Negative values indicate the need for emission reductions below 1990 levels, positive values indicate that emissions can be increased above 1990 levels. Copenhagen intensity targets for China and India are not implemented.

${ }^{10}$ These shares are sectoral averages that can overestimate or underestimate the free allowances for single installations.

${ }^{11} \mathrm{EU}(2009 \mathrm{~b})$, in particular Article (11).
} 
$40 \%$ of emissions in 2005 . The volume of free allowances is reduced to $80 \%$ of this share in 2015 , $30 \%$ in $2020,15 \%$ in 2025 , and $0 \%$ from 2030 onwards. ${ }^{12}$

Table 1 gives an overview of important macroeconomic indicators for the EU-27 and the world under the Reference scenario. The model is calibrated so that the indicators come close to the corresponding reference scenario values given by EU $(2009,2011)$. Therein, EU emissions targets and the distribution of emissions to ETS versus non-ETS sectors are strictly exogenous, denoted by 'exo.' Other indicators - such as the GDP growth rate of the EU-27 - denoted by 'en./cal.' are determined endogenously in the model, but the model has been adjusted in the calibration process so that they come close to the reference data given by EU $(2009,2011)$. The remaining indicators - such as the CO2 price - denoted by 'end.' are strictly endogenous. Global emissions are endogenous in this scenario but exogenous in later periods under Global Action when all model regions are subject to emissions caps. In any case, a comparison with real-world data and with other projections such as EU $(2009,2011)$ shows a good match.

Due to the recent economic turbulences, GDP growth is relatively low between 2005 and 2010, 0.5\% p.a. in the EU-27 and 1.3\% p.a. world-wide. It is assumed to recover thereafter to a rate of more than $2 \%$ p.a. until 2030 and declines after 2030 to around 1.5\% p.a. in the EU-27 and about $2 \%$ p.a. world-wide.

Energy use in the EU is characterized in the following way: Consumption of coal, the energy carrier with the highest carbon intensity in the model, declines drastically - more than in EU (2009a); and oil consumption declines moderately - very similar to EU (2009a). The consumption of gas, the fossil energy carrier with the lowest carbon intensity, rises until 2030 since it is a low-carbon substitute for coal and declines thereafter since renewable energies become more important. - On the contrary, it already declines until 2030 in EU (2009a). Despite sustained economic growth (scale effect), electricity generation rises only slightly over the time horizon - and goes even down in certain periods of time. As a consequence, the EU energy intensity, computed as the sum of the consumption of coal, oil and gas and electricity generation, divided by the value of GDP continuously improves over time - almost by a factor 4 over the whole time horizon. This development of electricity generation and energy consumption is mainly given by the IEO (2008/2010) data. It is driven by efficiency gains due to technical progress (technique effect). It also captures sectoral shifts in production (composition effect). Another driver is the oil price which rises exogenously in the Business as Usual scenario following the time path in EU (2009a, 2011). Nevertheless, the oil price is relaxed in our policy experiments (including the reference scenario). This means, the oil price can

\footnotetext{
${ }^{12} \mathrm{EU}(2009 \mathrm{~b})$, in particular Article (11).
} 
react to policy shocks. This will in particular be important when studying carbon leakage effects in the following sections. We assume that the gas price rises in the analogue way as the oil price, while the coal price stays constant over time. The real electricity price increases endogenously. According to our stylized model results, it will increase by less than 20\% until 2050 vis-à-vis 2005 .

Of course, decarbonisation does not only require a reduction in the energy intensity of GDP, but also in the carbon intensity of GDP. For this purpose, the share of renewable energies in electricity generation rises endogenously to around $27 \%$ in 2020 and $34 \%$ in $2050 .{ }^{13}$ Global emissions arise endogenously determined by emissions caps for the Annex-I regions as described before, and by economic growth in the regions without emissions caps. As a result, global emissions almost double until 2050 vis-à-vis 1990 in this scenario. Herein, all emissions generated by the model cover CO2 emissions only - no other greenhouse gas emissions. EU CO2 emissions decline by about $20 \%$ vis-à-vis 1990 until 2020 and 40\% until 2050. Herein, our model does not consider that other greenhouse gases contribute a 5 to $6 \%$ reduction. ${ }^{14}$ Furthermore, the share of emissions within the EU emissions trading scheme (ETS) of more than $50 \%$ in earlier periods declines in later periods so that relatively more emissions are allowed in non-ETS sectors - following EU (2009a, 2011). The emission intensity (CO2 per GDP) declines to less than one third of the 2005 level until 2050. This development of the emission intensity matches the development that can be calculated from the Reference Scenario in EU (2009a). The resulting growth rate of the carbon intensity is a measure for carbon (and energy) saving technical progress - as well as sectoral shifts and input substitution. Obviously, the decline rate of the carbon intensity must be higher than the GDP growth rate in order to achieve emissions reductions in total. Furthermore, the endogenous $\mathrm{CO} 2$ price reaches about $30 € / t$ in ETS sectors until 2030. The CO2 price will significantly increase in later periods when the emissions targets become tighter - possibly reaching up to $60 € / \mathrm{t}$ in 2050 - similar to EU (2011). ${ }^{15}$ Marginal abatement costs are substantially higher in non-ETS sectors than in ETS sectors - possibly reaching up to $250 € / \mathrm{t}$ around 2030 . The marginal abatement costs will substantially decrease thereafter due to the rising share of non-ETS emissions in all emissions given by EU (2009a). Therein, the model offers cheap reduction options in ETS sectors, in particular in electricity generation with a good possibility to substitute fossil inputs by non-fossil inputs. The production of non-ETS sectors is

\footnotetext{
${ }^{13}$ The use of renewables is determined endogenously. Nevertheless, the energy mix and thus the renewables share depend on the elasticities of substitution within each energy technology. This creates some degree of freedom. Therefore, we set the elasticities so that the $\mathrm{CO} 2$ price in 2050 comes close to the $\mathrm{CO} 2$ price in the Reference scenario in EU (2011). The resulting renewables share is somewhat lower than in EU (2011).

${ }^{14}$ The yearly emission reductions for the Reference as well as the Fragmented and Global action scenario for the EU-27 are taken from EU, 2011, short version, p. 5, Figure 1.

${ }^{15}$ While the CO2 prices reaches $50 € / t$ from 2035 on in EU (2011), it rises steadily and exceeds $50 € / t$ in 2050 in our simulation.
} 
often absorbed by final consumption without good substitution possibilities. Herein, we do not model cheap non-CO2 reduction possibilities in non-ETS sectors.

The European terms of trade are measured relative to the terms of trade in Business as Usual without any climate policy in 2005 (100\%). They are computed in form of a Laspeyres price index for exports divided by imports. They change slightly in the Reference scenario with a vague tendency to increase. Notably, regarding international trade, we do not take trade changes in trade deficits or surpluses into account. This means, trade deficits or surpluses can change over time or between policy scenarios without requiring a balanced trade budget.

The lower right column reports mitigation costs in form of welfare changes between the Reference Action scenario and a Business as Usual scenario without climate policy (in particular without any emissions caps) for the EU-27 within each time period. ${ }^{16}$ Herein, the welfare change is measured as the Hicks Equivalent Variation referring to the change in expenditures (in value form) of the representative EU consumer. Relative mitigation costs stay clearly below 1\% until 2020. Thereafter, they reach numbers around $1.5 \%$ and finally decline, presumably due to the extended use of renewable energies in our model. ${ }^{17}$

\subsection{Fragmented Action}

The Fragmented Action scenario assumes unilateral efforts by the EU-27 to reduce $\mathrm{CO} 2$ emissions by 80\% in 2050 vis-à-vis 1990. Emission reductions, as shown in Table 2, follow the EU Decarbonisation Roadmap 2050 (EU, 2011) over time. In this scenario free allowances for sectors exposed to a significant risk of carbon leakage are still abandoned from 2030 on. The revenues from auctioning the remaining allowances are given to the representative consumer in a lump-sum way.

Table 2 summarizes the results in form of the most important macro-economic indicators for the EU-27 and in form of global CO2 emissions. EU CO2 emissions are forced to decline by $25 \%$ relative to the 1990 level in $2020,40 \%$ in $2030,62 \%$ in 2040 , and $80 \%$ in 2050 . As a result, global emissions increase only by $90 \%$ instead of $97 \%$ in Reference by 2050 . As a consequence of the EU climate policy, the EU emission intensity, i.e. CO2 per GDP, has to decline drastically - almost by a factor ten. The EU share of renewable energies in electricity generation now increases endogenously

\footnotetext{
${ }^{16}$ For instance, Consumption ${ }_{\text {REF } 2020}$ / Consumption BAU $2020-1$.

${ }^{17}$ This is also on account of the rising elasticity of substitution between the fixed factor and the other input factors in the production functions of energy technologies.
} 
to over $50 \%$ in 2050 as in EU (2011). The electricity price increases by almost $60 \%$ until 2050 vis-à-vis 2005. ${ }^{18}$ The endogenous CO2 price in EU ETS sectors reaches almost 40€/t in 2020,50€/t in 2030, less than $150 € / t$ in 2040 and possibly more than $150 € / t$ in 2050 . The latter is very similar to the price of $147 € / t$ reported in EU (2011, extended version, p. 117) for the scenario 'fragmented action, reference fossil fuel prices'. ${ }^{19}$ In non-ETS sectors, marginal abatement costs could become very high.

Table 2 also reports leakage rates for the Fragmented Action scenario in comparison to the Reference scenario for each period. The leakage rate is defined as the increase in emissions in the regions without an emission cap (CHN, IND, MEX, BRA, SIM, ROW) divided by the decrease in emissions in Europe. Accordingly, the leakage rate rises to values just below $20 \%{ }^{20}$ Therein, leakage can occur through two channels: First, sectoral production can decline in Europe and increase elsewhere while commodities can be imported from elsewhere to Europe. This channel can be called 'relocation effect'. Second, EU climate policy induces a decline in fossil fuel demand which lowers global fossil fuel prices. This in turn enhances fossil fuel demand elsewhere. This channel can be called 'price effect'. Most numerical studies find that the price effect dominates the relocation effect by far (compare e.g. Böhringer et al., 2010). Given that the price effect dominates, the carbon leakage rate that we find does not directly translate into a firm relocation rate or an investment leakage rate. Moreover, the table reports the European terms of trade. According to the model results, the terms of trade improve slightly compared to the Reference scenario in later periods. ${ }^{21}$ The reason could be that the production cost increase due to the European carbon pricing can be transferred to product and thus export prices while import prices are hardly affected by European carbon pricing. In this sense, part of the climate policy costs is transmitted to consumers abroad via higher export good prices.

The right column of Table 2 reports mitigation costs in form of welfare changes between the Fragmented Action scenario and the Reference scenario for the EU-27 (measured as the Hicks Equivalent Variation referring to expenditure changes of the representative EU consumer). Relative mitigation costs stay close above $0 \%$ until 2020 . They might rise from $1 \%$ in 2025 to over $3 \%$ in 2040 and around $5 \%$ in the 2040s. The mitigation costs in the final periods need to be treated with caution, though: Obviously, the ambitious emission cuts in late periods create increasingly high costs

\footnotetext{
${ }^{18}$ All prices are absolute prices referring to the base year 2005; nominal prices can of course increase to a larger extent.

${ }^{19}$ The lower bound of the CO2 price in EU ETS sectors in the different scenarios reported in EU (2011, extended version, p. 117) is $104 € / t$, the upper bound is $370 € / t$.

${ }^{20}$ Other CGE studies find leakage rates in a range of 15 to 30\% (Babiker and Rutherford, 2005), but outliers are also possible.

${ }^{21}$ The terms of trade are defined as the price of exports relative to the price of imports based on a Laspeyres price index.
} 
(in form of increasing consumption losses) due to convex marginal abatement costs in our model. However, this is a technical outcome that can be different in reality and in other models. Allowing for higher elasticities of energy supply for the different energy technologies and different elasticities of substitution in the production function can reduce the carbon price and to some extent reduce mitigation costs. When taking backstop (breakthrough) technologies into account, mitigation costs could substantially drop. For instance, CCS is excluded in the scenarios. Furthermore, we only look at $\mathrm{CO} 2$ emissions, not at other greenhouse gases. Other greenhouse gases would enable new, cheaper reduction options. And as any other numerical analysis, our assessment is subject to uncertainties in future economic development including technical progress which is exogenous in our assessment.

Our detailed sectoral analysis for all sectors and all model periods in the EU (Table $\mathrm{O} 2$ in Appendix $\mathrm{O}^{22}$ ) also yields relative sectoral output changes between the Fragmented Action scenario and the Reference scenario measured within each year. ${ }^{23}$ Fossil fuel extraction and further production could drastically decline in Europe: GAS is reduced by 50 to $75 \%$ in the 2040 s, COL by 35 to $65 \%$, CRU by 10 to $20 \%$ and OIL by 35 to $60 \%$. 'Transport' (TRN) activities are reduced by around $20 \%$. Among the industrial production sectors, 'Other chemicals' (OCR) suffer the highest output reduction of around $15 \%$ in the 2040 s, followed by 'Fertilizers' (FER), 'Inorganic chemicals' (INO) and 'Organic chemicals' (ORG) with reductions of around 7\%. On the contrary, the sectors 'Electricity and heat' (ELE) and 'Machinery and other manufacturing' (MCH) could slightly benefit from drastic climate targets according to the model results. Herein, 'Electricity and heat' generation declines until 2040, but rises thereafter because the extended use of renewable energies enables electricity generation with low emissions. Notably, our sectoral results for 2020 and 2030 are very similar to those reported in EU (2011, extended version, pp. 44, 45). ${ }^{24}$

Moreover, our sectoral analysis (Table 12 in Appendix I) looks at relative changes in the sectoral capital stocks between the Fragmented Action scenario and the Reference scenario for each year in the EU. They are an indicator for investment in physical capital and how this is affected by climate policy. Besides investment in 'fresh' facilities, they also capture depreciation and shifts of

\footnotetext{
${ }^{22}$ The supplementary online appendix is available upon request.

${ }^{23}$ Table $\mathrm{O} 1$ is intentionally left out in the supplementary appendix since we do not study sectoral effects under the Reference scenario.

The investment good sector, 'CGD' is not reported since it is an artificial model sector rather than a real sector, and it differs from the other sectors in its functional form.

${ }^{24}$ The results have been computed using the model 'GEM E3'. Therein, 'GDP' impacts are around $-0.1 \%$ in 2020 and around $-0.8 \%$ in 2030 for the ETS industry (without including opportunity costs of free allocation in the presence of a carbon price in non-ETS sectors). Correspondingly, sectoral impacts are about $-1.8 \%$ in 2030 in energy intensive industries, $-2.3 \%$ in 2030 for chemicals and $-1.7 \%$ for ferrous and non-ferrous metals. We do not find positive impacts of free allocation without considering opportunity costs in 2020, though. There are no further sectoral results reported in EU (2011), either.
} 
existing capital across sectors. Changes in the capital stocks naturally show a similar structure as the changes in output values. But there are differences, though. A number of sectors show positive values (e.g. MIN, CEM, BRT, ISM, ISP, MCH, TWL, SER). This indicates an extension of the capital stock due to capital or investment reallocation effects induced by more stringent climate policy. Other sectors have negative values (e.g. the chemical and the fossil sectors, ALU, ONF, PPP and TRN) that can be higher or lower than the corresponding output reductions. Against this backdrop, the examination of investment patterns first reveals the shift of capital from certain sectors to other sectors. Second, it reveals that in sectors with smaller losses in investment than in output, the output reduction is to a smaller extent driven by capital reductions than reductions in other inputs. While sectoral investments show substantial shifts between sectors, total EU investment is hardly affected by climate policy in the model.

The analysis (Table E2 in Appendix E) also investigates relative changes in direct sectoral CO2 emissions for each year vis-à-vis the emissions in the same sector in 2005 under Fragmented Action in the EU. Direct emissions mean those emissions that are generated within sectors by burning fossil fuels, not emissions that are indirectly used via inputs such as electricity that implicitly contain fossil fuels. This is one reason why the emission effects can differ from the output or costs effects. Accordingly, relative emission reductions differ widely across sectors. Additionally, the underlying reductions in absolute terms can widely differ across sectors. Relative reductions are around $40 \%$ in energy intensive chemical sectors (FER, ORG, INO), 'Other non-ferrous metals' (ONF) and 'Paper, pulp and printing' (PPP) at the lower bound. They are roughly around $85 \%$ in fossil fuel sectors (OIL, GAS, $\mathrm{COL}$ ) and in not energy intensive non-ETS sectors (FAW, TWL, SER) as well as in 'Mining and construction' (MIN) and 'Machinery and other manufacturing' $(\mathrm{MCH}){ }^{25}$ In the remaining sectors, emission reductions lie between those. The sectoral development of emissions is visualized in Figure E1 in Appendix E. (The legend follows the ranking of emissions cuts in 2050 from top to bottom.) The figure reveals that in 2010 several sectors are still able to increase their emissions above 2005 levels due to EU emissions trading. In the following periods, all sectors need to cut emissions. Herein, the spread of relative emissions cuts across sectors becomes wider. In late periods the reduction spread reaches from less than $40 \%$ to $90 \%$.

The sectoral analysis (Table C2 in Appendix C) finally studies changes in the competitiveness of EU sectors. Competitiveness is measured in form of world trade shares following Balassa (1965), Reichel (2002) and Böhringer and Alexeeva-Talebi (2011). According to Böhringer and Alexeeva-

\footnotetext{
${ }^{25}$ Note that fossil fuels (COL, GAS, CRU) denote extraction and production in Europe or further processing in Europe (OIL).
} 
Talebi (2011), the index that we use first computes the share of the export value of a certain sector of a certain region in the world export value of this sector. The index second computes the share of the total export value of a certain region in the whole world export value summed up over all sectors. It third computes the ratio of both shares. If the sectoral share in world exports is identical to the economy-wide share in world exports, the index will take the value of one. A region is said to have a comparative advantage in a certain sector if the index exceeds one. Conversely, a region is said to have a comparative disadvantage in a sector if the index takes a value between zero and one. In this sense, the world trade share index shows the importance of a certain sector relative to other sectors in the economy regarding the global export market. It can also show how this importance is affected by policy shocks such as our policy scenarios. Again, the pattern of the competitiveness effects is naturally similar to the pattern of the output effects. We now look at relative changes in the competitiveness index relative to the Reference scenario. Now, differences between policy induced output changes and investment changes can occur because sectors are to different extents engaged in international trade; and producers and the consumer have different possibilities of switching their exports and (intermediate) imports between domestic and foreign markets. It turns out that many sectors could benefit from more stringent climate policy in terms of competitiveness (e.g. MIN, PPP, CEM, ONM, ISP, CRU, MCH, FAW, TWL, SER). The positive numbers express that these sectors have gained a higher importance among EU sectors in export markets due to more stringent climate policy. These outcomes might change when using different Armington elasticities (compare section 'Discussion').

Figures 1 and 2 summarize the sectoral findings. Figure 1 visualizes the sectoral emissions paths in the EU-27 under Fragmented Action over time. Emissions are reported as percentage changes for each period versus 2005 emissions levels within each sector. The emissions paths reflect the market-efficient allocation of allowances across sectors neglecting transaction costs. As a result, in 2010 low energy sectors (TWL, MCH, SER, MIN, FAW, OCR, plotted in green) are obviously able to increase emissions. But this is not observed from 2015 on anymore. Low-energy sectors then decrease emissions to a relatively large extent due to their low energy and emissions input shares and relatively low marginal abatement costs. These high relative emissions reductions represent small emissions reductions in absolute terms though because low-energy sectors produce small emissions volumes. Figure 2 which refers to the period 2040 also reveals that low-energy sectors gain in terms of investment and competitiveness. Since total EU investment is given, an investment reduction in energy-intensive sectors results in an investment increase in low-energy sectors. Similarly, the competitiveness with regard to exports decreases in energy-intensive sectors but increase in low-energy sectors. 


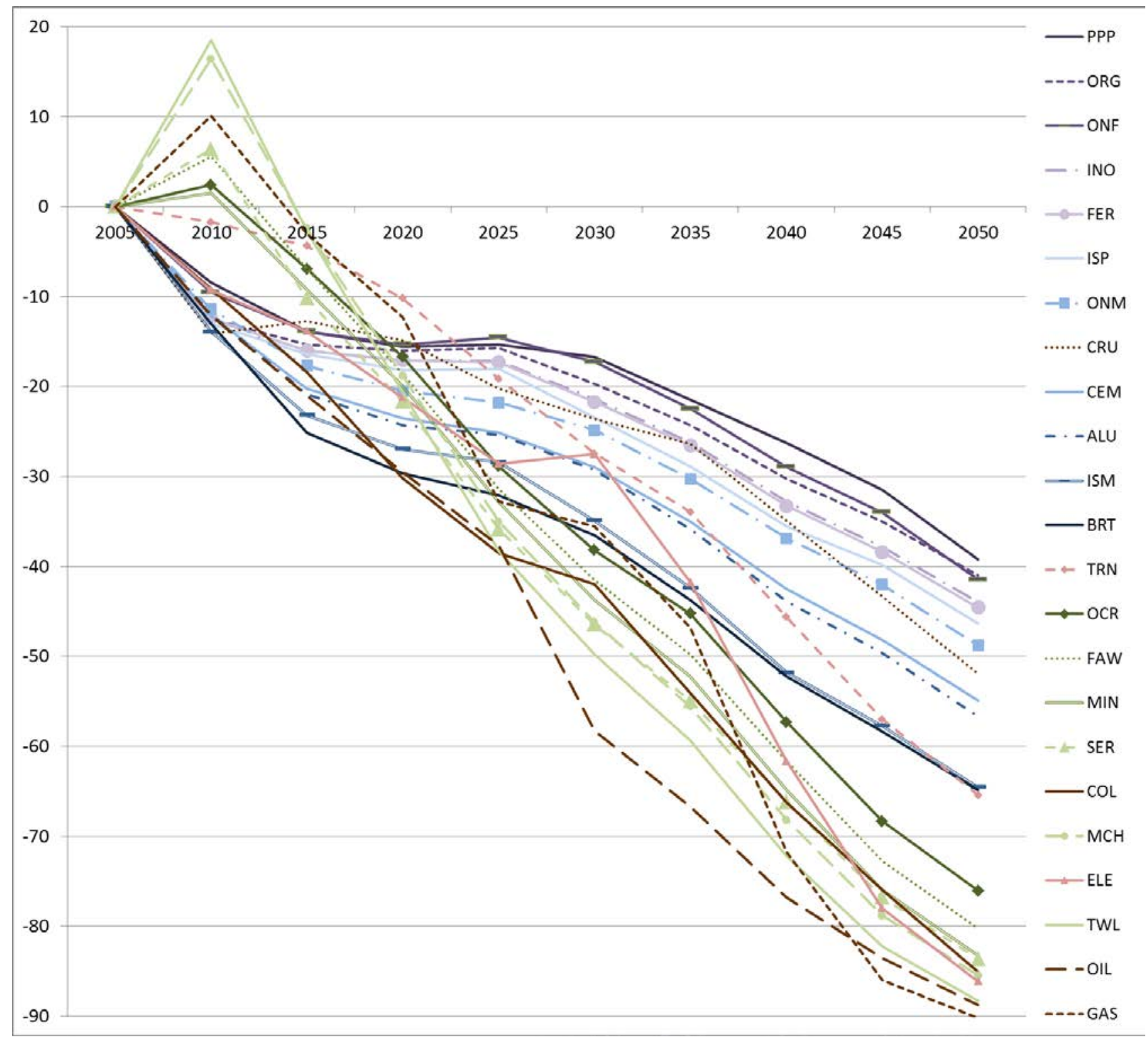

Figure 1: Relative emissions changes in the various model periods vis-à-vis 2005 under the Fragmented Action scenario in EU-27 sectors in \%

Among the fossil fuel sectors (fossil fuel extraction COL, GAS, CRU and refinement OIL, plotted in brown) 'Gas' also behaves as a low-energy sector in terms of its own direct emissions created when burning fossil fuels in gas extraction (and further production). As Figure 2 shows, the output of GAS (and investment and competitiveness) decreases strongly as well. This happens because the demand for gas declines due to climate policy. Following the same logic, direct emissions, fossil fuel output, investment and competitiveness strongly decline in the other fossil fuel sectors OIL and COL in later periods. 'Crude oil' extraction is less affected though. Two sectors are in general crucial for achieving stringent emissions targets since they contribute a large share to total emissions: 'Transport' (TRN) and 'Electricity and heat' (ELE). Indeed, these sectors show high relative emissions reductions in 
Figure 1 (in red), and high emissions and output reductions in Figure $2 .{ }^{26}$ Competitiveness losses with regard to exports are high in these sectors, but exports play in total only a minor role in these sectors. The energy intensive sectors (PPP, ORG, ONF, INO, FER, ISP, ONM, CEM, ALU, ISM, BRT, plotted in blue and magenta) reduce emissions to smaller extents in relative terms over time (Figure 1). Their emissions reductions in absolute terms are nonetheless rather high. At the same time, their relative output reductions (Figure 2 ) are rather high. This reflects their high marginal abatement costs.

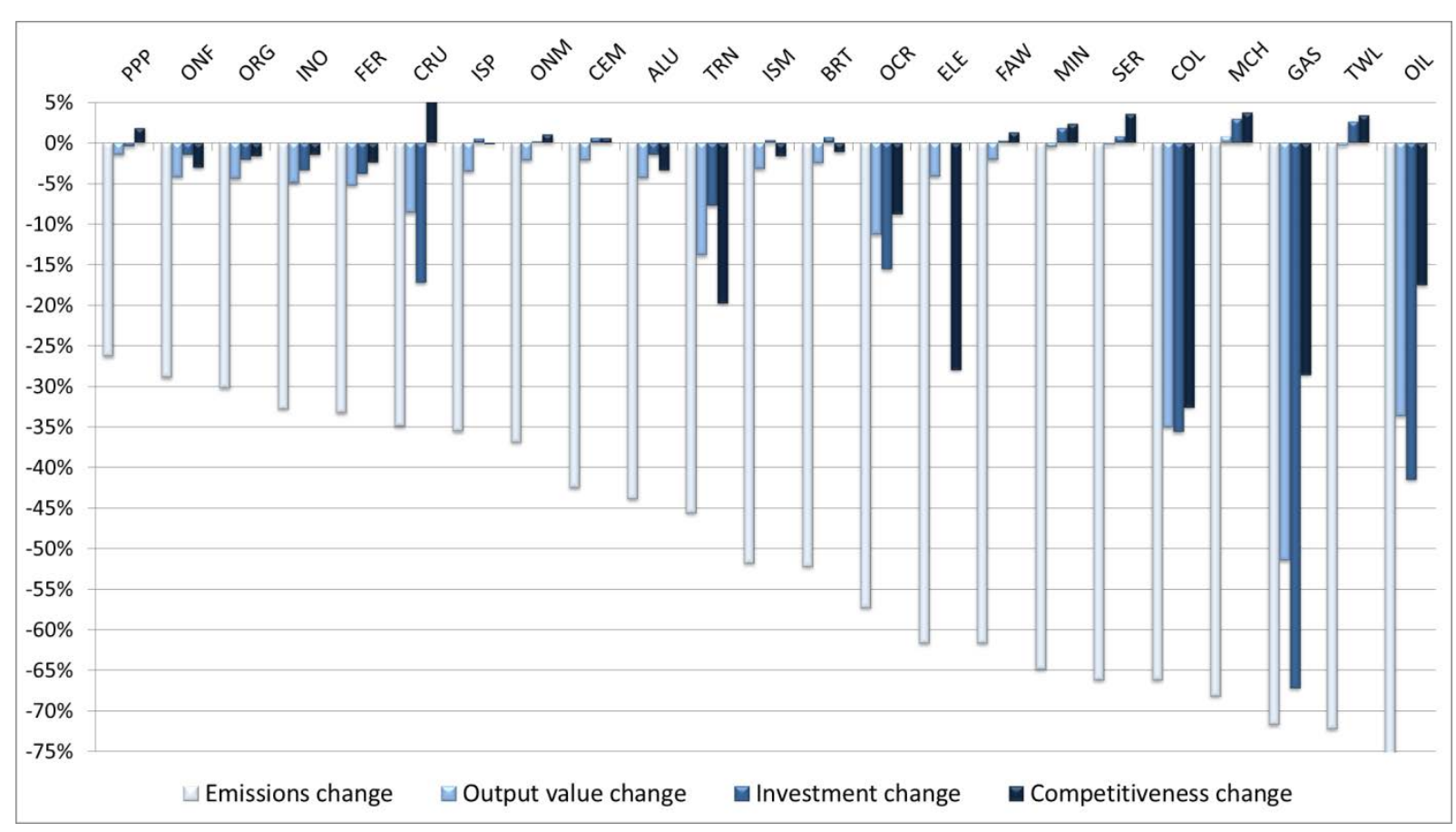

Figure 2: Relative emissions, output, investment and competitiveness changes in the period 2040 visà-vis 2005 under the Fragmented Action scenario in EU-27 sectors in \%

To conclude, our sectoral analysis shows that the sectoral differences in the impacts of climate policy can be pronounced and vary across the sectoral indicators under scrutiny. We abstain from such a detailed visualization and discussion of the results for every scenario. Yet the reader can find the underlying data in the supplementary appendix (available upon request).

\footnotetext{
${ }^{26}$ Investment changes are not available for ELE because different to the other sectors, ELE is modeled in a simple bottom-up module.
} 


\subsection{Fragmented Action Free}

The Fragmented Action Free scenario uses the same assumptions as the Fragmented Action scenario. The difference is that free allocation of allowances for sectors exposed to a significant risk of carbon leakage according to the existing EU benchmarking scheme is sustained until 2050. The shares of free allowances are the same as in the Reference scenario. Free allocation ceases in 2030 for other sectors, though.

Table 3 summarizes the macro-economic results. EU CO2 emissions are subject to the same targets as under Fragmented Action. Thus, global emissions are not affected either. The share of renewable energies in electricity generation is in general slightly lower than under Fragmented Action. The electricity price is in general higher than under Fragmented Action. It increases almost by $70 \%$ until 2050 vis-à-vis 2005. The CO2 price in ETS sectors reaches around 40€/t in 2020,60€/t in 2030 , and $150 € / t$ in 2045 . This is in general somewhat higher than under Fragmented Action. The CO2 price might reach $190 € / t$ in $2050 .{ }^{27}$ (190€/t equals the CO2 price in EU, 2011, under the scenario 'effective technology, fragmented action, low fossil fuel prices'.) In non-ETS sectors, marginal abatement costs would become extremely high in our analysis - even significantly higher than under Fragmented Action. The leakage rate seems to go down from 2030 on compared to Fragmented Action. Conversely, the terms of trade seem to slightly worsen from 2030 on. Mitigation costs, measured as the change in expenditures of the representative consumer (welfare change), become somewhat higher than under Fragmented Action, particularly in late periods. Obviously, the sustained free allocation of allowances for sectors exposed to a significant risk of carbon leakage creates extra macroeconomic costs.

Our sectoral analysis (Table $\mathrm{O} 3$ in the Appendix) identifies relative output changes between the Fragmented Action Free Allocation scenario and the Reference scenario in EU-27 sectors. The output of the non-ETS sectors, 'Natural gas' (GAS) and 'Coal' (COL), 'Electricity and heat' (ELE), 'Food, agriculture and wood' (FAW), 'Textiles, wearing, apparel and leather' (TWL), 'Transportation' (TRN) and 'Services' (SER) decreases under Fragmented Action Free until 2050 compared to Fragmented Action; the output of all other sectors rises due to sustained free allocation (or stays at least constant in case of 'Other chemicals', OCR). 'Manufacturing of iron and steel' (ISM) would in particular gain. Moreover, sustained allocation of free allowances triggers a shift from coal and gas to oil use - since only the latter is now supported in our model. This model result is to be taken with caution; it depends on the choice of elasticities of substitution and probably overstates the real effects.

\footnotetext{
${ }^{27}$ The results for 2050 should be taken with caution regarding its numerical feasibility, though.
} 
Interestingly, not only the leakage sectors (OIL, PPP, FER, ORG, INO, CEM, BRT, ISM, ALU) gain from the sustained free allocation policy but also the remaining ETS sectors (ISP, ONM, ONF) - but at the expense of non-ETS sectors. These effects are also reflected in the development of the sectoral capital stocks as an indicator for investment, in sectoral emission reductions, and in changes in the competitiveness. $^{28}$

In summary, a sustained allocation of free allowances to sectors exposed to a significant risk of carbon leakage (benchmarking) could be beneficial for almost all industry sectors - not only for those sectors that receive free allowances. This indicates advantages with respect to competitiveness of some EU sectors - but it comes at the expense of higher costs for the EU.

\subsection{Fragmented Action CDM}

The Fragmented Action CDM scenario assumes the availability of the Clean Development Mechanism (CDM) in its current form until 2020 and in an analogue way thereafter. Herein, we understand CDM in the sense of 'where'-flexibility, this means the reduction of emissions where it is cheapest, such as in developing countries without an emissions price, not in the sense of a projectbased mechanism associated with technology transfer. The EU-27 is the only recipient of CDM credits. Non-Annex-I countries (CHN, IND, BRA, MEX, SIM, ROW) are the sources of CDM credits. We neglect transaction costs and investment risks of CDM in this analysis. Until 2020, up to 50\% of the emissions reduction effort between the Business as Usual scenario and the Fragmented Action scenario for each year can be attributed to EU ETS sectors in form of CDM credits. Up to $3 \%$ of the emissions in 2005 can be attributed to non-ETS sectors via the government. After 2020, it is assumed that $50 \%$ of the reduction effort of ETS sectors can be attributed to CDM and 50\% of the reduction effort of non-ETS sectors can be attributed to CDM as well. This allows huge amounts of emission reductions via CDM. All other assumptions are the same as in the Fragmented Action scenario.

Table 4 summarizes the macro-economic impacts: Obviously, the EU-27 achieves substantial emission reductions abroad via CDM accounting for up to 41 percentage points of relative emissions in 2050 (compare the second column in Table 2 and Table 4). This leads to a CO2 intensity that is

\footnotetext{
${ }^{28}$ The competitiveness results for OIL, GAS, COL and CRU in late periods appear to be outliers. Obviously, a very strong switch from cola and gas to oil occurs due to the free allocation of allowances for refined oil and coal products. Nonetheless, the relative changes say nothing about the competitiveness index in absolute terms. In absolute terms, the competitiveness index is very low for CRU, COL and GAS, for instance, under Reference as well as Fragmented Action Free. In this sense, the tables show in some cases strong changes in relative terms, but small changes in absolute terms
} 
almost four times as high as without CDM. The renewables share declines to above $30 \%$ in the 2040 s. The relative electricity price is much lower than under Fragmented Action. This is due to a much lower ETS CO2 price of under 50€/t until 2050 as well as drastically lower non-ETS marginal abatement costs of around 100€/t in 2020 and 150€/t in 2040. Now the EU-27 achieves small welfare gains in all periods except 2045 compared to the Reference scenario. The question is, however, whether such an intensive use of CDM will be politically and technically feasible.

Furthermore, our analysis (Table $\mathrm{O}^{29}$ ) shows the sectoral impacts on the EU-27: Compared to Fragmented Action without CDM, all sectors are better off. (Only 'Investment good' production, CGD, is always kept constant). It also reveals that the investment pattern (Table 14), i.e. the expansion or reduction of sectoral capital stocks, changes due to the extension of CDM. Not surprisingly, the necessary sectoral emission reductions (Table E4) become lower than under Fragmented Action without CDM. Moreover, the competitiveness effects (Table C4) appear diverse relative to Reference and relative to Fragmented Action without CDM.

In summary, the EU would gain from an extensive use of CDM at the macro level, and this gain translates to the sectoral level: All sectors would gain from an extensive future use of CDM. However, the assumption on the extent of CDM use is very optimistic. Moreover, we model the import of emission reductions from abroad but not technology transfer to abroad. And importantly, reaching reasonable global climate targets requires global climate action. - European climate policy with CDM will not reduce global emissions sufficiently. Compared to the Global Action scenarios, the Fragmented Action CDM scenario leads to higher climate change related damages in the EU and elsewhere. These damages are not taken into account in the results in the tables. Compared to Global Action, CDM allows the EU to reap "low-hanging fruits" in developing countries that will be locally “harvested" under Global Action.

\subsection{Global Action}

The Global Action scenario assumes the same emissions targets for the EU-27 as the Fragmented Action scenario and the same Copenhagen Pledges for 2020 as well. The difference is that the industrialized countries subject to Copenhagen Pledges extend their climate efforts, now reaching a 80\% emission reduction in 2050 vis-à-vis 1990 as the EU does (EU, 2011, extended version, pp. 37, 38). The transition from the Copenhagen targets to the $80 \%$ targets occurs gradually over time. The

\footnotetext{
${ }^{29}$ The supplementary online appendix is available upon request.
} 
developing countries also take responsibility by reducing emissions after 2020 down to their 1990 levels in 2050 (compare EU, 2011). The resulting global emission reduction in 2050 vis-à-vis 1990 is $52 \%$ (as shown in the first column of Table 5). This means, we are now in another future with lower climate change related damages which results in lower costs compared to Fragmented Action. These avoided climate change damages are not captured in our simulations, though. All other assumptions are the same as in the Fragmented Action scenario. This includes the assumption that carbon prices differ across regions but are equal within regions except in the EU-27. Herein, we assume that the emissions targets cover all sectors in non-EU economies.

Table 5 summarizes the macro-economic impacts for the EU-27: The EU ETS CO2 price is higher than under Fragmented Action and the marginal abatement costs in non-ETS as well. A main reason for this is that imports from other regions become more expensive due to the introduction of carbon pricing. Therefore, EU demand shifts from imports to domestic production, which raises the EU use of fossil fuels and drives up the EU carbon price. Another likely reason is carbon leakage through the price effect - now in the opposite way as before: Carbon pricing abroad reduces the demand for fossil fuels and hence reduces the global fossil fuel prices. This might result in an extended use of fossil fuels in the EU, which again drives up the EU carbon price. (Our CO2 price is lower than the price of 190 to $370 € / t$ in the EU, 2011, Global Action scenarios.) Global Action slightly reduces the welfare loss compared to Fragmented Action. The terms of trade improve compared to Fragmented Action. The reason for this could be that foreign competitors now face a carbon price as well which levels off the carbon 'playing field'. The overall small macroeconomic differences between Fragmented and Global Action stem from the assumption that the climate targets for the EU-27 are kept equal to Fragmented Action and that international emissions trading is not allowed. As a consequence, the differences in the results stem from international trade and leakage effects. (Leakage rates are not reported in the global scenarios because all countries face emission caps in later periods.)

Our analysis furthermore shows that the sectoral impacts are diverse in late periods: Several sectors - in particular the chemical sectors (FER, ORG, INO, OCR) and 'Further processing of iron and steel' (ISP) - gain strongly compared to Fragmented Action. This indicates an improvement in the international competitiveness of these sectors. A number of other sectors (OIL, CEM, BRT, ONM, ISM, ISP, ALU, ONF, ELE and TRN) are better off too while the remaining sectors are worse off. 'Electricity and heat' (ELE) seems to benefit from Global Action. This can have several reasons: First, Global prices for fossil fuels decline since climate policy reduces demand for fossil fuels abroad. Second, demand shifts to some extent from (emissions intensive) imports to domestic sales. It can roughly be said in terms of competitiveness that ETS sectors are better off while non-ETS sectors are worse off. 
The sectors that gain strongly in terms of output also gain strongly in terms of competitiveness. Interestingly, Global Action appears to raise capital stocks and thus investment in the EU compared to Fragmented Action except EU fossil fuel extraction and production (COL, GAS, CRU, OIL) and 'Machinery and other manufacturing' (MCH). In accordance with the output effects that we observed, we find a strong competitiveness gain for 'Electricity and heat' due to Global Action.

In summary, global climate action is inevitable to reach the necessary climate targets. Without international emissions trading, the pure macroeconomic effects on the EU appear small, though. And the sectoral effects induced by changes in the trade pattern appear diverse. In particular, several energy intensive sectors could benefit because their competitiveness would improve towards foreign producers that would now also face carbon prices. However, like most CGE models, our model does not capture firm's decision to deliver foreign markets via exports or FDI or to stay with the domestic market instead (along the lines of the Melitz model, e.g. Melitz and Ottaviano, 2008). As a consequence, it probably underestimates firms' international relocation.

\subsection{Global Action National}

The Global Action National scenario assumes an equalisation of $\mathrm{CO} 2$ prices across ETS and non-ETS sectors in the EU. (There is no distinction between ETS and non-ETS sectors in other regions and no international emission trading as before). This assumption might be optimistic, but it has a clear intention: It shall reveal the costs created by the $\mathrm{CO} 2$ price differential between ETS and non-ETS sectors.

The results reported in Table 6 indicate a substantial reduction in mitigation costs (welfare losses) from around $4 \%$ to around $2 \%$ in the 2040s. The CO2 price in ETS sectors would substantially increase - to between 200 and 500€/t in the 2040s, since part of the burden of non-ETS sectors is shifted to ETS sectors. Herein, the sharp increase in the CO2 price in 2045 and 2050 indicates a strong convexity of marginal abatement costs that becomes obvious when emission cuts reach over $80 \%$. The $\mathrm{CO} 2$ price and the mitigation costs reported for late periods need to be taken with caution, though.

Again, we also examine sectoral output changes, which appear diverse. Several sectors such as 'Other chemicals' (OCR) 'Crude oil' (CRU) and 'Transportation' (TRN) clearly gain compared to Global Action. OIL, GAS, 'Electricity and heat' (ELE) and 'Food, agriculture and wood' (FAW) also appear to gain. The other sectors might lose or be equally off. 
In summary, in our model, the equalization of the carbon price across all sectors within the EU has a high potential to reduce European mitigation costs. On the sectoral level, the effects appear again diverse.

\subsection{Global Action International}

For Global Action International we assume an equalisation of $\mathrm{CO} 2$ prices across ETS and non-ETS sectors in the EU as well as across all world regions. Herein, we keep exactly the Global Action scenario until 2020. From 2025 on, when the developing regions will introduce climate policies, we allow for international emissions trading as well. ${ }^{30}$

Under this scenario, the EU-27 is even better off than under the Reference scenario in the periods 2025 to 2040 due to the efficiency gains from an equalised world market price for CO2 via international emissions trading. The CO2 price will drop in 2025 when the developing countries introduce emissions caps and participate in global emissions trading. By this means, the global ETS can almost disburden the EU from all mitigation costs in $2025 .{ }^{31}$ The positive effects also exceed those under Fragmented Action CDM between 2025 and 2035 because the potential of buying additional allowances at low costs is even larger via the global ETS than via CDM. In 2035, for example, the actual EU emissions reduction is $21 \%$ under Fragmented Action CDM but only $11 \%$ under Global Action International. In 2050 the EU can buy further allowances and reduce its emissions reduction to $67 \%$ instead of over $80 \%$ vis-à-vis 1990. From 2045 on, mitigation costs become higher than under Fragmented Action CDM, though. A look at the - now global - CO2 price in these years shows that $\mathrm{CO} 2$ allowances can become quite costly. This happens because all Annex-I regions will face tight emissions targets in 2045 and 2050 under Global Action, and the developing countries will go back to their 1990 emissions levels. This drives up the global CO2 price and raises EU mitigation costs reaching around $2 \%$ of the consumption value since the EU cannot buy cheap allowances from abroad anymore. (In later periods, the carbon price can become higher than under pure 'Global Action', but lower than under 'Global Action National'.) Nevertheless, mitigation costs decline compared to Global Action and Global Action National in all periods with global emissions trading. Obviously, a global CO2 price bears a high potential for achieving emission reductions in an efficient way.

\footnotetext{
${ }^{30}$ This creates a kind of structural break in the results between 2020 and 2025.

${ }^{31}$ The positive effect in 2025 Table 7 almost matches the negative effect in 2025 in Table 1.
} 
The sectoral effects show that those sectors that can benefit from Global Action can additionally benefit from international emissions trading. Besides that, the sectors that can benefit from Global Action National can do so under Global Action International (except ELE). The general picture is that more than half of the sectors are better off than under pure Global Action. The remaining sectoral effects reported in the Appendix can be interpreted along the lines of the previous sections. In this sense, Global Action International combines the benefits of pure Global Action, Global Action National and international emissions trading, which is visible in the sectoral results.

In summary, international emissions trading enables the EU to benefit significantly from global climate action. This positive effect also translates to most sectors.

\section{Discussion}

We have assessed the EU Decarbonisation Roadmap 2050 targeting at a $80 \%$ reduction in greenhouse gases until 2050 vis-à-vis 1990. The resulting time path of the CO2 price and of mitigation costs in the EU-27 indicates that the costs stay low to moderate - in the range of zero to $2 \%$ of consumption expenditures - until 2035 . Thereafter, the reduction target will come closer to $80 \%$ so that the $\mathrm{CO} 2$ price in EU ETS sectors might sharply increase, and marginal abatement costs in non-ETS sectors might become challenging. The following subsections discuss the results, first focusing on welfare effects and then on technological aspects, leading to a summarizing discussion.

\subsection{Welfare Effects}

Figure 3 summarizes the welfare analysis of the different policy scenarios for the time period 2040 . Our Reference scenario already embodies mitigation costs of more than $1 \%$ with respect to the total consumption value compared to a Business as Usual scenario without any climate policy. The costs reported for the other scenarios come on top of this. They amount to more than $3 \%$ under Fragmented Action - which slightly increases in case of sustained free allocation of allowances for leakage sectors. Mitigation costs are negative, i.e. they turn into a surplus relative to Reference, in case of an extensive future use of CDM. However, this surplus comes on top of the costs embodied in the Reference scenario such that there are still mitigation costs relative to Business as Usual. Similarly, Global Action International creates a small welfare gain compared to Reference while it still 
creates costs relative to Business as Usual. This means, the global CO2 price equalization removes the additional costs of the Roadmap for the EU in 2040. Compared to Global Action, our CDM scenario allows reaping "low-hanging fruits" in developing countries that will be locally "harvested" under Global Action. This is especially true for later periods (2045 and 2050) when global Action drives up the global $\mathrm{CO} 2$ price such that the EU cannot buy cheap allowances from abroad anymore (see section 3.7). However, such an extensive use of CDM involves concerns regarding its technical and political feasibility: Transaction costs and investment risks, both not taken into account in our analysis, hinder CDM activities. The large-scale use of CDM that we assume will probably require a new organizational framework which is not too much structured on a project level but maybe on a sectoral or economy-wide level. Moreover, it has been questions that CDM always creates new emissions reduction activities. It can rather happen that projects would have been realized anyway, even without CDM. Taking these aspects into account and making a less optimistic assumption regarding the limit of CDM use in the EU ETS would clearly reduce the positive impacts of CDM on the EU that we find. Finally, the ambitious reduction efforts of the EU can become mainly window dressing if half of the reduction actually occurs abroad. In this sense, the extensive use of CDM counteracts the achievement of drastic global reductions. Global Action, however, will only slightly reduce the costs compared to Fragmented Action if there is no equalization of carbon prices, though. Mitigation costs substantially drop when equalizing the carbon price across sectors and regions.

The costs we find are sometimes higher than in other studies that examine the $2^{\circ} \mathrm{C}$ climate target and find cumulated discounted costs of around 1\% (for example Leimbach et al., 2010, for the EU until 2100; Hübler, 2010, for the industrialized countries until 2050; Edenhofer et al., 2010, for the world until 2100 within the model comparison project ADAM). ${ }^{32}$ However, the costs we find strongly differ across scenarios: The costs under Global Action International or Fragmented Action CDM come close to the costs in other (Integrated Assessment) studies; whereas the costs become substantially higher in our scenarios that assume inefficiencies due to different $\mathrm{CO} 2$ prices across sectors or regions. Such inefficiencies are often not included in global-scale integrated assessment models. In our study, the high marginal abatement costs in non-ETS sectors and the resulting large price differential between ETS and non-ETS sectors drive the high mitigation costs to a large extent. Herein, one cost driver in the non-ETS field in our model is probably the unavailability of non-CO2 mitigation options. These options could lead to emission reductions at relatively low costs.

\footnotetext{
${ }^{32}$ Due to different scenario assumptions and accumulating and discounting, these costs are not directly comparable to ours, though. For example, different to our study, Leimbach et al. (2010) and Hübler (2010) assume a Contraction and Convergence $(\mathrm{GCl}, 1990)$ mechanism. These studies do not distinguish between ETS and non-ETS sectors, either, which is a major cost driver in our study.
} 


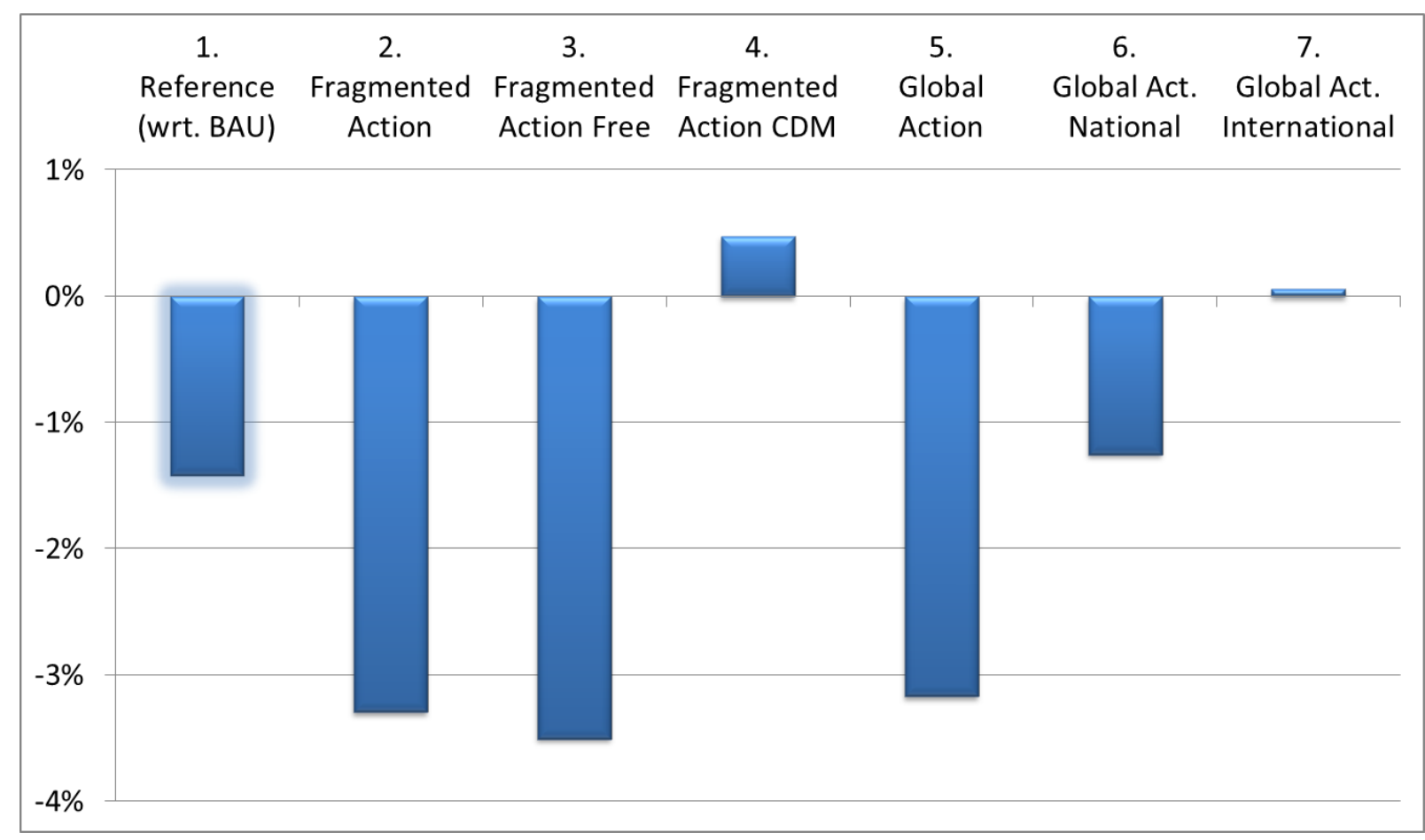

Figure 3: Summary of the welfare effects (= relative changes in total consumption = measure for mitigation costs) of the different climate policy scenarios for the EU-27 in 2040; 1. Reference is measured with respect to Business as Usual without any climate policy; all other scenarios (2. to 7.) are measured with respect to 1 . Reference

\subsection{Technological Options}

Moreover, we do not differentiate between different kinds of renewable energies such as biomass, wind and solar that can expand to different extents. Herein, we model renewable energies as they were available in 2004/2005 and let them expand over time. We abstract from the costs of capacity building though, which would require a forward-looking model type. We do not consider carbon capture and storage (CCS), large-scale solar or any other backstop breakthrough (backstop) technology, either. The use of such technologies might substantially reduce mitigation costs. However, the market-based realization of such technologies is currently highly uncertain. There are severe caveats regarding CCS and nuclear power in society, and large-scale solar projects are questionable for economic, political and technical reasons. It seems currently rather unclear at which costs CCS would work - carbon capture at low costs appears, nevertheless, possible. The uncertainties concerning CCS use in industries appear even higher than concerning CCS use in electricity generation. Thus, we refer to conservative data based on the technologies available in 2004. These technologies can then endogenously expand or go down over time due to economic 
progress and climate policy. Notwithstanding, we assess the impact of a larger availability of renewable energies and the availability of CCS on our results in a robustness check:

First, we keep our model of electricity generation based on the 2004 data but increase the supply elasticity of renewable energies from 2025 on until it reaches three instead of one by 2050 . This represents a higher flexibility in the energy system and a political and technical environment that supports a further expansion of renewable energies. It results in an expansion of renewables in electricity generation to $50 \%$ instead of $40 \%$ in 2040 and to $63 \%$ instead of $51 \%$ in 2050 in the Fragmented Action scenario. The EU ETS CO2 price falls to $72 € / t$ instead of $94 € / t$ in 2040 and 104€/t instead of $144 € / t$ in 2050 . However, the stronger expansion of renewables comes at a cost. As a result, the negative welfare effect of the Roadmap climate policy falls only by between 0.1 and 0.3 percentage points. Obviously, the benefit of a further expansion of renewables becomes smaller relative to its costs. Similarly, the negative welfare effect of Global Action National with international emissions trading could be reduced by 0.3 percentage points in 2050 via the expansion of renewables. Yet, this positive effect vanishes in earlier periods in this scenario. Presumably, there is less room for cost reductions left since there have already been no additional costs compared to the Reference scenario in this most cost efficient scenario.

Second, we additionally allow for CCS use in electricity generation by implementing CCS in a stylized straight-forward way: $90 \%$ of the emissions of burning fossil fuels (mainly coal and gas since oil plays a very minor role in future electricity generation in the model) are assumed to vanish due to sequestration. At the same time, the costs of fossil electricity generation are assumed to rise by roughly $20 \%$ following Paltsev et al. (2005). Moreover, we assume for simplicity that renewable energies are subject to a cost reduction of the same magnitude as the cost increase of fossil electricity generation due to CCS. This cost reduction for renewables may stem from stronger learning effects over time. As a result, we find on the one hand that coal use as a share in electricity generation is almost sustained - falling to only $22 \%$ at the end of the time horizon. Gas use is expanded to almost $24 \%$ in 2050 , while it rather phased out in our standard fragmented Action scenario. We find on the other hand that the share of renewables now increases only weakly reaching almost $27 \%$ in 2050 . This means, the expansion of renewables is replaced by the deployment of fossil CCS technologies. As a result, the EU ETS CO2 price drops quasi to zero accept in late periods with drastic emissions targets. This is however not true for the marginal abatement costs in non-ETS sectors, they stay high. Against this backdrop, it is not surprising that the cost reduction through CCS in combination with cheaper and more flexible renewables is limited: The reduction of the negative welfare effect of the Roadmap policy in late periods is reduced by between 0.6 and 0.8 percentage points under Fragmented Action, and by up to 0.4 percentage points under Global Action 
National - the most cost effective scenario. Under the latter scenario there is again little room for additional cost reduction in earlier periods.

In summary, our robustness check yields observable, but relatively small additional cost reductions via extended technological options. This also alludes to an important characteristic of our model: The largest part of the emissions reductions is achieved via the reduction of energy use (by replacing energy inputs by other inputs - compare the resulting improvement in the energy intensity of GDP reported in Table 1) rather than the decarbonisation of energy supply. This is a difference to models with a flexible, high-resolution energy system that allows a strong decarbonisation of energy supply.

As another caveat, we look at $\mathrm{CO} 2$ emissions only, not at other greenhouse gases. The reduction in other greenhouse gases opens new and cheaper reduction options via technologies and substitution options not taken into account in our model.

And as any other numerical analysis, our assessment is subject to uncertainties in future economic development, in particular economic growth and technical progress. Against the backdrop of recent economic turmoil, lower future economic growth would result in lower mitigation costs. Stronger energy and emissions saving technical progress would reduce mitigation costs if it can be achieved in a cost-efficient way. Notably, we do not model endogenous (directed) technical progress, either (like for example Popp, 2004; Otto et al., 2008; Bosetti et al., 2008). Endogenous technical progress in combination with perfect foresight of economic agents could help anticipate the drastic emissions reductions in late periods and therefore shift some of the costs to earlier periods - for example, through early investment in advanced low-carbon technologies. Forward-looking behaviour in combination with a climate target (temperature increase or carbon budget) could also result in emissions targets that differ from those given by the Decarbonisation Roadmap that stem from other model simulations.

Additionally, there are uncertainties in the choice of elasticities of substitution, for example, between fossil and non-fossil inputs in production and of energy supply from different technologies. Different elasticities of substitution can significantly change mitigation costs. The direction and magnitude of these effects are not clear-cut, though: On the one hand, a better possibility to substitute inputs enhances the possibility to replace fossil inputs in case of climate policy. On the other hand, it raises output in the Business as Usual scenario and thus enlarges the mitigation effort. Elasticities of substitution may also changes over time, becoming higher in the long-run than in the short-run, which is not taken into account in this study. Higher Armington elasticities will presumably result in stronger trade and leakage effects of climate policy. The existing uncertainties in Armington 
elasticities might not only affect the magnitude of policy effects, but possibly even the sign (positive or negative; compare Saito, 2004). This is in particular relevant for sectoral effects.

\subsection{Sectoral Effects}

Our study provides a detailed sectoral analysis. This allows us to better understand the drivers of the macroeconomic results that we observe and to get a feeling of sectoral differences in the impacts of climate policy. Both appear essential for breaking down the macro level Decarbonisation Roadmap to sectoral roadmaps and to finally realize decarbonisation. This sectoral view has often been neglected in climate policy analysis. However, any detailed sectoral view also involves simplifications and uncertainties: For example, the sector 'PPP' comprises production of pulp and paper as well as printing, which have rather different energy intensities and will thus be differently affected by climate policy. The emissions in the 'Cement' sectors (CEM) consist to 50 to $70 \%$ of process emissions in reality. These emissions can thus not be reduced via pure input factor substitution. This is not taken into account in our model. Moreover, CGE models usually do not explicitly consider multinational enterprises, foreign direct investment (FDI) and international location decisions of firms. In the extreme case, production facilities might be completely closed down in Europe, and new facilities might be installed elsewhere. Suppose, for example, 'Manufacturing of iron and steel' (ISM) is more labour intensive and less capital intensive than 'Further processing of iron and steel' (ISP). Then there can be a higher risk of relocation for ISM facilities than for ISP facilities ex ante. More technically speaking, our model does not capture firm's decision to deliver foreign markets via exports or FDI or to stay with the domestic market instead along the lines of the Melitz model. ${ }^{33}$ As a consequence, it probably underestimates firms' international relocation. Nevertheless, the model does capture a reduction in production in Europe, an expansion of production abroad, and enhanced related imports to Europe. We measure such effects in form of leakage and competitiveness measures in our analysis. Finally, the standard assumption of perfect competition that we make is more or less realistic for different sectors. We can thus not report in how far climate policy impacts on profit margins and investments taken from profits. Nevertheless, we can identify changes in sectoral investment patterns and thus changes in the development of sectoral capital stocks. In this sense, sectoral decarbonisation roadmaps such as IEA (2010) can be a helpful complement to the EU Decarbonisation Roadmap regarding the sectoral realization of macro policy. They can take sectoral technological solutions into account that are relevant for energy and emissions reductions, which is

\footnotetext{
${ }^{33}$ E.g. Melitz and Ottaviano (2008). For a CGE implementation of the Melitz model see Balistreri et al. (2011).
} 
only in a limited way possible in a top-down macro model. And for a successful realization of ambitious climate policy targets it appears useful if not inevitable to look deeper into strategies to implement them on a sectoral level or even on a firm level.

\subsection{Summary}

In summary, our model results become less robust the later the time periods under scrutiny. Additionally, they become less robust on the sectoral level than on the macro level. ${ }^{34}$ In this sense, it is not the main strength and purpose of such policy analyses to predict costs in absolute terms, but to highlight the different economic effects of alternative policy options in qualitative terms.

Against this backdrop, we find that in case of no carbon pricing in certain countries, an extensive future use of the Clean Development Mechanism (CDM) could exploit the cheap mitigation options in these countries. It could in this way drastically reduce the marginal abatement costs in EU ETS and non-ETS sectors and the resulting $\mathrm{CO} 2$ price differential. However, the assumption that $50 \%$ of each ETS and non-ETS reduction effort can stem from CDM appears optimistic. It is questionable whether such a CDM policy is politically feasible and technically and economically feasible regarding its transaction costs and given that it does not solve the global climate problem. And we do not model technology transfer associated with project-based CDM either. We understand CDM in the sense of 'where'-flexibility, this means the reduction of emissions where it is cheapest, such as in developing countries. Technology transfer associated with CDM could create additional emissions reductions abroad. And the availability of cheap mitigation options abroad relies on the assumption that the developing countries do not exploit these options by themselves. Nonetheless, one can still expect significant positive effects of CDM in a more limited form than assumed in our scenario.

Furthermore, the results show that Global Action will hardly benefit the EU in the absence of international emissions trading regarding its macroeconomic effects. Only the equalization of the CO2 price across EU ETS and non-ETS sectors as well as across countries within Global Action would drastically reduce the mitigation costs that show up in our model. Nonetheless, Global Action results in much lower emissions and thus lower climate change damages than Fragmented Action. Thus, while damages are neglected in our model, Global Action is clearly preferable compared to fragmented action in reality. Stern (2006), for example, estimates that damages due to climate change related extreme weather events could amount to between 0.5 and $1 \%$ of world GDP by the

\footnotetext{
${ }^{34}$ Results for single sectors can react sensitively and also depend on the sectoral disaggregation. The sectoral uncertainties average out on the macro level to some extent.
} 
middle of the century. ${ }^{35}$ These damages are not captured by our model simulations. Therefore, there will be additional costs under Fragmented Action compared to Global Action. Global Action is inevitable for reaching the $2^{\circ}$ climate target or any other acceptable temperature target independent of the realization of international emissions trading. ${ }^{36}$

\section{Conclusion}

We have carried out a detailed economic CGE analysis of the EU Decarbonisation Roadmap 2050 on a macroeconomic and on a sectoral level. We can basically learn three lessons:

(1) Technology: In comparison to other studies that implement more technological options such as CCS, extensive use of biomass or large-scale solar, we find higher mitigation costs in the case that technologies for electricity generation are restricted to those that are available today. Research and development and the wide use of advanced energy generation technologies as well as the use of energy-saving technologies in firms and households appear therefore inevitable. In particular when targeting emissions reductions of around $80 \%$ because our analysis indicates that mitigation costs can rise more than proportionately when reductions come close to $80 \%$.

(2) Policy: Mitigation costs also depend strongly on the policy design. Fragmented action, or in other words unilateral European climate action without using CDM to attribute emission reduction elsewhere, can lead to relatively high mitigation costs. Global climate action in combination with emissions trading between all countries and all EU sectors could avoid these costs to a large extent. An extended form of CDM could be applied to countries that are not part of the coalition and help disburden the EU regarding decarbonisation costs. However, the avoidance of severe climate change damages requires global action. In this sense, as a feasible policy option, one could make use of CDM in (smaller) countries that are not part of the climate coalition, while the main emitters were within the climate coalition. To conclude, not only the formulation of emissions targets but also the design of an appropriate, detailed policy strategy with a global perspective to implement them appears crucial.

(3) Sectors: sectoral policy effects can significantly differ from each other and from the macroeconomic effects. It appears therefore important for the practical realization of the

\footnotetext{
${ }^{35}$ For a comparison of estimates of climate change costs and damages see for example the Stern (2006) Review on Climate Change, in particular chapter 5 . The Stern estimates have been very controversially discussed.

${ }^{36}$ Our analysis does not target at a constant global temperature target. It rather assumes the same emissions target for the EU independent of other countries' climate efforts. Our analysis does not take climate damages stemming from higher global emissions into account, either.
} 
Decarbonisation Roadmap to look deeper into the sector-specific challenges and technological solution options and the related investments.

These three aspects are interlinked. For example, technological solutions are necessary to achieve ambitious climate targets at acceptable costs from a global perspective. An appropriate climate policy design is necessary to transfer the benefits from global level to the EU macro level and further to the sectoral level. And sectoral strategies by firms in correspondence with policy makers can be helpful to avoid structural and technological lock-in effects that might create high costs in certain sectors. In this light, this study has shown directions for Europe to make decarbonisation reality in an efficient way.

With regard to future research, our analysis shows that the sectoral impacts of climate policy can substantially deviate from the macro effects, and they also differ depending on the sectoral indicator applied. Moreover, sectoral results are often less robust than macro results. Hence, it is worthwhile shifting the focus of (numerical) climate policy assessment more to the sectoral level. This may also include sectoral climate policy approaches such as sectoral emissions caps.

\section{References}

Armington, P. (1969). A theory of demand for products distinguished by place of production. IMF Staff Papers 16, 159-178, Washington, DC, USA.

Babiker, M.H. and T.F. Rutherford (2005). The Economic Effects of Border Measures in Subglobal Climate Agreements. Energy Journal 26(4), 99-126.

Badri, N. and T. Walmsley, eds. (2008). The GTAP 7 data base. Purdue University, West Lafayette, Indiana, USA. https://www.gtap.agecon.purdue.edu/ (accessed 08/2011).

Balassa B. (1965). Trade Liberalization and Revealed Comparative Advantage, The Manchester School of Economic and Social Studies, 33, 99-123.

Balistreri, E.J., R.H. Hillberry and T.F. Rutherford (2011). Structural estimation and solution of international trade models with heterogeneous firms. Journal of International Economics 83, 95-108.

Böhringer, C. and A. Lange (2003). Efficiency, Compensation, and Discrimination: What is at Stake When Implementing the EU Emissions Trading Scheme? ZEW Discussion Paper No. 03-73, Mannheim, Germany.

Böhringer, C. and A. Löschel (2006). Promoting Renewable Energy in Europe: A Hybrid Computable General Equilibrium Approach. The Hybrid Modelling: New Answers to Old Challenges. The Energy Journal, 123-138.

Böhringer, C. and T.F. Rutherford (2008). Combining bottom-up and top-down. Energy Economics 30, 574-596. 
Böhringer, C., A. Löschel, U. Moslener and T.F. Rutherford (2009). EU climate policy up to 2020: An economic impact assessment. Energy Economics 31(2), 295-305.

Böhringer, C., C. Fischer and K.E. Rosendahl (2010). The Global Effects of Subglobal Climate Policies. The B.E. Journal of Economic Analysis \& Policy 10(2), 13.

Böhringer, C. and V. Alexeeva-Talebi (2011). Unilateral climate policy and competitiveness: The implications of differential emission pricing. Wirtschaftswissenschaftliche Diskussionspapiere des Instituts für Volkswirtschaftslehre Oldenburg V-338-11, 35 pp.

Bosetti, V., C. Carraro, E. Massetti and M. Tavoni (2008). International energy R\\&D spillovers and the economics of greenhouse gas atmospheric stabilization. Energy Economics 30(6), 2912-2929.

Brooke, A., D. Kendrick and A. Meeraus (2010). GAMS: A User's Guide. Tutorial by R. Rosenthal. GAMS Development Corporation, Washington, DC, USA, http://www.gams.com/dd/docs/bigdocs/GAMSUsersGuide.pdf (accessed 08/2011).

Dirkse, S. and M. Ferris (1995). The PATH Solver: A Non-monotone Stabilization Scheme for Mixed Complementarity Problems. Optimization Methods and Software 5, 123-156.

Edenhofer, O., B. Knopf, M. Leimbach and N. Bauer (guest editors) (2010). ADAM Modeling Comparison Project. The Economics of Low Stabilization. The Energy Journal 31 (Special Issue 1).

Edwards, T.H. and J.P. Hutton (2001). Allocation of carbon permits within a country: a general equilibrium analysis of the United Kingdom. Energy Economics 23(4), 371-386.

EU (2007). EU Energy Policy Data. European Commission, Brussels, Belgium. http://ec.europa.eu/energy/energy policy/doc/02 eu energy policy data en.pdf (accessed 09/ 2011).

EU (2009a). EU Energy Trends to 2030. European Commission, Brussels, Belgium. http://ec.europa.eu/energy/observatory/trends 2030/index en.htm (accessed 08/2011).

EU (2009b). Commission Decision of 24 December 2009 determining, pursuant to Directive 2003/87/EC of the European Parliament and of the Council, a list of sectors and subsectors which are deemed to be exposed to a significant risk of carbon leakage. Document $C(2009)$ 10251, Brussels, Belgium, http://eur-lex.europa.eu/LexUriServ/LexUriServ.do?uri=OJ:L:2010:001:0010:0018:EN:PDF (accessed 08/2011).

EU (2011). Roadmap for moving to a low-carbon economy in 2050. European Commission, Brussels, Belgium. Short version: http://ec.europa.eu/clima/policies/roadmap/index en.htm (accessed 08/2011).

Eurostat (2009). European economic indicators. Statistical Offices of the European Union, Luxembourg, http://epp.eurostat.ec.europa.eu/portal/page/portal/eurostat/home (accessed 01/2009).

$\mathrm{GCl}$ (1990). Contraction and Convergence (C\&C) is the science-based, global climate policy framework proposed to the UN since 1990 by the Global Commons Institute. http://www.gci.org.uk/ (accessed 12/2011)

Graichen, V., S. Healy, H. Hermann, K. Schumacher, A. Löschel, V. Alexeeva-Talebi, H. Kremers and S. Voigt (2010). Sectoral Approaches to fostering international action on climate change. Öko-Institut and ZEW, Berlin and Mannheim, Germany (available upon request).

Horridge, M. (2005) SplitCom: Programs to disaggregate a GTAP sector. Centre of Policy Studies, Monash University, Melbourne, Australia.

Hübler, M. (2011). Technology Diffusion under Contraction and Convergence: A CGE Analysis of China. Energy Economics 33(1), 131-142. 
IEA (2010). Cement Technology Roadmap 2009 - Carbon emissions reductions up to 2050. Paris, France, http://www.iea.org/papers/2009/Cement Roadmap.pdf (accessed 11/2011).

IEO (2008/2010). International Energy Outlook. EIA, US Energy Information Administration, Washington, DC, USA. http://www.eia.doe.gov/oiaf/ieo/ (accessed 08/2011). Detailed tables of the 2011 version: http://www.eia.gov/forecasts/ieo/ieo tables.cfm (accessed 10/2011).

Jensen, J. and T.N. Rasmussen (2000). Allocation of CO2 Permits: A General Equilibrium Analysis of Policy Instruments. Journal of Environmental Economics and Management 40(2), 111-136.

Klepper, G. and S. Peterson (2006). Emissions Trading, CDM, Jl, and More: The Climate Strategy of the EU. The Energy Journal 27 (2), 1-26.

Leimbach, M., N. Bauer, L. Baumstark and O. Edenhofer (2010). Mitigation costs in a globalized world: climate policy analysis with REMIND-R. Environmental Modeling and Assessment 15, 155-173.

Löschel, A., C. Böhringer, V. Alexeeva-Talebi, J. Kremers and S. Voigt (2009). Broadening the scope of the analysis of the possible risk of Carbon leakage induced by the third revision of the Emission Trading Scheme on Energy Intensive Industries. ZEW, Mannheim, Germany (available upon request).

Melitz M.J. and G.I.P. Ottaviano (2008). Market size, trade, and productivity. The Review of Economic Studies 75(1), 295-316.

Otto, V.M., A. Löschel and J. Reilly (2008). Directed Technical Change and Differentiated Climate Policy. Energy Economics 30 (6), 2855-2878.

Paltsev, S., J.M. Reilly, H.D. Jacoby, R.S. Eckaus, J. McFarland, M. Sarofim, M. Asadoorian and M. Babiker (2005). The MIT Emissions Prediction and Policy Analysis (EPPA) Model: Version 4. The MIT Joint Program on the Science and Policy of Global Change, Cambridge MA, USA, 78 pp.

Popp, D. (2004). ENTICE: endogenous technological change in the DICE model of global warming. Journal of Environmental Economics and Management 48, 742-768.

Reichel, R. (2002). Ökonomische Theorie der internationalen Wettbewerbsfähigkeit von Volkswirtschaften. Deutscher Universitäts-Verlag GmbH, Wiesbaden, Germany.

Rutherford, T.F. (1999). Applied General Equilibrium Modeling with MPSGE as a GAMS Subsystem: An Overview of the Modeling Framework and Syntax. Computational Economics 14, 1-46.

Saito, M. (2004). Armington elasticities in intermediate inputs trade: a problem in using multilateral trade data. Canadian Journal of Economics 37(4), 1097-1117.

Stern, N. (2006). Review on Climate Change. HM Treasury, London, UK, http://webarchive.nationalarchives.gov.uk/+/http://www.hmtreasury.gov.uk/stern review report.htm (accessed 11/2011).

UN (2009a). United Nations Industrial Commodity Statistics Database. USA, http://data.un.org/Browse.aspx?d=ICS (accessed 08/2011).

UN (2009b). United Nations Commodity Trade Statistics Database. USA, http://comtrade.un.org/ (accessed 08/2011). 


\section{Supplementary Appendix}

\subsection{Appendix M}

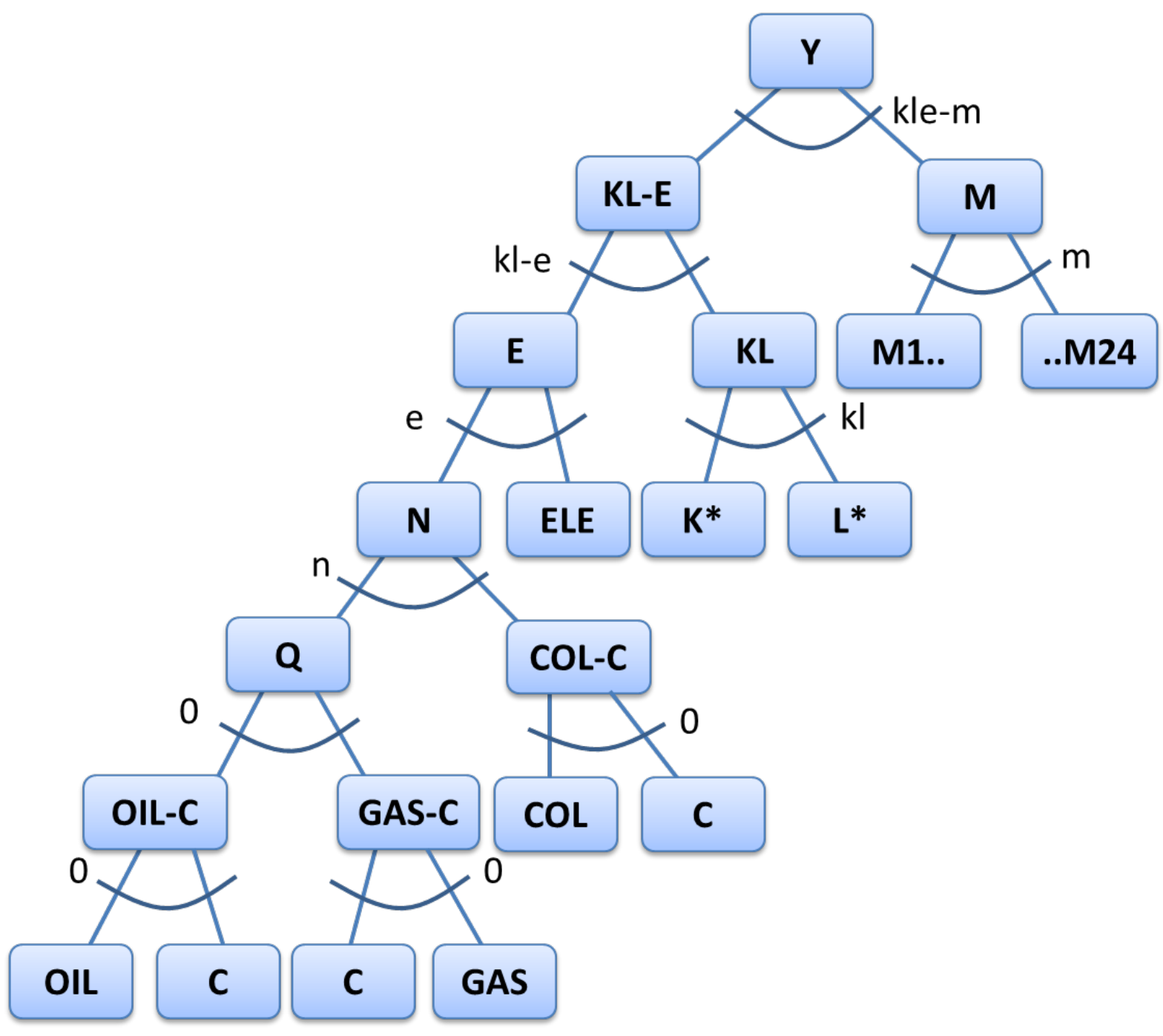

Figure M1: The main CES production structure for each sector and region. Inputs are written in capital letters, elasticities of substitution in lower case letters; $Y=$ output, $K=$ capital, $L=$ labour, ${ }^{*}$ the sectorspecific production factor natural resources additionally enters here, $E=$ energy, $M 1 . . M 24=$ intermediates, $N=$ non-electricity, $Q=$ liquid, $C=\mathrm{CO} 2$ 


\begin{tabular}{|l|rrrrrrrr|}
\hline & \multicolumn{1}{l}{$\mathrm{kle}-\mathrm{m}$} & $\mathrm{kl}-\mathrm{e}$ & $\mathrm{m}$ & $\mathrm{e}$ & $\mathrm{kl}$ & $\mathrm{n}$ & \multicolumn{1}{c|}{$\mathrm{a} 1$} & $\mathrm{a} 2$ \\
\cline { 2 - 9 } OIL & 0.848 & 0.250 & 0.082 & 0.500 & 0.334 & 0.500 & 4.200 & 2.100 \\
GAS & 0.250 & 0.256 & 0.391 & 0.500 & 0.460 & 0.500 & 4.000 & 2.000 \\
MIN & 0.729 & 0.553 & 0.309 & 0.500 & 0.139 & 0.500 & 2.347 & 1.836 \\
PPP & 0.187 & 0.211 & 0.250 & 0.500 & 0.381 & 0.500 & 5.900 & 2.950 \\
FER & 0.848 & 0.250 & 0.082 & 0.500 & 0.334 & 0.500 & 6.600 & 3.300 \\
ORG & 0.848 & 0.250 & 0.082 & 0.500 & 0.334 & 0.500 & 6.600 & 3.300 \\
INO & 0.848 & 0.250 & 0.082 & 0.500 & 0.334 & 0.500 & 6.600 & 3.300 \\
OCR & 0.848 & 0.250 & 0.082 & 0.500 & 0.334 & 0.500 & 6.600 & 3.300 \\
CEM & 0.306 & 0.411 & 0.191 & 0.500 & 0.358 & 0.500 & 5.800 & 2.900 \\
BRT & 0.306 & 0.411 & 0.191 & 0.500 & 0.358 & 0.500 & 5.800 & 2.900 \\
ONM & 0.306 & 0.411 & 0.191 & 0.500 & 0.358 & 0.500 & 5.800 & 2.900 \\
ISM & 1.173 & 0.644 & 0.253 & 0.500 & 0.220 & 0.500 & 5.900 & 2.950 \\
ISP & 1.173 & 0.644 & 0.253 & 0.500 & 0.220 & 0.500 & 5.900 & 2.950 \\
ALU & 0.306 & 0.411 & 0.191 & 0.500 & 0.358 & 0.500 & 8.400 & 4.200 \\
ONF & 0.306 & 0.411 & 0.191 & 0.500 & 0.358 & 0.500 & 8.400 & 4.200 \\
ELE & - & - & - & - & - & - & - & - \\
COL & 0.729 & 0.553 & 0.309 & 0.500 & 0.139 & 0.500 & 6.100 & 3.050 \\
CRU & 0.729 & 0.553 & 0.309 & 0.500 & 0.139 & 0.500 & 10.400 & 5.200 \\
MCH & 0.548 & 0.519 & 1.087 & 0.500 & 0.144 & 0.500 & 7.717 & 3.863 \\
FAW & 0.329 & 0.395 & 0.250 & 0.500 & 0.382 & 0.500 & 5.289 & 2.647 \\
TWL & 0.722 & 0.637 & 0.597 & 0.500 & 0.161 & 0.500 & 7.572 & 3.772 \\
TRN & 0.352 & 0.281 & 0.331 & 0.500 & 0.310 & 0.500 & 3.800 & 1.900 \\
SER & 0.492 & 0.320 & 0.250 & 0.500 & 0.264 & 0.500 & 3.803 & 1.908 \\
\hline
\end{tabular}

Table M1: Sectoral CES elasticities of substitution corresponding to Figure M1; additionally a1 denotes the Armington elasticity between imported varieties and a2 between imported varieties and the domestic variety of each good

This section lists the key model equations, i.e. it describes the model in a stylized way that highlights the principal structure. The model equations are written as a mixed complementarity problem (MCP) for each region $(r)$ described in section 2.3 and each period $(t)$. An MCP consists of zero-profit and market clearance conditions and a consumer's budget condition. The model equations are implicitly programmed under GAMS/MSPGE. $p$ denotes a price, $X$ denotes a pecuniary quantity. $i$ or $j$ denote a sector described in section 2.3. $f$ denotes the production factors capital $(K)$, labour $(L)$ and natural fossil resources. $\theta_{f, i}^{G}$ represents a set of taxes and subsidy rates on output and inputs. $M$ indicates an Armington (intermediate) good. $C$ is $\mathrm{CO} 2$ associated with fossil fuel inputs in fixed proportion. $\pi$ denotes profits, CES a constant elasticity of substitution function with the elasticity written as an upper index, and $L T F$ a Leontief function. 


\section{Zero-profit conditions:}

(Z1a) Goods $(Y)$ production (in sectors $i$ except ELE in EUR) with the notation explained below Figure M1:

$$
\begin{gathered}
\pi_{i}^{Y}=p_{i}^{Y}-C E S_{i}^{k l e-m}\left\lceil C E S_{i}^{k l-e}\lfloor\right. \\
\left.C E S_{i}^{e}\left\langle C E S_{i}^{n}\left\{\operatorname{LTF}\left[\operatorname{LTF}\left(p^{O I L}, p^{C}\right), \operatorname{LTF}\left(p^{G A S}, p^{C}\right)\right], \operatorname{LTF}\left(p^{C O L}, p^{C}\right)\right\}, p^{E L E}\right\rangle,\left.C E S_{i}^{k l}\right|_{f}\left(p_{f}^{F}, p_{f, i}^{F}\right) \quad\right], \\
\left.\left.C E S_{i}^{m}\right|_{j}\left(p_{j}^{M}\right)\right\rceil \mid \theta_{f, i}^{G} \leq 0 \forall(r, t)
\end{gathered}
$$

(Z1b) Electricity generation (ELE) in Europe (EUR) including a specific input factor ( $M, E L E)$ and a fixed factor ( $F$, ELE):

$$
\pi_{\mathrm{ELE}}^{Y}=p_{\mathrm{ELE}}-C E S_{\mathrm{ELE}}^{f-e l e}\left[p^{F, \mathrm{ELE}}, \operatorname{LTF}\left(p_{j}^{M}, p^{C}, p^{M, \mathrm{ELE}}\right)\right] \mid \theta_{f, i}^{G} \leq 0 \quad \forall(\mathrm{EUR}, t)
$$

(Z2) Armington aggregation ( $M$ ) of imports from foreign regions ( $s$ ), associated with a price for transportation $\left(p_{s, r, i}^{T}\right)$ and an elasticity of substitution (a1), and of domestic goods (a2):

$$
\pi_{i}^{M}=p_{i}^{M}-C E S_{i}^{a 2}\left\{p_{i}^{Y},\left.C E S_{i}^{a 1}\right|_{S}\left[\operatorname{LTF}\left(p_{s, i}^{Y}, p_{s, r, i}^{T}\right)\right]\right\} \mid \theta_{f, i}^{G} \leq 0 \forall(r, t)
$$

(Z3) Utility $(U)$ generation of the representative consumer in each region $(r)$ follows the nest structure shown in Figure M1 excluding factor inputs, i.e. it combines an energy with a nonenergy input bundle:

$$
\pi^{U}=p^{U}-\left.C E S^{u}\right|_{i}\left(p_{i}^{Y},\right) \leq 0 \forall(r, t)
$$

\section{Market clearance conditions:}

(M1) Goods markets (domestic inputs, Armington exports and domestic consumption):

$$
\sum_{j} \frac{\partial \pi_{j}^{Y}}{\partial p_{i}^{Y}} X_{j}^{Y}+\sum_{s} \frac{\partial \pi_{s, i}^{M}}{\partial p_{i}^{Y}} X_{s, i}^{M}+\frac{\partial \pi^{U}}{\partial p_{i}^{Y}} X^{U} \leq X_{i}^{Y} \forall(r, t)
$$


(M2) Armington goods (M) markets:

$$
\sum_{j} \frac{\partial \pi_{j}^{Y}}{\partial p_{i}^{M}} Y_{j} \leq X_{i}^{M} \quad \forall(r, t)
$$

(M3a) Intratemporal utility condition referring to the consumer's budget $(B):{ }^{37}$

$$
\frac{X^{B}}{p^{U}} \leq X^{U} \forall(r, t)
$$

(M3b) Factor $(F)$ markets (for mobile and immobile factors given regional factor endowments):

$$
\sum_{i} \frac{\partial \pi_{i}^{Y}}{\partial p_{f}^{F}} Y_{i}+\sum_{i} X_{f, i}^{F} \leq \bar{X}_{f}^{F} \forall(r, t)
$$

\section{Budget condition:}

(B1) Consumers' purchases and investments (I) must not exceed their factor income (from the sectorally mobile and immobile parts of factors including natural fossil resources) plus revenues from selling $\mathrm{CO} 2(C)$ allowances plus tax minus subsidy $(Q)$ revenues as a function of given tax and subsidy rates, plus net financial inflows from abroad $(D)$ :

$1 \cdot X^{B}=\sum_{i} p_{i}^{Y} X_{i}^{Y}+p^{I} X^{I} \leq \sum_{f}\left[p_{f, i}^{F} X_{f, i}^{F}+p_{f}^{F}\left(\bar{X}_{f}^{F}-X_{f, i}^{F}\right)\right]+p^{C} \bar{X}^{C}+X^{G}\left(\theta_{f, i}^{G}\right)+p^{D} X^{D} \quad \forall(r, t)$

\footnotetext{
${ }^{37}$ Compare Markusen's tutorial, http://spot.colorado.edu/ markusen/teaching.html (accessed 12/2011).
} 
7.2. Appendix 0

(Table $\mathrm{O} 1$ is intentionally left out since we do not study sectoral changes under the Reference scenario.)

\begin{tabular}{|lrrrrrrrrrr|}
\hline & 2005 & 2010 & 2015 & 2020 & 2025 & 2030 & 2035 & 2040 & 2045 & 2050 \\
\cline { 2 - 9 } OIL & 0.0 & 0.0 & -1.8 & -2.5 & -7.2 & -15.4 & -21.1 & -33.6 & -46.2 & -55.9 \\
GAS & 0.0 & 0.0 & -5.5 & -7.6 & -18.6 & -20.1 & -30.5 & -51.4 & -71.2 & -75.0 \\
MIN & 0.0 & 0.0 & 0.0 & -0.1 & -0.2 & -0.2 & -0.3 & -0.5 & -0.7 & -0.8 \\
PPP & 0.0 & 0.0 & -0.1 & -0.1 & -0.4 & -0.6 & -0.8 & -1.5 & -2.0 & -2.6 \\
FER & 0.0 & 0.0 & -0.4 & -0.5 & -1.6 & -2.3 & -2.9 & -5.2 & -7.2 & -8.7 \\
ORG & 0.0 & 0.0 & -0.3 & -0.4 & -1.3 & -1.9 & -2.5 & -4.4 & -6.1 & -7.5 \\
INO & 0.0 & 0.0 & -0.3 & -0.5 & -1.5 & -2.2 & -2.8 & -5.0 & -6.8 & -8.3 \\
OCR & 0.0 & 0.0 & -1.0 & -1.4 & -4.3 & -4.8 & -6.3 & -11.3 & -15.8 & -18.8 \\
CEM & 0.0 & 0.0 & -0.1 & -0.2 & -0.5 & -0.9 & -1.2 & -2.1 & -2.8 & -3.6 \\
BRT & 0.0 & 0.0 & -0.1 & -0.2 & -0.6 & -1.2 & -1.5 & -2.5 & -3.2 & -4.0 \\
ONM & 0.0 & 0.0 & -0.2 & -0.3 & -0.7 & -1.0 & -1.2 & -2.2 & -2.8 & -3.6 \\
ISM & 0.0 & 0.0 & -0.2 & -0.2 & -0.6 & -1.6 & -2.0 & -3.2 & -3.9 & -4.8 \\
ISP & 0.0 & 0.0 & -0.4 & -0.4 & -1.1 & -1.8 & -2.2 & -3.5 & -4.2 & -5.1 \\
ALU & 0.0 & 0.0 & -0.5 & -0.7 & -1.6 & -2.1 & -2.7 & -4.3 & -5.0 & -5.8 \\
ONF & 0.0 & 0.0 & -0.6 & -0.7 & -1.8 & -2.0 & -2.6 & -4.2 & -4.9 & -5.7 \\
ELE & 0.0 & 0.0 & -1.5 & -1.9 & -3.6 & -3.9 & -3.8 & -4.2 & 1.2 & 2.1 \\
COL & 0.0 & 0.0 & -2.0 & -4.0 & -12.7 & -13.1 & -20.0 & -35.1 & -48.3 & -66.3 \\
CRU & 0.0 & 0.0 & -0.3 & -0.6 & -2.1 & -3.0 & -4.4 & -8.6 & -14.3 & -19.6 \\
MCH & 0.0 & 0.0 & 0.1 & 0.1 & 0.4 & 0.4 & 0.5 & 0.9 & 1.2 & 1.4 \\
FAW & 0.0 & 0.0 & -0.1 & -0.2 & -0.7 & -0.8 & -1.1 & -2.1 & -3.1 & -3.8 \\
TWL & 0.0 & 0.0 & 0.0 & 0.0 & 0.0 & 0.0 & -0.1 & -0.3 & -0.6 & -0.9 \\
TRN & 0.0 & 0.0 & -1.1 & -1.7 & -5.2 & -5.9 & -7.8 & -13.9 & -19.5 & -23.2 \\
SER & 0.0 & 0.0 & 0.0 & 0.0 & 0.0 & -0.1 & -0.1 & -0.3 & -0.4 & -0.6 \\
\hline
\end{tabular}

Table 02: Relative output changes between the Fragmented Action scenario and the Reference scenario in each year in EU-27 sectors in \% 


\begin{tabular}{|lrrrrrrrrrr|}
\hline & 2005 & 2010 & 2015 & 2020 & 2025 & 2030 & 2035 & 2040 & 2045 & 2050 \\
\cline { 2 - 5 } & 0.0 & 0.0 & -1.8 & -2.5 & -7.2 & 6.4 & 6.8 & 3.9 & 3.1 & 6.3 \\
GAS & 0.0 & 0.0 & -5.5 & -7.6 & -18.6 & -29.0 & -42.1 & -62.3 & -74.6 & -77.6 \\
MIN & 0.0 & 0.0 & 0.0 & -0.1 & -0.2 & -0.2 & -0.2 & -0.4 & -0.6 & -0.8 \\
PPP & 0.0 & 0.0 & -0.1 & -0.1 & -0.4 & -0.5 & -0.7 & -1.4 & -2.0 & -2.5 \\
FER & 0.0 & 0.0 & -0.4 & -0.5 & -1.6 & -1.1 & -1.6 & -3.4 & -5.2 & -6.6 \\
ORG & 0.0 & 0.0 & -0.3 & -0.4 & -1.3 & -0.7 & -1.0 & -2.5 & -4.0 & -5.2 \\
INO & 0.0 & 0.0 & -0.3 & -0.5 & -1.5 & -1.0 & -1.5 & -3.3 & -5.0 & -6.4 \\
OCR & 0.0 & 0.0 & -1.0 & -1.4 & -4.3 & -4.8 & -6.4 & -11.4 & -15.8 & -18.8 \\
CEM & 0.0 & 0.0 & -0.1 & -0.2 & -0.5 & -0.1 & -0.3 & -0.8 & -1.4 & -2.0 \\
BRT & 0.0 & 0.0 & -0.1 & -0.2 & -0.6 & -0.1 & -0.2 & -0.8 & -1.5 & -2.0 \\
ONM & 0.0 & 0.0 & -0.2 & -0.3 & -0.7 & -0.6 & -0.8 & -1.5 & -2.2 & -2.8 \\
ISM & 0.0 & 0.0 & -0.2 & -0.2 & -0.6 & 0.8 & 0.8 & 0.6 & 0.5 & 0.3 \\
ISP & 0.0 & 0.0 & -0.4 & -0.4 & -1.1 & -0.3 & -0.5 & -1.0 & -1.2 & -1.6 \\
ALU & 0.0 & 0.0 & -0.5 & -0.7 & -1.6 & -1.3 & -1.8 & -3.0 & -3.0 & -3.4 \\
ONF & 0.0 & 0.0 & -0.6 & -0.7 & -1.8 & -1.9 & -2.5 & -3.9 & -4.2 & -4.9 \\
ELE & 0.0 & 0.0 & -1.5 & -1.9 & -3.6 & -5.9 & -5.8 & -5.3 & 0.8 & 2.0 \\
COL & 0.0 & 0.0 & -2.0 & -4.0 & -12.7 & -19.8 & -28.2 & -45.8 & -76.9 & -98.3 \\
CRU & 0.0 & 0.0 & -0.3 & -0.6 & -2.1 & -2.3 & -3.6 & -7.5 & -12.2 & -16.3 \\
MCH & 0.0 & 0.0 & 0.1 & 0.1 & 0.4 & 0.5 & 0.6 & 1.0 & 1.4 & 1.8 \\
FAW & 0.0 & 0.0 & -0.1 & -0.2 & -0.7 & -0.9 & -1.2 & -2.3 & -3.4 & -4.2 \\
TWL & 0.0 & 0.0 & 0.0 & 0.0 & 0.0 & -0.2 & -0.3 & -0.6 & -0.9 & -1.2 \\
TRN & 0.0 & 0.0 & -1.1 & -1.7 & -5.2 & -5.8 & -7.7 & -13.9 & -19.5 & -23.3 \\
SER & 0.0 & 0.0 & 0.0 & 0.0 & 0.0 & -0.1 & -0.1 & -0.3 & -0.5 & -0.7 \\
\hline
\end{tabular}

Table 03: Relative output changes between the Fragmented Action Free scenario and the Reference scenario in each year in EU-27 sectors in \% 


\begin{tabular}{|lrrrrrrrrrr|}
\hline & 2005 & 2010 & 2015 & 2020 & 2025 & 2030 & 2035 & 2040 & 2045 & 2050 \\
\cline { 2 - 6 } & 5.5 & 5.7 & 0.8 & 0.2 & 7.6 & 16.5 & 15.9 & 9.5 & 2.4 & -1.5 \\
GAS & 6.2 & 2.9 & 4.3 & 5.1 & 14.1 & 18.5 & 17.9 & 10.7 & 3.1 & -0.8 \\
MIN & 0.0 & 0.0 & 0.0 & 0.1 & 0.1 & 0.2 & 0.1 & 0.1 & 0.0 & 0.0 \\
PPP & 0.1 & 0.1 & 0.1 & 0.2 & 0.2 & 0.3 & 0.4 & 0.3 & 0.2 & 0.1 \\
FER & 0.6 & 0.6 & 0.3 & 0.3 & 1.2 & 1.9 & 1.7 & 1.1 & 0.4 & 0.0 \\
ORG & 0.5 & 0.6 & 0.3 & 0.3 & 0.9 & 1.5 & 1.4 & 1.0 & 0.4 & 0.1 \\
INO & 0.5 & 0.6 & 0.3 & 0.3 & 1.1 & 1.7 & 1.6 & 1.0 & 0.4 & 0.1 \\
OCR & 1.2 & 1.1 & 0.3 & 0.1 & 3.5 & 4.7 & 3.8 & 1.9 & 0.0 & -1.0 \\
CEM & 0.2 & 0.3 & 0.2 & 0.3 & 0.3 & 0.6 & 0.7 & 0.5 & 0.3 & 0.2 \\
BRT & 0.3 & 0.4 & 0.3 & 0.4 & 0.4 & 0.8 & 0.8 & 0.7 & 0.4 & 0.3 \\
ONM & 0.2 & 0.3 & 0.4 & 0.5 & 0.4 & 0.6 & 0.7 & 0.6 & 0.4 & 0.3 \\
ISM & 0.5 & 0.7 & 0.5 & 0.8 & 0.3 & 1.0 & 1.2 & 1.2 & 0.9 & 0.8 \\
ISP & 0.6 & 0.9 & 1.0 & 1.4 & 0.5 & 1.1 & 1.3 & 1.3 & 1.0 & 0.9 \\
ALU & 0.7 & 1.1 & 1.4 & 2.0 & 0.7 & 1.2 & 1.5 & 1.6 & 1.4 & 1.4 \\
ONF & 0.7 & 1.0 & 1.5 & 2.1 & 0.8 & 1.1 & 1.5 & 1.5 & 1.3 & 1.3 \\
ELE & 0.3 & 0.9 & 3.8 & 5.3 & 1.6 & 2.1 & 2.5 & 2.2 & 1.2 & 0.8 \\
COL & 1.2 & 2.1 & 3.6 & 7.9 & 7.3 & 9.3 & 13.1 & 11.6 & 9.0 & 7.0 \\
CRU & 0.7 & 0.5 & -0.1 & -0.3 & 1.6 & 2.6 & 2.2 & 1.0 & -0.2 & -1.0 \\
MCH & -0.1 & -0.1 & 0.0 & 0.0 & -0.3 & -0.3 & -0.2 & -0.1 & 0.1 & 0.1 \\
FAW & 0.1 & 0.1 & 0.0 & 0.0 & 0.5 & 0.7 & 0.5 & 0.3 & 0.0 & -0.1 \\
TWL & -0.1 & -0.1 & 0.0 & 0.0 & 0.0 & 0.0 & 0.0 & 0.1 & 0.0 & 0.0 \\
TRN & 1.4 & 1.2 & 0.1 & -0.2 & 4.4 & 5.9 & 4.7 & 2.2 & -0.2 & -1.4 \\
SER & 0.0 & 0.0 & 0.0 & 0.0 & 0.0 & 0.0 & 0.0 & 0.0 & 0.0 & 0.0 \\
\hline
\end{tabular}

Table 04: Relative output changes between the Fragmented Action CDM scenario and the Reference scenario in each year in EU-27 sectors in \% 


\begin{tabular}{|lrrrrrrrrrr|}
\hline & 2005 & 2010 & 2015 & 2020 & 2025 & 2030 & 2035 & 2040 & 2045 & 2050 \\
\cline { 2 - 5 } & 0.0 & 0.0 & -1.8 & -2.5 & -6.7 & -14.7 & -20.2 & -31.4 & -44.7 & -54.1 \\
GAS & 0.0 & 0.0 & -5.5 & -7.6 & -19.4 & -22.2 & -36.3 & -59.8 & -82.4 & -92.5 \\
MIN & 0.0 & 0.0 & 0.0 & -0.1 & -0.2 & -0.2 & -0.3 & -0.6 & -0.8 & -1.1 \\
PPP & 0.0 & 0.0 & -0.1 & -0.1 & -0.4 & -0.6 & -0.8 & -1.6 & -2.3 & -2.9 \\
FER & 0.0 & 0.0 & -0.4 & -0.5 & -1.1 & -1.1 & -0.4 & -0.3 & 0.3 & 2.9 \\
ORG & 0.0 & 0.0 & -0.3 & -0.4 & -0.9 & -0.9 & -0.3 & -0.1 & 1.0 & 4.2 \\
INO & 0.0 & 0.0 & -0.3 & -0.5 & -1.2 & -1.3 & -1.0 & -1.5 & -1.3 & 0.8 \\
OCR & 0.0 & 0.0 & -1.0 & -1.4 & -3.9 & -3.6 & -3.9 & -6.7 & -8.6 & -7.1 \\
CEM & 0.0 & 0.0 & -0.1 & -0.2 & -0.5 & -0.8 & -1.0 & -1.8 & -2.4 & -2.6 \\
BRT & 0.0 & 0.0 & -0.1 & -0.2 & -0.6 & -1.1 & -1.3 & -2.3 & -3.0 & -3.3 \\
ONM & 0.0 & 0.0 & -0.2 & -0.3 & -0.6 & -0.7 & -0.6 & -1.2 & -1.5 & -1.3 \\
ISM & 0.0 & 0.0 & -0.2 & -0.2 & -0.4 & -1.2 & -1.2 & -1.9 & -2.4 & -2.8 \\
ISP & 0.0 & 0.0 & -0.4 & -0.4 & -0.7 & -0.8 & -0.2 & 0.1 & 0.8 & 2.1 \\
ALU & 0.0 & 0.0 & -0.5 & -0.7 & -1.5 & -1.6 & -1.7 & -2.9 & -3.7 & -4.3 \\
ONF & 0.0 & 0.0 & -0.6 & -0.7 & -1.6 & -1.5 & -1.6 & -2.9 & -3.8 & -4.4 \\
ELE & 0.0 & 0.0 & -1.5 & -1.9 & -3.6 & -3.5 & -3.1 & -4.3 & 2.5 & 5.7 \\
COL & 0.0 & 0.0 & -2.0 & -4.0 & -16.4 & -22.6 & -43.2 & -70.0 & -75.5 & -83.0 \\
CRU & 0.0 & 0.0 & -0.3 & -0.6 & -2.4 & -4.1 & -7.8 & -16.6 & -31.6 & -55.4 \\
MCH & 0.0 & 0.0 & 0.1 & 0.1 & 0.2 & 0.0 & -0.3 & -0.6 & -1.3 & -2.7 \\
FAW & 0.0 & 0.0 & -0.1 & -0.2 & -0.7 & -0.9 & -1.4 & -2.7 & -4.2 & -5.4 \\
TWL & 0.0 & 0.0 & 0.0 & 0.0 & -0.1 & -0.2 & -0.5 & -1.0 & -1.5 & -2.2 \\
TRN & 0.0 & 0.0 & -1.1 & -1.7 & -5.1 & -5.6 & -7.1 & -12.4 & -17.3 & -19.3 \\
SER & 0.0 & 0.0 & 0.0 & 0.0 & -0.1 & -0.1 & -0.2 & -0.5 & -0.8 & -1.1 \\
\hline
\end{tabular}

Table 05: Relative output changes between the Global Action scenario and the Reference scenario in each year in EU-27 sectors in \% 


\begin{tabular}{|lrrrrrrrrrr|}
\hline & 2005 & 2010 & 2015 & 2020 & 2025 & 2030 & 2035 & 2040 & 2045 & 2050 \\
\cline { 2 - 5 } & -6.6 & -2.4 & -13.4 & -14.9 & -14.9 & -1.6 & -7.4 & -18.2 & -38.4 & -48.9 \\
GAS & 19.1 & 4.8 & 8.1 & 11.0 & 2.0 & 0.7 & -17.8 & -38.9 & -63.6 & -82.4 \\
MIN & 0.0 & 0.0 & -0.1 & -0.1 & -0.2 & -0.2 & -0.2 & -0.4 & -0.7 & -1.0 \\
PPP & -0.3 & -0.1 & -0.3 & -0.5 & -0.8 & -0.9 & -1.3 & -2.1 & -2.7 & -3.3 \\
FER & -0.3 & -0.1 & -1.2 & -1.5 & -1.8 & -0.3 & 0.2 & 0.3 & -1.1 & -0.5 \\
ORG & -0.7 & -0.2 & -1.4 & -1.8 & -2.2 & -0.8 & -0.5 & -0.6 & -1.9 & -1.1 \\
INO & -0.4 & -0.1 & -1.2 & -1.5 & -2.0 & -0.7 & -0.7 & -1.3 & -3.0 & -2.8 \\
OCR & 3.2 & 1.2 & 0.7 & 1.6 & 1.9 & 4.0 & 3.7 & 2.9 & 0.7 & 1.9 \\
CEM & -0.8 & -0.3 & -1.2 & -1.6 & -2.2 & -1.8 & -2.0 & -3.1 & -4.7 & -6.0 \\
BRT & -1.2 & -0.5 & -1.5 & -2.0 & -2.8 & -2.4 & -2.7 & -4.1 & -6.0 & -7.3 \\
ONM & -1.1 & -0.4 & -1.2 & -1.5 & -2.1 & -1.9 & -2.0 & -2.9 & -4.5 & -5.6 \\
ISM & -2.7 & -1.0 & -3.3 & -4.5 & -5.9 & -4.8 & -5.2 & -6.7 & -8.4 & -10.1 \\
ISP & -3.3 & -1.2 & -3.4 & -4.5 & -6.0 & -5.1 & -5.1 & -5.7 & -6.3 & -7.0 \\
ALU & -3.8 & -1.5 & -3.7 & -5.3 & -7.6 & -7.8 & -8.8 & -11.2 & -11.2 & -12.3 \\
ONF & -3.4 & -1.3 & -3.1 & -4.5 & -6.7 & -7.1 & -8.2 & -10.5 & -10.6 & -11.7 \\
ELE & -3.1 & -1.3 & -3.3 & -6.8 & -9.8 & -13.5 & -9.4 & -7.0 & 4.5 & 6.4 \\
COL & -1.7 & -2.0 & -3.1 & -9.0 & -33.4 & -65.4 & -70.8 & -98.6 & -99.5 & -99.8 \\
CRU & 1.3 & 0.4 & 0.1 & 0.8 & 1.2 & 2.2 & 0.0 & -4.8 & -14.9 & -33.0 \\
MCH & -0.5 & -0.2 & -0.2 & -0.3 & -0.5 & -0.8 & -1.2 & -1.9 & -2.5 & -4.0 \\
FAW & 0.4 & 0.1 & 0.2 & 0.3 & 0.2 & 0.2 & -0.3 & -1.3 & -2.7 & -3.9 \\
TWL & 0.0 & 0.0 & 0.2 & 0.2 & 0.1 & -0.2 & -0.6 & -1.1 & -1.5 & -2.1 \\
TRN & 4.2 & 1.5 & 1.0 & 2.3 & 2.6 & 4.9 & 3.9 & 1.4 & -4.1 & -6.4 \\
SER & 0.0 & 0.0 & 0.0 & 0.0 & -0.1 & -0.1 & -0.2 & -0.5 & -0.7 & -0.9 \\
\hline
\end{tabular}

Table 06: Relative output changes between the Global Action National scenario and the Reference scenario in each year in EU-27 sectors in \% 


\begin{tabular}{|lrrrrrrrrrr|}
\hline & 2005 & 2010 & 2015 & 2020 & 2025 & 2030 & 2035 & 2040 & 2045 & 2050 \\
\cline { 2 - 6 } & 0.0 & 0.0 & -1.8 & -2.5 & 16.2 & 33.6 & 29.1 & 15.3 & -2.0 & -22.3 \\
GAS & 0.0 & 0.0 & -5.5 & -7.6 & 31.3 & 32.6 & 28.4 & 7.4 & -39.6 & -73.4 \\
MIN & 0.0 & 0.0 & 0.0 & -0.1 & 0.2 & 0.3 & 0.2 & 0.1 & -0.2 & -0.5 \\
PPP & 0.0 & 0.0 & -0.1 & -0.1 & 0.5 & 0.6 & 0.5 & -0.1 & -1.4 & -2.3 \\
FER & 0.0 & 0.0 & -0.4 & -0.5 & 2.3 & 4.3 & 4.8 & 5.4 & 5.0 & 5.4 \\
ORG & 0.0 & 0.0 & -0.3 & -0.4 & 1.8 & 3.4 & 3.9 & 4.5 & 4.3 & 5.2 \\
INO & 0.0 & 0.0 & -0.3 & -0.5 & 2.1 & 3.6 & 3.6 & 3.6 & 2.6 & 2.5 \\
OCR & 0.0 & 0.0 & -1.0 & -1.4 & 6.8 & 9.2 & 9.0 & 8.9 & 7.7 & 8.8 \\
CEM & 0.0 & 0.0 & -0.1 & -0.2 & 0.8 & 1.4 & 1.3 & 0.7 & -0.9 & -2.6 \\
BRT & 0.0 & 0.0 & -0.1 & -0.2 & 1.0 & 1.6 & 1.3 & 0.4 & -1.6 & -3.6 \\
ONM & 0.0 & 0.0 & -0.2 & -0.3 & 1.1 & 1.5 & 1.5 & 1.2 & -0.3 & -1.7 \\
ISM & 0.0 & 0.0 & -0.2 & -0.2 & 1.2 & 2.7 & 2.7 & 1.9 & -1.4 & -3.9 \\
ISP & 0.0 & 0.0 & -0.4 & -0.4 & 1.9 & 3.2 & 3.8 & 3.9 & 1.4 & 0.3 \\
ALU & 0.0 & 0.0 & -0.5 & -0.7 & 2.9 & 3.5 & 3.7 & 2.1 & -3.6 & -5.6 \\
ONF & 0.0 & 0.0 & -0.6 & -0.7 & 3.1 & 3.6 & 3.9 & 2.6 & -2.7 & -4.5 \\
ELE & 0.0 & 0.0 & -1.5 & -1.9 & 6.2 & 4.7 & 3.2 & -2.1 & -0.1 & 4.1 \\
COL & 0.0 & 0.0 & -2.0 & -4.0 & 25.0 & 5.9 & -7.6 & -40.3 & -84.5 & -99.5 \\
CRU & 0.0 & 0.0 & -0.3 & -0.6 & 3.0 & 4.1 & 3.0 & -0.6 & -7.6 & -22.3 \\
MCH & 0.0 & 0.0 & 0.1 & 0.1 & -0.3 & -0.5 & -0.4 & -0.4 & -1.2 & -2.6 \\
FAW & 0.0 & 0.0 & -0.1 & -0.2 & 0.9 & 0.9 & 0.5 & -0.3 & -1.7 & -3.2 \\
TWL & 0.0 & 0.0 & 0.0 & 0.0 & 0.1 & 0.0 & 0.0 & 0.0 & -0.7 & -1.6 \\
TRN & 0.0 & 0.0 & -1.1 & -1.7 & 8.2 & 10.7 & 9.3 & 7.5 & 4.8 & 2.8 \\
SER & 0.0 & 0.0 & 0.0 & 0.0 & -0.1 & -0.1 & -0.2 & -0.3 & -0.6 & -1.0 \\
\hline
\end{tabular}

Table 07: Relative output changes between the Global Action International scenario and the Reference scenario in each year in EU-27 sectors in \% 
7.3. Appendix I

(Table I1 is intentionally left out since we do not study sectoral changes under the Reference scenario.)

\begin{tabular}{|lrrrrrrrrrr|}
\hline & 2005 & 2010 & 2015 & 2020 & 2025 & 2030 & 2035 & 2040 & 2045 & 2050 \\
\cline { 2 - 9 } OIL & 0.0 & 0.0 & -2.9 & -3.8 & -10.2 & -19.8 & -26.8 & -41.5 & -54.9 & -65.4 \\
GAS & 0.0 & 0.0 & -6.8 & -9.8 & -27.0 & -28.7 & -40.7 & -67.2 & -84.3 & -88.8 \\
MIN & 0.0 & 0.0 & 0.1 & 0.2 & 0.6 & 0.7 & 1.0 & 1.8 & 2.7 & 3.3 \\
PPP & 0.0 & 0.0 & 0.0 & 0.0 & -0.1 & -0.2 & -0.2 & -0.4 & -0.6 & -0.8 \\
FER & 0.0 & 0.0 & -0.4 & -0.4 & -1.1 & -1.9 & -2.4 & -3.8 & -4.5 & -5.6 \\
ORG & 0.0 & 0.0 & -0.2 & -0.2 & -0.4 & -1.1 & -1.3 & -2.1 & -2.1 & -2.7 \\
INO & 0.0 & 0.0 & -0.3 & -0.4 & -0.9 & -1.7 & -2.1 & -3.3 & -3.8 & -4.8 \\
OCR & 0.0 & 0.0 & -1.2 & -1.8 & -5.6 & -6.4 & -8.6 & -15.6 & -22.1 & -26.9 \\
CEM & 0.0 & 0.0 & 0.1 & 0.2 & 0.4 & 0.2 & 0.3 & 0.6 & 0.9 & 1.0 \\
BRT & 0.0 & 0.0 & 0.2 & 0.2 & 0.6 & 0.3 & 0.4 & 0.7 & 1.0 & 1.2 \\
ONM & 0.0 & 0.0 & 0.0 & 0.0 & 0.1 & 0.1 & 0.1 & 0.2 & 0.4 & 0.5 \\
ISM & 0.0 & 0.0 & 0.0 & 0.1 & 0.4 & -0.2 & -0.1 & 0.4 & 1.5 & 2.0 \\
ISP & 0.0 & 0.0 & -0.1 & -0.1 & 0.2 & -0.2 & -0.1 & 0.6 & 1.9 & 2.6 \\
ALU & 0.0 & 0.0 & -0.3 & -0.3 & -0.5 & -0.9 & -1.1 & -1.4 & -1.2 & -1.2 \\
ONF & 0.0 & 0.0 & -0.3 & -0.4 & -0.8 & -0.9 & -1.0 & -1.4 & -1.2 & -1.3 \\
ELE & - & - & - & - & - & - & - & - & - & - \\
COL & 0.0 & 0.0 & -2.3 & -4.4 & -13.7 & -13.9 & -20.6 & -35.6 & -48.7 & -66.6 \\
CRU & 0.0 & 0.0 & -0.5 & -1.0 & -4.2 & -5.8 & -8.4 & -17.2 & -27.4 & -37.0 \\
MCH & 0.0 & 0.0 & 0.3 & 0.4 & 1.1 & 1.3 & 1.7 & 3.0 & 4.2 & 5.2 \\
FAW & 0.0 & 0.0 & 0.1 & 0.1 & 0.1 & 0.2 & 0.2 & 0.3 & 0.4 & 0.4 \\
TWL & 0.0 & 0.0 & 0.2 & 0.3 & 1.0 & 1.2 & 1.5 & 2.6 & 3.6 & 4.4 \\
TRN & 0.0 & 0.0 & -0.7 & -1.0 & -3.1 & -3.5 & -4.4 & -7.8 & -10.7 & -12.6 \\
SER & 0.0 & 0.0 & 0.1 & 0.1 & 0.3 & 0.4 & 0.5 & 0.8 & 1.2 & 1.4 \\
\hline
\end{tabular}

Table 12: Relative capital stock changes between the Fragmented Action scenario and the Reference scenario in each year in EU-27 sectors in \% 


\begin{tabular}{|lrrrrrrrrrr|}
\hline & 2005 & 2010 & 2015 & 2020 & 2025 & 2030 & 2035 & 2040 & 2045 & 2050 \\
\cline { 2 - 6 } & 0.0 & 0.0 & -2.9 & -3.8 & -10.2 & 5.1 & 4.9 & 0.0 & -5.3 & -6.0 \\
GAS & 0.0 & 0.0 & -6.8 & -9.8 & -27.0 & -39.5 & -53.2 & -76.6 & -86.6 & -90.3 \\
MIN & 0.0 & 0.0 & 0.1 & 0.2 & 0.6 & 0.7 & 0.9 & 1.8 & 2.6 & 3.3 \\
PPP & 0.0 & 0.0 & 0.0 & 0.0 & -0.1 & -0.1 & -0.1 & -0.3 & -0.5 & -0.6 \\
FER & 0.0 & 0.0 & -0.4 & -0.4 & -1.1 & 0.1 & 0.1 & -0.3 & -0.9 & -1.6 \\
ORG & 0.0 & 0.0 & -0.2 & -0.2 & -0.4 & 0.7 & 0.9 & 1.2 & 1.3 & 1.2 \\
INO & 0.0 & 0.0 & -0.3 & -0.4 & -0.9 & 0.2 & 0.2 & 0.0 & -0.5 & -1.0 \\
OCR & 0.0 & 0.0 & -1.2 & -1.8 & -5.6 & -6.6 & -8.8 & -16.0 & -22.4 & -27.2 \\
CEM & 0.0 & 0.0 & 0.1 & 0.2 & 0.4 & 0.9 & 1.0 & 1.5 & 2.1 & 2.4 \\
BRT & 0.0 & 0.0 & 0.2 & 0.2 & 0.6 & 1.3 & 1.6 & 2.3 & 3.0 & 3.5 \\
ONM & 0.0 & 0.0 & 0.0 & 0.0 & 0.1 & 0.2 & 0.3 & 0.5 & 0.7 & 0.9 \\
ISM & 0.0 & 0.0 & 0.0 & 0.1 & 0.4 & 1.9 & 2.3 & 3.8 & 5.6 & 6.8 \\
ISP & 0.0 & 0.0 & -0.1 & -0.1 & 0.2 & 1.1 & 1.5 & 2.9 & 4.8 & 6.1 \\
ALU & 0.0 & 0.0 & -0.3 & -0.3 & -0.5 & 0.1 & 0.0 & 0.1 & 1.1 & 1.6 \\
ONF & 0.0 & 0.0 & -0.3 & -0.4 & -0.8 & -0.7 & -0.8 & -1.1 & -0.4 & -0.2 \\
ELE & - & - & - & - & - & - & - & - & - & - \\
COL & 0.0 & 0.0 & -2.3 & -4.4 & -13.7 & -20.8 & -28.9 & -46.3 & -77.1 & -98.3 \\
CRU & 0.0 & 0.0 & -0.5 & -1.0 & -4.2 & -4.5 & -6.9 & -15.2 & -23.9 & -32.0 \\
MCH & 0.0 & 0.0 & 0.3 & 0.4 & 1.1 & 1.3 & 1.7 & 3.1 & 4.5 & 5.5 \\
FAW & 0.0 & 0.0 & 0.1 & 0.1 & 0.1 & 0.1 & 0.1 & 0.2 & 0.2 & 0.1 \\
TWL & 0.0 & 0.0 & 0.2 & 0.3 & 1.0 & 1.0 & 1.4 & 2.4 & 3.4 & 4.1 \\
TRN & 0.0 & 0.0 & -0.7 & -1.0 & -3.1 & -3.4 & -4.4 & -7.7 & -10.7 & -12.6 \\
SER & 0.0 & 0.0 & 0.1 & 0.1 & 0.3 & 0.3 & 0.4 & 0.8 & 1.1 & 1.3 \\
\hline
\end{tabular}

Table 13: Relative capital stock changes between the Fragmented Action Free scenario and the Reference scenario in each year in EU-27 sectors in $\%^{38}$

\footnotetext{
${ }^{38}$ Some results, for instance for GAS and COL, appear extreme and need to be taken with caution.
} 


\begin{tabular}{|lrrrrrrrrrr|}
\hline & 2005 & 2010 & 2015 & 2020 & 2025 & 2030 & 2035 & 2040 & 2045 & 2050 \\
\cline { 2 - 5 } OIL & 6.9 & 7.6 & 3.4 & 3.6 & 9.8 & 21.1 & 21.6 & 14.4 & 6.0 & 1.8 \\
GAS & 6.5 & 4.2 & 5.7 & 6.9 & 24.9 & 33.0 & 31.2 & 20.4 & 5.8 & -1.6 \\
MIN & -0.2 & -0.2 & -0.1 & -0.1 & -0.5 & -0.6 & -0.5 & -0.3 & -0.1 & 0.1 \\
PPP & 0.0 & 0.0 & 0.1 & 0.1 & 0.0 & 0.0 & 0.1 & 0.1 & 0.1 & 0.1 \\
FER & 0.5 & 0.7 & 0.8 & 1.2 & 0.5 & 1.1 & 1.3 & 1.3 & 1.2 & 1.3 \\
ORG & 0.4 & 0.5 & 0.6 & 0.9 & 0.1 & 0.5 & 0.7 & 0.9 & 1.0 & 1.1 \\
INO & 0.5 & 0.6 & 0.8 & 1.1 & 0.3 & 0.9 & 1.1 & 1.2 & 1.2 & 1.3 \\
OCR & 1.5 & 1.4 & 0.4 & 0.1 & 4.7 & 6.4 & 5.2 & 2.7 & -0.1 & -1.5 \\
CEM & -0.1 & 0.0 & -0.2 & -0.2 & -0.3 & -0.2 & -0.2 & -0.1 & -0.1 & 0.0 \\
BRT & -0.1 & -0.1 & -0.4 & -0.4 & -0.4 & -0.3 & -0.3 & -0.2 & -0.1 & -0.1 \\
ONM & 0.0 & 0.1 & 0.0 & 0.1 & -0.1 & -0.1 & -0.1 & 0.0 & 0.1 & 0.1 \\
ISM & 0.2 & 0.5 & 0.6 & 1.0 & -0.6 & -0.3 & 0.1 & 0.7 & 1.1 & 1.4 \\
ISP & 0.3 & 0.6 & 1.0 & 1.5 & -0.5 & -0.4 & 0.1 & 0.6 & 1.0 & 1.3 \\
ALU & 0.4 & 0.8 & 1.0 & 1.4 & 0.1 & 0.3 & 0.6 & 0.9 & 0.9 & 1.0 \\
ONF & 0.4 & 0.7 & 1.1 & 1.6 & 0.2 & 0.3 & 0.6 & 0.8 & 0.9 & 1.0 \\
ELE & - & - & - & - & - & - & - & - & - & - \\
COL & 1.5 & 2.6 & 4.3 & 9.0 & 8.2 & 10.2 & 14.1 & 12.2 & 9.4 & 7.2 \\
CRU & 0.9 & 0.9 & -0.2 & -0.5 & 3.5 & 5.5 & 4.7 & 2.4 & -0.6 & -2.4 \\
MCH & -0.3 & -0.2 & -0.1 & -0.1 & -0.8 & -1.1 & -0.9 & -0.4 & 0.0 & 0.2 \\
FAW & -0.1 & -0.1 & 0.0 & 0.0 & -0.2 & -0.2 & -0.2 & -0.1 & 0.0 & 0.0 \\
TWL & -0.3 & -0.3 & -0.2 & -0.1 & -0.7 & -1.0 & -0.8 & -0.5 & 0.0 & 0.2 \\
TRN & 0.9 & 0.8 & 0.1 & -0.2 & 2.6 & 3.4 & 2.6 & 1.2 & -0.1 & -0.8 \\
SER & -0.1 & -0.1 & 0.0 & 0.0 & -0.3 & -0.4 & -0.3 & -0.2 & 0.0 & 0.1 \\
\hline
\end{tabular}

Table 14: Relative capital stock changes between the Fragmented Action CDM scenario and the Reference scenario in each year in EU-27 sectors in \% 


\begin{tabular}{|lrrrrrrrrrr|}
\hline & 2005 & 2010 & 2015 & 2020 & 2025 & 2030 & 2035 & 2040 & 2045 & 2050 \\
\cline { 2 - 5 } & 0.0 & 0.0 & -2.9 & -3.8 & -10.3 & -21.2 & -31.3 & -49.2 & -67.0 & -81.5 \\
GAS & 0.0 & 0.0 & -6.8 & -9.8 & -27.9 & -31.3 & -47.2 & -74.6 & -91.4 & -97.5 \\
MIN & 0.0 & 0.0 & 0.1 & 0.2 & 0.6 & 0.8 & 1.0 & 1.9 & 2.8 & 3.4 \\
PPP & 0.0 & 0.0 & 0.0 & 0.0 & -0.1 & -0.2 & -0.2 & -0.5 & -0.7 & -0.9 \\
FER & 0.0 & 0.0 & -0.4 & -0.4 & -0.5 & -0.5 & 0.7 & 2.5 & 6.0 & 12.4 \\
ORG & 0.0 & 0.0 & -0.2 & -0.2 & 0.0 & 0.1 & 1.3 & 3.6 & 7.6 & 14.6 \\
INO & 0.0 & 0.0 & -0.3 & -0.4 & -0.5 & -0.7 & 0.2 & 1.4 & 4.4 & 10.3 \\
OCR & 0.0 & 0.0 & -1.2 & -1.8 & -5.2 & -5.2 & -6.0 & -11.0 & -15.1 & -15.5 \\
CEM & 0.0 & 0.0 & 0.1 & 0.2 & 0.5 & 0.4 & 0.6 & 0.9 & 1.3 & 1.5 \\
BRT & 0.0 & 0.0 & 0.2 & 0.2 & 0.7 & 0.4 & 0.6 & 1.0 & 1.4 & 1.7 \\
ONM & 0.0 & 0.0 & 0.0 & 0.0 & 0.2 & 0.4 & 0.7 & 1.1 & 1.6 & 2.1 \\
ISM & 0.0 & 0.0 & 0.0 & 0.1 & 0.6 & 0.3 & 1.0 & 2.4 & 4.4 & 6.1 \\
ISP & 0.0 & 0.0 & -0.1 & -0.1 & 0.6 & 1.0 & 2.4 & 5.3 & 9.0 & 13.0 \\
ALU & 0.0 & 0.0 & -0.3 & -0.3 & -0.4 & -0.3 & 0.0 & 0.1 & 0.6 & 0.8 \\
ONF & 0.0 & 0.0 & -0.3 & -0.4 & -0.6 & -0.3 & 0.0 & -0.1 & 0.2 & 0.5 \\
ELE & - & - & - & - & - & - & - & - & - & - \\
COL & 0.0 & 0.0 & -2.3 & -4.4 & -17.5 & -23.7 & -43.9 & -70.4 & -75.7 & -83.1 \\
CRU & 0.0 & 0.0 & -0.5 & -1.0 & -4.7 & -7.8 & -14.0 & -29.9 & -49.7 & -73.3 \\
MCH & 0.0 & 0.0 & 0.3 & 0.4 & 1.0 & 0.9 & 0.9 & 1.6 & 2.0 & 1.2 \\
FAW & 0.0 & 0.0 & 0.1 & 0.1 & 0.1 & 0.1 & 0.0 & -0.3 & -0.5 & -1.0 \\
TWL & 0.0 & 0.0 & 0.2 & 0.3 & 0.9 & 1.0 & 1.2 & 2.2 & 3.1 & 3.5 \\
TRN & 0.0 & 0.0 & -0.7 & -1.0 & -3.0 & -3.1 & -3.5 & -5.9 & -7.8 & -7.4 \\
SER & 0.0 & 0.0 & 0.1 & 0.1 & 0.3 & 0.3 & 0.4 & 0.7 & 0.9 & 1.0 \\
\hline
\end{tabular}

Table 15: Relative capital stock changes between the Global Action scenario and the Reference scenario in each year in EU-27 sectors in ${ }^{39}$

\footnotetext{
${ }^{39}$ Some results, for instance for OIL, GAS, COL and CRU, appear extreme and need to be taken with caution.
} 


\begin{tabular}{l|rrrrrrrrrr|}
\hline & 2005 & 2010 & 2015 & 2020 & 2025 & 2030 & 2035 & 2040 & 2045 & 2050 \\
\cline { 2 - 5 } & -12.3 & -4.7 & -18.1 & -21.9 & -26.0 & -16.6 & -29.0 & -50.7 & -78.5 & -92.0 \\
GAS & 20.7 & 7.1 & 10.8 & 15.6 & 3.2 & 1.1 & -25.3 & -54.6 & -78.8 & -92.9 \\
MIN & -0.2 & -0.1 & 0.1 & 0.0 & 0.2 & 0.0 & 0.3 & 1.0 & 1.9 & 2.7 \\
PPP & -0.3 & -0.1 & -0.3 & -0.4 & -0.6 & -0.7 & -0.8 & -1.2 & -1.3 & -1.5 \\
FER & -2.6 & -1.0 & -2.8 & -4.2 & -5.9 & -5.3 & -5.2 & -6.7 & -11.2 & -13.9 \\
ORG & -2.6 & -0.9 & -2.6 & -3.8 & -5.2 & -4.5 & -4.2 & -4.8 & -7.5 & -8.2 \\
INO & -2.6 & -1.0 & -2.7 & -4.0 & -5.9 & -5.5 & -5.7 & -7.6 & -12.0 & -14.7 \\
OCR & 4.1 & 1.6 & 1.1 & 2.2 & 2.6 & 5.2 & 4.7 & 2.9 & -1.0 & -1.2 \\
CEM & -0.1 & -0.1 & -0.4 & -0.5 & -0.3 & 0.2 & 0.5 & 1.1 & 2.0 & 2.7 \\
BRT & 0.0 & 0.0 & -0.6 & -0.7 & -0.3 & 0.4 & 0.8 & 1.5 & 2.6 & 3.5 \\
ONM & -0.6 & -0.2 & -0.6 & -0.6 & -0.6 & -0.4 & 0.0 & 0.3 & 0.7 & 1.2 \\
ISM & -3.6 & -1.3 & -3.4 & -4.8 & -6.4 & -6.1 & -6.2 & -7.0 & -7.5 & -8.3 \\
ISP & -3.9 & -1.5 & -3.3 & -4.7 & -6.1 & -5.7 & -5.2 & -4.6 & -3.1 & -2.0 \\
ALU & -3.3 & -1.3 & -3.1 & -4.4 & -5.9 & -5.7 & -6.1 & -7.0 & -6.0 & -6.1 \\
ONF & -3.0 & -1.2 & -2.6 & -3.7 & -5.1 & -5.3 & -5.7 & -6.7 & -5.9 & -6.1 \\
ELE & - & - & - & - & - & - & - & - & - & - \\
COL & -2.1 & -2.4 & -3.6 & -9.9 & -34.8 & -66.2 & -71.3 & -98.7 & -99.5 & -99.8 \\
CRU & 1.6 & 0.7 & 0.1 & 1.4 & 2.6 & 4.6 & -0.1 & -10.2 & -28.3 & -53.4 \\
MCH & -0.7 & -0.2 & -0.1 & -0.2 & -0.2 & -0.6 & -0.7 & -0.6 & -0.4 & -1.1 \\
FAW & -0.1 & 0.0 & 0.1 & 0.0 & 0.0 & -0.2 & -0.3 & -0.5 & -0.8 & -1.2 \\
TWL & -0.4 & -0.1 & 0.2 & 0.1 & 0.2 & -0.2 & -0.2 & 0.2 & 1.1 & 1.6 \\
TRN & 2.8 & 1.0 & 0.7 & 1.5 & 1.8 & 3.2 & 2.9 & 2.1 & -0.1 & 0.1 \\
SER & -0.2 & -0.1 & 0.0 & -0.1 & -0.1 & -0.2 & -0.2 & 0.0 & 0.3 & 0.4 \\
\hline
\end{tabular}

Table 16: Relative capital stock changes between the Global Action National scenario and the Reference scenario in each year in EU-27 sectors in \% ${ }^{40}$

\footnotetext{
${ }^{40}$ Some results, for instance for OIL, GAS, COL and CRU, appear extreme and need to be taken with caution.
} 


\begin{tabular}{|lrrrrrrrrrr|}
\hline & 2005 & 2010 & 2015 & 2020 & 2025 & 2030 & 2035 & 2040 & 2045 & 2050 \\
\cline { 2 - 5 } & 0.0 & 0.0 & -2.9 & -3.8 & 25.2 & 44.1 & 33.0 & 0.8 & -41.1 & -78.0 \\
GAS & 0.0 & 0.0 & -6.8 & -9.8 & 62.5 & 64.3 & 52.8 & 13.7 & -56.6 & -87.8 \\
MIN & 0.0 & 0.0 & 0.1 & 0.2 & -0.9 & -1.1 & -0.9 & -0.4 & 0.4 & 1.3 \\
PPP & 0.0 & 0.0 & 0.0 & 0.0 & 0.0 & 0.0 & 0.0 & -0.3 & -0.9 & -1.3 \\
FER & 0.0 & 0.0 & -0.4 & -0.4 & 1.5 & 3.2 & 3.7 & 3.8 & 1.4 & -1.5 \\
ORG & 0.0 & 0.0 & -0.2 & -0.2 & 0.5 & 1.8 & 2.4 & 3.0 & 2.2 & 1.7 \\
INO & 0.0 & 0.0 & -0.3 & -0.4 & 1.3 & 2.4 & 2.5 & 2.0 & -0.7 & -3.6 \\
OCR & 0.0 & 0.0 & -1.2 & -1.8 & 9.1 & 12.3 & 12.0 & 11.3 & 8.9 & 8.8 \\
CEM & 0.0 & 0.0 & 0.1 & 0.2 & -0.7 & -0.2 & 0.1 & 0.5 & 1.2 & 2.1 \\
BRT & 0.0 & 0.0 & 0.2 & 0.2 & -1.1 & -0.4 & -0.1 & 0.5 & 1.5 & 2.7 \\
ONM & 0.0 & 0.0 & 0.0 & 0.0 & -0.1 & 0.1 & 0.4 & 0.9 & 1.2 & 1.8 \\
ISM & 0.0 & 0.0 & 0.0 & 0.1 & -0.2 & 0.6 & 1.0 & 0.8 & -1.6 & -3.2 \\
ISP & 0.0 & 0.0 & -0.1 & -0.1 & 0.0 & 0.8 & 1.9 & 3.1 & 2.4 & 3.3 \\
ALU & 0.0 & 0.0 & -0.3 & -0.3 & 1.3 & 2.0 & 2.5 & 2.1 & -0.9 & -1.1 \\
ONF & 0.0 & 0.0 & -0.3 & -0.4 & 1.7 & 2.1 & 2.7 & 2.5 & -0.3 & -0.5 \\
ELE & - & - & - & - & - & - & - & - & - & - \\
COL & 0.0 & 0.0 & -2.3 & -4.4 & 29.2 & 6.5 & -8.0 & -40.9 & -84.6 & -99.5 \\
CRU & 0.0 & 0.0 & -0.5 & -1.0 & 6.7 & 9.0 & 6.3 & -1.3 & -15.9 & -40.6 \\
MCH & 0.0 & 0.0 & 0.3 & 0.4 & -1.3 & -1.7 & -1.4 & -0.9 & -0.6 & -1.1 \\
FAW & 0.0 & 0.0 & 0.1 & 0.1 & -0.4 & -0.6 & -0.7 & -1.1 & -1.5 & -2.0 \\
TWL & 0.0 & 0.0 & 0.2 & 0.3 & -1.4 & -1.8 & -1.5 & -0.8 & -0.1 & 0.2 \\
TRN & 0.0 & 0.0 & -0.7 & -1.0 & 4.8 & 6.2 & 5.5 & 5.0 & 4.4 & 4.8 \\
SER & 0.0 & 0.0 & 0.1 & 0.1 & -0.6 & -0.7 & -0.7 & -0.6 & -0.4 & -0.4 \\
\hline
\end{tabular}

Table 17: Relative capital stock changes between the Global Action International scenario and the Reference scenario in each year in EU-27 sectors in ${ }^{41}$

\footnotetext{
${ }^{41}$ Some results, for instance for OIL, GAS, COL and CRU, appear extreme and need to be taken with caution.
} 
7.4. Appendix E

(Table E1 is intentionally left out since we do not study sectoral changes under the Reference scenario.)

\begin{tabular}{|lrrrrrrrrrr|}
\hline & 2005 & 2010 & 2015 & 2020 & 2025 & 2030 & 2035 & 2040 & 2045 & 2050 \\
\cline { 2 - 8 } OIL & 0.0 & -12.1 & -21.0 & -29.5 & -37.7 & -58.3 & -66.7 & -76.8 & -83.5 & -88.8 \\
GAS & 0.0 & 10.1 & -3.0 & -12.3 & -32.8 & -35.6 & -46.8 & -71.7 & -86.0 & -90.2 \\
MIN & 0.0 & 1.5 & -9.2 & -19.9 & -32.9 & -43.8 & -52.2 & -64.9 & -75.9 & -83.2 \\
PPP & 0.0 & -8.4 & -13.9 & -15.6 & -15.3 & -16.7 & -21.5 & -26.3 & -31.5 & -39.2 \\
FER & 0.0 & -12.4 & -16.0 & -17.1 & -17.3 & -21.7 & -26.6 & -33.3 & -38.4 & -44.6 \\
ORG & 0.0 & -12.5 & -15.3 & -16.0 & -15.7 & -19.7 & -24.3 & -30.2 & -35.0 & -40.9 \\
INO & 0.0 & -12.5 & -16.0 & -17.1 & -17.2 & -21.4 & -26.2 & -32.8 & -37.8 & -43.9 \\
OCR & 0.0 & 2.4 & -6.9 & -16.7 & -28.9 & -38.2 & -45.2 & -57.3 & -68.3 & -76.0 \\
CEM & 0.0 & -12.1 & -20.2 & -23.5 & -25.2 & -29.0 & -35.0 & -42.5 & -48.2 & -54.9 \\
BRT & 0.0 & -13.0 & -25.2 & -29.7 & -32.1 & -36.6 & -43.7 & -52.2 & -58.3 & -64.9 \\
ONM & 0.0 & -11.4 & -17.7 & -20.5 & -21.8 & -24.9 & -30.3 & -36.9 & -42.0 & -48.8 \\
ISM & 0.0 & -13.9 & -23.2 & -26.9 & -28.4 & -34.9 & -42.4 & -51.8 & -57.7 & -64.5 \\
ISP & 0.0 & -13.1 & -16.4 & -18.2 & -18.0 & -23.5 & -28.9 & -35.6 & -39.8 & -46.3 \\
ALU & 0.0 & -12.0 & -20.9 & -24.3 & -25.4 & -29.2 & -35.8 & -43.9 & -49.6 & -56.7 \\
ONF & 0.0 & -9.5 & -13.9 & -15.3 & -14.6 & -17.3 & -22.5 & -28.9 & -34.0 & -41.4 \\
ELE & 0.0 & -9.3 & -13.9 & -21.2 & -28.6 & -27.5 & -41.8 & -61.7 & -78.0 & -86.1 \\
COL & 0.0 & -9.1 & -18.4 & -30.2 & -38.6 & -42.0 & -54.0 & -66.2 & -76.0 & -85.1 \\
CRU & 0.0 & -14.1 & -12.8 & -14.9 & -20.2 & -23.6 & -26.3 & -34.9 & -43.4 & -51.9 \\
MCH & 0.0 & 16.4 & -2.5 & -18.8 & -35.0 & -46.2 & -55.6 & -68.1 & -78.8 & -85.5 \\
FAW & 0.0 & 5.5 & -6.9 & -18.6 & -31.4 & -41.5 & -49.8 & -61.7 & -72.8 & -80.3 \\
TWL & 0.0 & 18.5 & -2.7 & -20.6 & -38.3 & -49.8 & -59.4 & -72.2 & -82.2 & -88.3 \\
TRN & 0.0 & -1.7 & -4.4 & -10.2 & -19.1 & -27.4 & -33.9 & -45.6 & -57.0 & -65.4 \\
SER & 0.0 & 6.4 & -10.2 & -21.7 & -35.9 & -46.5 & -54.9 & -66.2 & -76.8 & -83.6 \\
\hline
\end{tabular}

Table E2: Relative emission changes vis-à-vis 2005 in each year under the Fragmented Action scenario in EU-27 sectors in \% 


\begin{tabular}{|lrrrrrrrrrr|}
\hline & 2005 & 2010 & 2015 & 2020 & 2025 & 2030 & 2035 & 2040 & 2045 & 2050 \\
\cline { 2 - 10 } OIL & 0.0 & -12.1 & -21.0 & -29.5 & -37.7 & -44.9 & -51.4 & -58.9 & -64.8 & -68.7 \\
MIN & 0.0 & 10.1 & -3.0 & -12.3 & -32.8 & -45.3 & -58.0 & -79.8 & -88.0 & -91.5 \\
PPP & 0.0 & 1.5 & -9.2 & -19.9 & -32.9 & -44.1 & -52.6 & -65.3 & -76.3 & -83.5 \\
FER & 0.0 & -8.4 & -13.9 & -15.6 & -15.3 & -17.7 & -22.5 & -27.0 & -37.6 & -44.4 \\
ORG & 0.0 & -12.4 & -16.0 & -17.1 & -17.3 & -18.8 & -22.6 & -27.4 & -34.1 & -39.4 \\
INO & 0.0 & -12.5 & -15.3 & -16.0 & -15.7 & -16.7 & -20.2 & -24.2 & -30.4 & -35.3 \\
OCR & 0.0 & -12.5 & -16.0 & -17.1 & -17.2 & -18.6 & -22.4 & -27.0 & -33.6 & -38.9 \\
CEM & 0.0 & 2.4 & -6.9 & -16.7 & -28.9 & -38.4 & -45.4 & -57.5 & -68.5 & -76.1 \\
BRT & 0.0 & -12.1 & -20.2 & -23.5 & -25.2 & -28.5 & -34.1 & -40.5 & -48.6 & -54.6 \\
ONM & 0.0 & -13.0 & -25.2 & -29.7 & -32.1 & -36.8 & -43.6 & -51.2 & -59.8 & -65.8 \\
ISM & 0.0 & -11.4 & -17.7 & -20.5 & -21.8 & -24.5 & -29.4 & -34.9 & -42.6 & -48.3 \\
ISP & 0.0 & -13.9 & -23.2 & -26.9 & -28.4 & -32.4 & -39.1 & -47.0 & -55.1 & -61.3 \\
ALU & 0.0 & -13.1 & -16.4 & -18.2 & -18.0 & -19.4 & -23.5 & -27.7 & -33.3 & -38.2 \\
ONF & 0.0 & -12.0 & -20.9 & -24.3 & -25.4 & -29.0 & -35.3 & -42.4 & -51.2 & -57.4 \\
ELE & 0.0 & -9.5 & -13.9 & -15.3 & -14.6 & -16.6 & -21.3 & -26.8 & -35.4 & -41.7 \\
COL & 0.0 & -9.3 & -13.9 & -21.2 & -28.6 & -34.8 & -50.2 & -71.7 & -88.0 & -97.0 \\
CRU & 0.0 & -9.1 & -18.4 & -30.2 & -38.6 & -46.6 & -58.9 & -71.8 & -89.3 & -99.2 \\
MCH & 0.0 & -14.1 & -12.8 & -14.9 & -20.2 & -22.6 & -25.1 & -33.3 & -40.7 & -48.1 \\
FAW & 0.0 & 16.4 & -2.5 & -18.8 & -35.0 & -48.2 & -57.6 & -69.7 & -79.8 & -86.1 \\
TWL & 0.0 & 5.5 & -6.9 & -18.6 & -31.4 & -42.3 & -50.6 & -62.4 & -73.4 & -80.7 \\
TRN & 0.0 & 18.5 & -2.7 & -20.6 & -38.3 & -52.1 & -61.6 & -74.0 & -83.4 & -89.0 \\
SER & 0.0 & -1.7 & -4.4 & -10.2 & -19.1 & -27.2 & -33.7 & -45.6 & -57.1 & -65.5 \\
\hline
\end{tabular}

Table E3: Relative emission changes vis-à-vis 2005 in each year under the Fragmented Action Free scenario in EU-27 sectors in \% 


\begin{tabular}{l|rrrrrrrrrr|}
\hline & 2005 & 2010 & 2015 & 2020 & 2025 & 2030 & 2035 & 2040 & 2045 & 2050 \\
\cline { 2 - 5 } & 9.2 & -2.7 & -10.1 & -18.0 & -17.6 & -30.3 & -37.4 & -46.9 & -53.4 & -58.4 \\
GAS & 6.5 & 14.7 & 10.0 & 4.0 & 14.9 & 20.3 & 17.8 & 3.9 & -5.3 & -13.7 \\
MIN & 4.5 & 6.1 & -4.4 & -15.1 & -2.6 & -8.3 & -14.0 & -22.3 & -30.5 & -36.6 \\
PPP & 2.1 & -6.5 & -7.8 & -8.4 & -8.4 & -8.4 & -11.2 & -14.3 & -17.2 & -19.2 \\
FER & 2.1 & -10.3 & -11.1 & -11.1 & -11.6 & -12.8 & -15.9 & -19.9 & -23.4 & -26.2 \\
ORG & 1.7 & -10.7 & -11.0 & -10.8 & -11.3 & -12.3 & -15.2 & -18.8 & -22.1 & -24.8 \\
INO & 2.0 & -10.5 & -11.2 & -11.2 & -11.7 & -12.9 & -16.0 & -19.9 & -23.3 & -26.1 \\
OCR & 4.4 & 7.2 & -2.6 & -12.6 & 0.0 & -4.6 & -9.5 & -16.7 & -23.9 & -29.3 \\
CEM & 3.1 & -8.8 & -12.4 & -14.4 & -16.5 & -17.8 & -22.0 & -27.2 & -31.3 & -34.5 \\
BRT & 4.9 & -8.1 & -14.6 & -17.7 & -20.5 & -22.4 & -27.6 & -34.2 & -39.0 & -42.9 \\
ONM & 2.4 & -8.8 & -11.1 & -12.6 & -14.3 & -15.2 & -18.8 & -23.4 & -27.0 & -29.9 \\
ISM & 4.0 & -9.5 & -13.3 & -15.0 & -18.2 & -20.8 & -25.7 & -32.3 & -36.9 & -40.6 \\
ISP & 2.2 & -10.5 & -10.6 & -10.7 & -12.8 & -14.7 & -17.9 & -22.3 & -25.6 & -28.1 \\
ALU & 3.6 & -8.1 & -11.6 & -13.2 & -15.4 & -16.7 & -20.8 & -26.2 & -30.2 & -33.2 \\
ONF & 2.1 & -7.4 & -7.8 & -7.6 & -7.8 & -8.1 & -10.8 & -14.3 & -17.3 & -19.4 \\
ELE & 2.4 & -6.2 & -4.4 & -5.2 & -9.4 & -6.5 & -13.0 & -21.0 & -28.8 & -32.8 \\
COL & 1.5 & -6.8 & -12.9 & -20.4 & -23.0 & -25.7 & -33.9 & -41.1 & -48.8 & -52.2 \\
CRU & 0.9 & -13.4 & -12.5 & -14.5 & -13.7 & -14.5 & -15.8 & -19.5 & -22.5 & -25.6 \\
MCH & 6.1 & 24.6 & 5.2 & -12.3 & 8.3 & 1.1 & -6.9 & -17.9 & -28.6 & -36.2 \\
FAW & 4.5 & 11.1 & -2.0 & -14.3 & -0.1 & -5.7 & -11.8 & -20.0 & -28.5 & -34.6 \\
TWL & 6.8 & 27.7 & 6.3 & -12.7 & 8.9 & 1.1 & -7.5 & -19.6 & -30.9 & -38.8 \\
TRN & 3.1 & 1.0 & -1.5 & -7.0 & 2.6 & -0.8 & -4.5 & -10.3 & -16.1 & -20.7 \\
SER & 4.9 & 12.4 & -5.4 & -17.9 & -1.6 & -8.3 & -15.5 & -24.6 & -33.9 & -40.7 \\
\hline
\end{tabular}

Table E4: Relative emission changes vis-à-vis 2005 in each year under the Fragmented Action CDM scenario in EU-27 sectors in \% 


\begin{tabular}{|lrrrrrrrrrr|}
\hline & 2005 & 2010 & 2015 & 2020 & 2025 & 2030 & 2035 & 2040 & 2045 & 2050 \\
\cline { 2 - 5 } & 0.0 & -12.1 & -21.0 & -29.5 & -37.7 & -59.2 & -68.9 & -79.8 & -87.6 & -93.4 \\
GAS & 0.0 & 10.1 & -3.0 & -12.3 & -33.7 & -37.9 & -52.6 & -78.1 & -92.3 & -97.8 \\
MIN & 0.0 & 1.5 & -9.2 & -19.9 & -33.0 & -44.0 & -52.8 & -65.7 & -76.9 & -83.9 \\
PPP & 0.0 & -8.4 & -13.9 & -15.6 & -15.4 & -16.6 & -21.1 & -25.6 & -29.1 & -30.5 \\
FER & 0.0 & -12.4 & -16.0 & -17.1 & -16.9 & -20.6 & -24.0 & -27.8 & -28.4 & -24.3 \\
ORG & 0.0 & -12.5 & -15.3 & -16.0 & -15.3 & -18.6 & -21.7 & -24.8 & -24.8 & -19.7 \\
INO & 0.0 & -12.5 & -16.0 & -17.1 & -16.9 & -20.5 & -24.2 & -28.3 & -29.2 & -25.5 \\
OCR & 0.0 & 2.4 & -6.9 & -16.7 & -28.6 & -37.5 & -44.1 & -55.5 & -66.2 & -72.7 \\
CEM & 0.0 & -12.1 & -20.2 & -23.5 & -25.2 & -28.9 & -34.7 & -41.6 & -45.7 & -47.5 \\
BRT & 0.0 & -13.0 & -25.2 & -29.7 & -32.3 & -37.0 & -44.5 & -53.0 & -58.2 & -61.6 \\
ONM & 0.0 & -11.4 & -17.7 & -20.5 & -21.7 & -24.3 & -28.8 & -34.1 & -36.9 & -37.0 \\
ISM & 0.0 & -13.9 & -23.2 & -26.9 & -28.3 & -34.6 & -41.5 & -49.8 & -53.8 & -54.8 \\
ISP & 0.0 & -13.1 & -16.4 & -18.2 & -17.3 & -21.5 & -24.1 & -26.1 & -24.1 & -15.9 \\
ALU & 0.0 & -12.0 & -20.9 & -24.3 & -25.3 & -28.9 & -35.1 & -42.6 & -46.9 & -49.0 \\
ONF & 0.0 & -9.5 & -13.9 & -15.3 & -14.3 & -16.2 & -20.1 & -25.0 & -27.4 & -26.6 \\
ELE & 0.0 & -9.3 & -13.9 & -21.2 & -28.6 & -27.2 & -40.9 & -60.7 & -77.0 & -85.6 \\
COL & 0.0 & -9.1 & -18.4 & -30.2 & -41.3 & -48.6 & -67.5 & -84.5 & -88.6 & -92.5 \\
CRU & 0.0 & -14.1 & -12.8 & -14.9 & -20.7 & -25.3 & -30.8 & -44.9 & -60.8 & -79.7 \\
MCH & 0.0 & 16.4 & -2.5 & -18.8 & -35.3 & -46.8 & -56.6 & -69.7 & -80.5 & -86.9 \\
FAW & 0.0 & 5.5 & -6.9 & -18.6 & -31.6 & -41.9 & -50.6 & -62.9 & -74.1 & -81.3 \\
TWL & 0.0 & 18.5 & -2.7 & -20.6 & -38.5 & -50.2 & -60.2 & -73.5 & -83.5 & -89.3 \\
TRN & 0.0 & -1.7 & -4.4 & -10.2 & -19.1 & -27.3 & -33.7 & -45.1 & -56.4 & -64.0 \\
SER & 0.0 & 6.4 & -10.2 & -21.7 & -36.0 & -46.8 & -55.6 & -67.3 & -77.9 & -84.3 \\
\hline
\end{tabular}

Table E5: Relative emission changes vis-à-vis 2005 in each year under the Global Action scenario in EU-27 sectors in \% 


\begin{tabular}{|lrrrrrrrrrr|}
\hline & 2005 & 2010 & 2015 & 2020 & 2025 & 2030 & 2035 & 2040 & 2045 & 2050 \\
\cline { 2 - 5 } & -20.5 & -19.5 & -35.8 & -46.2 & -53.1 & -61.0 & -71.4 & -83.6 & -94.6 & -98.5 \\
GAS & 20.7 & 17.9 & 15.3 & 12.5 & -5.0 & -8.6 & -33.0 & -60.8 & -81.0 & -93.8 \\
MIN & 17.8 & 9.0 & 1.9 & -3.2 & -7.2 & -12.4 & -20.2 & -33.2 & -54.2 & -67.1 \\
PPP & -11.4 & -12.7 & -17.2 & -20.5 & -21.6 & -25.3 & -31.0 & -42.6 & -65.8 & -76.9 \\
FER & -10.1 & -15.9 & -21.1 & -24.9 & -27.7 & -30.9 & -35.9 & -45.1 & -61.2 & -70.5 \\
ORG & -9.6 & -15.8 & -20.3 & -23.6 & -25.9 & -28.8 & -33.4 & -42.0 & -57.8 & -66.8 \\
INO & -10.0 & -15.9 & -21.0 & -24.8 & -27.6 & -30.9 & -36.1 & -45.4 & -61.4 & -70.6 \\
OCR & 19.7 & 11.2 & 6.1 & 2.1 & -0.4 & -3.4 & -8.5 & -18.8 & -39.3 & -50.4 \\
CEM & -14.1 & -17.2 & -25.0 & -30.8 & -34.9 & -39.9 & -46.6 & -57.3 & -72.8 & -81.3 \\
BRT & -19.0 & -19.8 & -30.5 & -37.7 & -42.9 & -48.9 & -56.6 & -67.1 & -80.6 & -87.5 \\
ONM & -12.0 & -15.8 & -22.1 & -27.2 & -30.6 & -34.8 & -40.6 & -50.9 & -67.7 & -76.7 \\
ISM & -19.4 & -20.7 & -31.6 & -39.4 & -45.2 & -51.4 & -59.0 & -70.1 & -82.7 & -89.2 \\
ISP & -13.0 & -17.7 & -24.1 & -29.6 & -33.0 & -36.9 & -41.5 & -51.0 & -66.2 & -74.6 \\
ALU & -17.3 & -18.2 & -27.3 & -33.9 & -38.1 & -43.4 & -50.5 & -62.0 & -77.3 & -85.2 \\
ONF & -11.8 & -13.9 & -19.6 & -23.8 & -25.8 & -29.7 & -35.6 & -47.4 & -66.4 & -76.6 \\
ELE & - & - & - & - & - & - & - & - & - & - \\
COL & -2.1 & -11.3 & -19.5 & -34.2 & -53.6 & -77.2 & -83.4 & -99.3 & -99.8 & -99.9 \\
CRU & 1.6 & -13.5 & -12.2 & -12.8 & -14.5 & -15.2 & -19.6 & -29.4 & -44.1 & -64.4 \\
MCH & 34.5 & 33.3 & 24.3 & 16.8 & 12.6 & 4.1 & -7.6 & -28.3 & -57.8 & -72.8 \\
FAW & 24.1 & 17.0 & 10.2 & 5.0 & 1.5 & -4.0 & -12.3 & -26.9 & -51.1 & -64.7 \\
TWL & 36.1 & 36.4 & 25.2 & 15.9 & 10.1 & 0.2 & -12.8 & -34.7 & -62.6 & -76.7 \\
TRN & 10.2 & 1.9 & 1.0 & -0.5 & -1.8 & -3.9 & -8.2 & -15.9 & -32.0 & -42.7 \\
SER & 30.2 & 20.3 & 11.5 & 9.3 & 6.5 & 0.6 & -7.9 & -23.8 & -53.3 & -68.1 \\
\hline
\end{tabular}

Table E6: Relative emission changes vis-à-vis 2005 in each year under the Global Action National scenario in EU-27 sectors in \% 


\begin{tabular}{|lrrrrrrrrrr|}
\hline & 2005 & 2010 & 2015 & 2020 & 2025 & 2030 & 2035 & 2040 & 2045 & 2050 \\
\cline { 2 - 5 } OIL & 0.0 & -12.1 & -21.0 & -29.5 & 5.0 & -11.6 & -31.1 & -56.6 & -79.0 & -94.1 \\
GAS & 0.0 & 10.1 & -3.0 & -12.3 & 49.5 & 48.5 & 37.2 & -1.9 & -61.2 & -89.3 \\
MIN & 0.0 & 1.5 & -9.2 & -19.9 & 19.9 & 17.0 & 9.3 & -2.6 & -20.9 & -42.3 \\
PPP & 0.0 & -8.4 & -13.9 & -15.6 & -1.4 & -3.5 & -9.9 & -18.5 & -33.6 & -58.1 \\
FER & 0.0 & -12.4 & -16.0 & -17.1 & -5.6 & -7.5 & -13.1 & -21.7 & -35.1 & -51.1 \\
ORG & 0.0 & -12.5 & -15.3 & -16.0 & -6.4 & -8.0 & -12.9 & -20.3 & -32.2 & -47.1 \\
INO & 0.0 & -12.5 & -16.0 & -17.1 & -6.0 & -8.2 & -14.0 & -22.9 & -36.2 & -51.9 \\
OCR & 0.0 & 2.4 & -6.9 & -16.7 & 22.8 & 21.8 & 16.8 & 9.3 & -4.3 & -22.7 \\
CEM & 0.0 & -12.1 & -20.2 & -23.5 & -4.7 & -10.8 & -20.3 & -33.3 & -49.9 & -67.2 \\
BRT & 0.0 & -13.0 & -25.2 & -29.7 & -2.5 & -13.2 & -26.8 & -44.0 & -61.8 & -77.1 \\
ONM & 0.0 & -11.4 & -17.7 & -20.5 & -5.1 & -9.0 & -16.4 & -26.4 & -41.4 & -60.0 \\
ISM & 0.0 & -13.9 & -23.2 & -26.9 & -4.2 & -12.1 & -23.5 & -40.4 & -60.7 & -77.0 \\
ISP & 0.0 & -13.1 & -16.4 & -18.2 & -6.9 & -8.6 & -13.4 & -20.1 & -33.6 & -52.2 \\
ALU & 0.0 & -12.0 & -20.9 & -24.3 & -2.8 & -8.5 & -18.0 & -32.3 & -51.9 & -70.7 \\
ONF & 0.0 & -9.5 & -13.9 & -15.3 & -1.9 & -2.5 & -6.8 & -14.9 & -32.5 & -55.3 \\
ELE & 0.0 & -9.3 & -13.9 & -21.2 & 5.9 & 1.9 & -10.5 & -38.5 & -90.3 & -39.5 \\
COL & 0.0 & -9.1 & -18.4 & -30.2 & -8.0 & -28.3 & -46.7 & -69.0 & -92.8 & -99.8 \\
CRU & 0.0 & -14.1 & -12.8 & -14.9 & -11.1 & -11.7 & -14.5 & -22.4 & -34.4 & -54.7 \\
MCH & 0.0 & 16.4 & -2.5 & -18.8 & 54.1 & 50.6 & 41.0 & 22.9 & -10.4 & -47.4 \\
FAW & 0.0 & 5.5 & -6.9 & -18.6 & 30.4 & 26.5 & 17.7 & 4.6 & -15.8 & -41.1 \\
TWL & 0.0 & 18.5 & -2.7 & -20.6 & 59.7 & 55.0 & 43.9 & 22.2 & -15.6 & -52.8 \\
TRN & 0.0 & -1.7 & -4.4 & -10.2 & 13.5 & 12.8 & 8.6 & 2.8 & -6.3 & -18.8 \\
SER & 0.0 & 6.4 & -10.2 & -21.7 & 32.2 & 29.3 & 21.3 & 9.7 & -11.6 & -42.8 \\
\hline
\end{tabular}

Table E7: Relative emission changes vis-à-vis 2005 in each year under the Global Action International scenario in EU-27 sectors in \% 
7.5. Appendix C

(Table C1 is intentionally left out since we do not study sectoral changes under the Reference scenario.)

\begin{tabular}{|lrrrrrrrrrr|}
\hline & 2005 & 2010 & 2015 & 2020 & 2025 & 2030 & 2035 & 2040 & 2045 & 2050 \\
\cline { 2 - 9 } OIL & 0.0 & 0.0 & 0.1 & 0.4 & 1.4 & -8.8 & -11.5 & -17.5 & -23.3 & -28.4 \\
GAS & 0.0 & 0.0 & -2.7 & -4.3 & -10.2 & -11.7 & -18.8 & -28.5 & -40.1 & -43.4 \\
MIN & 0.0 & 0.0 & 0.2 & 0.3 & 0.8 & 1.0 & 1.3 & 2.4 & 3.4 & 4.2 \\
PPP & 0.0 & 0.0 & 0.1 & 0.2 & 0.7 & 0.8 & 1.0 & 1.9 & 2.7 & 3.3 \\
FER & 0.0 & 0.0 & -0.1 & -0.1 & -0.3 & -1.3 & -1.5 & -2.4 & -2.8 & -3.6 \\
ORG & 0.0 & 0.0 & -0.1 & -0.1 & -0.2 & -0.9 & -1.0 & -1.6 & -1.9 & -2.4 \\
INO & 0.0 & 0.0 & -0.1 & -0.1 & -0.1 & -0.8 & -1.0 & -1.5 & -1.6 & -2.1 \\
OCR & 0.0 & 0.0 & -0.8 & -1.2 & -3.5 & -3.8 & -4.9 & -8.8 & -12.3 & -14.6 \\
CEM & 0.0 & 0.0 & 0.2 & 0.3 & 0.9 & -0.2 & 0.0 & 0.6 & 1.8 & 2.1 \\
BRT & 0.0 & 0.0 & 0.0 & 0.1 & 0.4 & -1.2 & -1.1 & -1.1 & -0.4 & -0.3 \\
ONM & 0.0 & 0.0 & 0.0 & 0.1 & 0.3 & 0.3 & 0.5 & 1.0 & 1.8 & 2.1 \\
ISM & 0.0 & 0.0 & -0.1 & -0.1 & -0.2 & -1.2 & -1.3 & -1.6 & -1.3 & -1.3 \\
ISP & 0.0 & 0.0 & -0.1 & -0.1 & -0.1 & -0.3 & -0.3 & -0.1 & 0.4 & 0.7 \\
ALU & 0.0 & 0.0 & -0.6 & -0.7 & -1.4 & -1.9 & -2.3 & -3.4 & -3.3 & -3.5 \\
ONF & 0.0 & 0.0 & -0.6 & -0.7 & -1.6 & -1.6 & -2.0 & -3.0 & -3.0 & -3.2 \\
ELE & 0.0 & 0.0 & -4.0 & -5.3 & -12.2 & -12.0 & -16.5 & -27.9 & -32.4 & -36.3 \\
COL & 0.0 & 0.0 & -0.7 & -2.0 & -7.8 & -9.4 & -16.8 & -32.5 & -47.4 & -64.5 \\
CRU & 0.0 & 0.0 & 0.1 & 0.1 & 0.3 & 3.0 & 3.9 & 5.6 & 6.3 & 5.6 \\
MCH & 0.0 & 0.0 & 0.3 & 0.4 & 1.3 & 1.6 & 2.1 & 3.8 & 5.4 & 6.6 \\
FAW & 0.0 & 0.0 & 0.1 & 0.1 & 0.4 & 0.6 & 0.7 & 1.3 & 1.9 & 2.4 \\
TWL & 0.0 & 0.0 & 0.3 & 0.4 & 1.1 & 1.5 & 1.9 & 3.4 & 4.8 & 5.9 \\
TRN & 0.0 & 0.0 & -1.7 & -2.6 & -8.0 & -8.9 & -11.3 & -19.7 & -27.2 & -31.9 \\
SER & 0.0 & 0.0 & 0.3 & 0.5 & 1.3 & 1.6 & 2.0 & 3.6 & 5.0 & 5.9 \\
\hline
\end{tabular}

Table C2: Competitiveness changes between the Fragmented Action scenario and the Reference scenario in each year in EU-27 sectors in \% 


\begin{tabular}{|lrrrrrrrrrr|}
\hline & 2005 & 2010 & 2015 & 2020 & 2025 & 2030 & 2035 & 2040 & 2045 & 2050 \\
\cline { 2 - 6 } & 0.0 & 0.0 & 0.1 & 0.4 & 1.4 & 23.3 & 31.7 & 47.4 & 67.4 & 86.7 \\
GAS & 0.0 & 0.0 & -2.7 & -4.3 & -10.2 & -16.5 & -25.9 & -33.5 & -46.2 & -48.6 \\
MIN & 0.0 & 0.0 & 0.2 & 0.3 & 0.8 & 0.8 & 1.0 & 2.0 & 2.7 & 3.3 \\
PPP & 0.0 & 0.0 & 0.1 & 0.2 & 0.7 & 0.6 & 0.8 & 1.4 & 2.1 & 2.5 \\
FER & 0.0 & 0.0 & -0.1 & -0.1 & -0.3 & 1.3 & 1.4 & 1.5 & 1.2 & 0.8 \\
ORG & 0.0 & 0.0 & -0.1 & -0.1 & -0.2 & 0.7 & 0.7 & 0.7 & 0.4 & 0.1 \\
INO & 0.0 & 0.0 & -0.1 & -0.1 & -0.1 & 1.1 & 1.2 & 1.4 & 1.2 & 0.9 \\
OCR & 0.0 & 0.0 & -0.8 & -1.2 & -3.5 & -4.1 & -5.4 & -9.4 & -13.0 & -15.4 \\
CEM & 0.0 & 0.0 & 0.2 & 0.3 & 0.9 & 3.1 & 3.6 & 5.3 & 6.6 & 7.3 \\
BRT & 0.0 & 0.0 & 0.0 & 0.1 & 0.4 & 3.3 & 3.7 & 5.1 & 5.9 & 6.5 \\
ONM & 0.0 & 0.0 & 0.0 & 0.1 & 0.3 & 0.4 & 0.6 & 1.2 & 1.6 & 1.9 \\
ISM & 0.0 & 0.0 & -0.1 & -0.1 & -0.2 & 1.8 & 2.0 & 2.9 & 4.0 & 4.6 \\
ISP & 0.0 & 0.0 & -0.1 & -0.1 & -0.1 & 0.4 & 0.6 & 1.1 & 1.8 & 2.2 \\
ALU & 0.0 & 0.0 & -0.6 & -0.7 & -1.4 & -1.0 & -1.4 & -2.2 & -1.4 & -1.3 \\
ONF & 0.0 & 0.0 & -0.6 & -0.7 & -1.6 & -1.8 & -2.3 & -3.3 & -2.9 & -3.1 \\
ELE & 0.0 & 0.0 & -4.0 & -5.3 & -12.2 & -17.7 & -23.7 & -37.6 & -40.2 & -45.3 \\
COL & 0.0 & 0.0 & -0.7 & -2.0 & -7.8 & -14.0 & -23.5 & -42.2 & -70.9 & -90.1 \\
CRU & 0.0 & 0.0 & 0.1 & 0.1 & 0.3 & -6.3 & -8.1 & -11.7 & -18.3 & -25.3 \\
MCH & 0.0 & 0.0 & 0.3 & 0.4 & 1.3 & 1.4 & 1.8 & 3.4 & 5.0 & 6.1 \\
FAW & 0.0 & 0.0 & 0.1 & 0.1 & 0.4 & 0.2 & 0.3 & 0.6 & 0.9 & 1.2 \\
TWL & 0.0 & 0.0 & 0.3 & 0.4 & 1.1 & 1.0 & 1.3 & 2.6 & 3.9 & 4.8 \\
TRN & 0.0 & 0.0 & -1.7 & -2.6 & -8.0 & -9.0 & -11.5 & -20.2 & -27.9 & -32.7 \\
SER & 0.0 & 0.0 & 0.3 & 0.5 & 1.3 & 1.3 & 1.7 & 3.0 & 4.2 & 5.0 \\
\hline
\end{tabular}

Table C3: Competitiveness changes between the Fragmented Action Free scenario and the Reference scenario in each year in EU-27 sectors in $\%$

\footnotetext{
${ }^{42}$ The results for OIL, GAS, COL and CRU in late periods appear to be outliers. Obviously, a very strong switch from coal and gas to oil occurs due to the free allocation of allowances for refined oil and coal products. Nonetheless, the relative changes say nothing about the competitiveness index in absolute terms. In absolute terms, the competitiveness index is very low for CRU, COL and GAS, for instance, under Reference as well as Fragmented Action Free. In this sense, the tables show in some cases strong changes in relative terms, but small changes in absolute terms.
} 


\begin{tabular}{|lrrrrrrrrrr|}
\hline & 2005 & 2010 & 2015 & 2020 & 2025 & 2030 & 2035 & 2040 & 2045 & 2050 \\
\cline { 2 - 5 } & 3.3 & 3.9 & -0.5 & -1.2 & 0.6 & 7.6 & 8.0 & 5.7 & 3.0 & 1.7 \\
GAS & 5.1 & 0.7 & 0.4 & 0.0 & 5.7 & 8.0 & 6.8 & 2.0 & -2.0 & -4.2 \\
MIN & -0.2 & -0.2 & -0.1 & -0.1 & -0.7 & -0.9 & -0.8 & -0.5 & -0.1 & 0.1 \\
PPP & -0.2 & -0.2 & 0.0 & 0.1 & -0.6 & -0.8 & -0.7 & -0.3 & 0.1 & 0.3 \\
FER & 0.6 & 0.7 & 0.4 & 0.5 & 0.1 & 0.7 & 0.9 & 0.8 & 0.7 & 0.7 \\
ORG & 0.4 & 0.5 & 0.3 & 0.4 & 0.1 & 0.5 & 0.6 & 0.6 & 0.4 & 0.4 \\
INO & 0.4 & 0.5 & 0.4 & 0.5 & -0.1 & 0.3 & 0.5 & 0.6 & 0.6 & 0.6 \\
OCR & 1.1 & 0.9 & 0.2 & 0.0 & 2.8 & 3.7 & 2.9 & 1.4 & -0.1 & -0.8 \\
CEM & 0.4 & 0.7 & 0.5 & 0.8 & -1.0 & -0.5 & 0.0 & 0.5 & 1.0 & 1.2 \\
BRT & 0.6 & 1.0 & 0.8 & 1.2 & -0.6 & 0.2 & 0.6 & 1.1 & 1.3 & 1.6 \\
ONM & 0.0 & 0.1 & 0.3 & 0.5 & -0.4 & -0.5 & -0.3 & 0.0 & 0.3 & 0.5 \\
ISM & 0.6 & 1.0 & 0.7 & 1.1 & -0.1 & 0.5 & 0.9 & 1.1 & 1.1 & 1.2 \\
ISP & 0.2 & 0.4 & 0.6 & 1.0 & -0.2 & -0.1 & 0.2 & 0.5 & 0.6 & 0.8 \\
ALU & 0.8 & 1.3 & 1.8 & 2.5 & 0.4 & 0.8 & 1.3 & 1.6 & 1.6 & 1.8 \\
ONF & 0.7 & 1.1 & 1.8 & 2.6 & 0.5 & 0.6 & 1.1 & 1.4 & 1.5 & 1.7 \\
ELE & 3.1 & 4.5 & 8.7 & 12.8 & 5.0 & 6.0 & 8.3 & 9.2 & 8.4 & 9.1 \\
COL & 0.6 & 0.4 & 0.8 & 2.2 & 3.4 & 5.5 & 8.5 & 7.9 & 6.0 & 4.3 \\
CRU & -1.5 & -1.7 & 0.7 & 1.1 & -1.4 & -3.5 & -3.3 & -1.9 & -0.3 & 0.7 \\
MCH & -0.4 & -0.3 & -0.1 & -0.1 & -1.0 & -1.4 & -1.1 & -0.6 & 0.0 & 0.2 \\
FAW & -0.1 & -0.2 & -0.1 & -0.1 & -0.3 & -0.5 & -0.4 & -0.3 & -0.1 & 0.0 \\
TWL & -0.4 & -0.3 & -0.2 & -0.1 & -0.8 & -1.2 & -1.0 & -0.5 & -0.1 & 0.1 \\
TRN & 2.3 & 1.9 & 0.0 & -0.6 & 6.7 & 8.8 & 6.6 & 2.9 & -0.5 & -2.1 \\
SER & -0.4 & -0.4 & -0.2 & -0.2 & -1.0 & -1.4 & -1.2 & -0.7 & -0.1 & 0.1 \\
\hline
\end{tabular}

Table C4: Competitiveness changes between the Fragmented Action CDM scenario and the Reference scenario in each year in EU-27 sectors in \% 


\begin{tabular}{|lrrrrrrrrrr|}
\hline & 2005 & 2010 & 2015 & 2020 & 2025 & 2030 & 2035 & 2040 & 2045 & 2050 \\
\cline { 2 - 5 } & 0.0 & 0.0 & 0.1 & 0.4 & 2.9 & -6.2 & -6.1 & -7.0 & -8.5 & -6.1 \\
GAS & 0.0 & 0.0 & -2.7 & -4.3 & -9.2 & -9.8 & -16.0 & -25.8 & -40.7 & -63.1 \\
MIN & 0.0 & 0.0 & 0.2 & 0.3 & 0.7 & 0.5 & 0.3 & 0.2 & -0.1 & -1.5 \\
PPP & 0.0 & 0.0 & 0.1 & 0.2 & 0.5 & 0.5 & 0.2 & 0.2 & 0.4 & 0.0 \\
FER & 0.0 & 0.0 & -0.1 & -0.1 & 1.3 & 2.7 & 7.2 & 15.1 & 23.3 & 33.6 \\
ORG & 0.0 & 0.0 & -0.1 & -0.1 & 0.6 & 1.3 & 3.3 & 7.1 & 12.4 & 20.1 \\
INO & 0.0 & 0.0 & -0.1 & -0.1 & 0.8 & 1.4 & 3.5 & 7.2 & 12.4 & 20.0 \\
OCR & 0.0 & 0.0 & -0.8 & -1.2 & -3.0 & -2.3 & -1.9 & -2.8 & -2.5 & 1.5 \\
CEM & 0.0 & 0.0 & 0.2 & 0.3 & 1.1 & 3.5 & 7.9 & 14.1 & 21.7 & 33.0 \\
BRT & 0.0 & 0.0 & 0.0 & 0.1 & 0.4 & -0.6 & 0.1 & 0.6 & 3.4 & 10.3 \\
ONM & 0.0 & 0.0 & 0.0 & 0.1 & 0.5 & 0.8 & 1.3 & 2.2 & 3.4 & 4.5 \\
ISM & 0.0 & 0.0 & -0.1 & -0.1 & 0.6 & 0.8 & 2.8 & 5.2 & 7.7 & 10.1 \\
ISP & 0.0 & 0.0 & -0.1 & -0.1 & 0.4 & 0.7 & 1.7 & 3.7 & 6.0 & 8.0 \\
ALU & 0.0 & 0.0 & -0.6 & -0.7 & -1.1 & -1.0 & -0.7 & -0.8 & -0.3 & 0.2 \\
ONF & 0.0 & 0.0 & -0.6 & -0.7 & -1.4 & -0.9 & -0.8 & -1.4 & -1.2 & -0.9 \\
ELE & 0.0 & 0.0 & -4.0 & -5.3 & -10.2 & -5.3 & -2.0 & 1.5 & 13.9 & 36.7 \\
COL & 0.0 & 0.0 & -0.7 & -2.0 & -14.0 & -4.4 & 30.1 & 55.2 & 83.1 & 99.4 \\
CRU & 0.0 & 0.0 & 0.1 & 0.1 & -0.8 & 0.4 & -3.6 & -12.1 & -25.3 & -49.6 \\
MCH & 0.0 & 0.0 & 0.3 & 0.4 & 1.0 & 0.6 & -0.1 & -0.5 & -1.6 & -4.9 \\
FAW & 0.0 & 0.0 & 0.1 & 0.1 & 0.1 & -0.1 & -0.7 & -1.5 & -2.5 & -4.0 \\
TWL & 0.0 & 0.0 & 0.3 & 0.4 & 0.9 & 0.7 & 0.2 & 0.4 & 0.6 & -0.3 \\
TRN & 0.0 & 0.0 & -1.7 & -2.6 & -7.7 & -8.0 & -8.8 & -14.4 & -18.4 & -16.6 \\
SER & 0.0 & 0.0 & 0.3 & 0.5 & 1.0 & 0.4 & -0.5 & -1.4 & -3.0 & -7.0 \\
\hline
\end{tabular}

Table C5: Competitiveness changes between the Global Action scenario and the Reference scenario in each year in EU-27 sectors in \% ${ }^{43}$

\footnotetext{
${ }^{43}$ The results for GAS, FER, ELE and COL appear as outliers. The results show a very strong switch towards coal that probably overestimates the real effects. Nonetheless, the relative changes say nothing about the competitiveness index in absolute terms. In absolute terms, the competitiveness index is very low for CRU, COL and GAS, for instance, under Reference as well as Global Action. In this sense, the table shows strong changes in small values.
} 


\begin{tabular}{|lrrrrrrrrrr|}
\hline & 2005 & 2010 & 2015 & 2020 & 2025 & 2030 & 2035 & 2040 & 2045 & 2050 \\
\cline { 2 - 4 } & -10.8 & -4.0 & -17.3 & -21.6 & -22.0 & -9.2 & -10.0 & -13.0 & -22.9 & -20.6 \\
GAS & 15.0 & 1.6 & 4.6 & 8.5 & 11.0 & 15.8 & 20.7 & 32.2 & 25.0 & -15.7 \\
MIN & -0.4 & -0.2 & 0.1 & 0.0 & 0.0 & -0.6 & -0.8 & -1.2 & -1.6 & -3.1 \\
PPP & -0.6 & -0.3 & -0.2 & -0.4 & -0.6 & -1.3 & -1.6 & -2.2 & -2.0 & -2.4 \\
FER & -3.1 & -1.1 & -3.4 & -4.4 & -4.0 & -0.8 & 3.0 & 8.9 & 12.2 & 18.1 \\
ORG & -1.9 & -0.6 & -2.1 & -2.7 & -2.6 & -0.8 & 0.8 & 3.3 & 5.0 & 9.5 \\
INO & -2.7 & -1.0 & -2.7 & -3.6 & -3.8 & -1.9 & -0.3 & 1.8 & 3.0 & 7.2 \\
OCR & 3.2 & 1.2 & 1.0 & 1.9 & 2.5 & 4.3 & 4.7 & 5.3 & 5.4 & 8.9 \\
CEM & -5.4 & -2.1 & -5.4 & -6.9 & -8.4 & -4.1 & -0.5 & 2.3 & 4.2 & 10.0 \\
BRT & -6.4 & -2.6 & -6.8 & -8.8 & -11.2 & -9.0 & -8.9 & -11.4 & -13.9 & -11.3 \\
ONM & -1.7 & -0.7 & -1.2 & -1.6 & -2.0 & -2.1 & -1.8 & -1.9 & -2.4 & -2.6 \\
ISM & -4.1 & -1.5 & -4.6 & -6.0 & -7.2 & -5.0 & -3.7 & -3.0 & -2.6 & -2.3 \\
ISP & -2.5 & -0.9 & -2.2 & -3.0 & -3.8 & -3.4 & -2.9 & -2.1 & -0.9 & -0.4 \\
ALU & -4.9 & -1.9 & -4.6 & -6.5 & -9.0 & -9.3 & -10.2 & -12.3 & -10.9 & -11.1 \\
ONF & -4.3 & -1.7 & -3.7 & -5.4 & -7.9 & -8.6 & -9.7 & -12.0 & -11.0 & -11.4 \\
ELE & -11.8 & -4.8 & -11.8 & -20.3 & -30.9 & -35.7 & -38.8 & -40.8 & -8.7 & 22.1 \\
COL & -1.5 & 0.0 & -0.9 & -3.7 & -23.9 & -44.4 & -17.0 & -76.6 & -77.0 & -73.3 \\
CRU & 1.9 & 0.6 & 5.5 & 6.1 & 4.4 & -2.9 & -5.2 & -10.3 & -15.9 & -28.8 \\
MCH & -0.7 & -0.2 & 0.1 & -0.1 & -0.2 & -1.3 & -2.1 & -3.2 & -4.3 & -7.6 \\
FAW & 0.2 & 0.1 & 0.4 & 0.5 & 0.5 & -0.2 & -0.9 & -1.9 & -2.9 & -4.5 \\
TWL & -0.2 & 0.0 & 0.5 & 0.5 & 0.6 & -0.4 & -1.1 & -1.6 & -1.3 & -2.3 \\
TRN & 7.7 & 2.7 & 2.2 & 4.4 & 5.6 & 9.4 & 8.7 & 7.3 & 2.3 & 3.5 \\
SER & -0.4 & -0.2 & 0.3 & 0.3 & 0.2 & -1.0 & -1.8 & -3.0 & -4.5 & -8.2 \\
\hline
\end{tabular}

Table C6: Competitiveness changes between the Global Action National scenario and the Reference scenario in each year in EU-27 sectors in ${ }^{44}$

\footnotetext{
${ }^{44}$ The results for $\mathrm{COL}$ in late periods appear to be outliers. See the caveats below the previous tables.
} 


\begin{tabular}{|lrrrrrrrrrr|}
\hline & 2005 & 2010 & 2015 & 2020 & 2025 & 2030 & 2035 & 2040 & 2045 & 2050 \\
\cline { 2 - 5 } & 0.0 & 0.0 & 0.1 & 0.4 & 1.2 & 17.7 & 17.6 & 14.1 & 10.7 & 7.6 \\
GAS & 0.0 & 0.0 & -2.7 & -4.3 & 4.3 & 5.1 & 2.4 & -1.1 & 7.8 & -21.0 \\
MIN & 0.0 & 0.0 & 0.2 & 0.3 & -1.2 & -2.0 & -2.3 & -3.1 & -3.9 & -5.6 \\
PPP & 0.0 & 0.0 & 0.1 & 0.2 & -1.1 & -1.9 & -2.2 & -3.2 & -4.5 & -5.8 \\
FER & 0.0 & 0.0 & -0.1 & -0.1 & 0.0 & 4.8 & 8.7 & 14.2 & 19.1 & 25.0 \\
ORG & 0.0 & 0.0 & -0.1 & -0.1 & -0.2 & 1.7 & 3.0 & 5.0 & 7.6 & 12.3 \\
INO & 0.0 & 0.0 & -0.1 & -0.1 & -0.5 & 1.2 & 2.2 & 3.3 & 4.7 & 8.1 \\
OCR & 0.0 & 0.0 & -0.8 & -1.2 & 5.1 & 6.9 & 6.9 & 6.9 & 7.3 & 10.3 \\
CEM & 0.0 & 0.0 & 0.2 & 0.3 & 0.0 & 5.5 & 10.2 & 16.1 & 18.7 & 21.0 \\
BRT & 0.0 & 0.0 & 0.0 & 0.1 & 0.1 & 2.4 & 4.2 & 6.5 & 5.5 & 3.4 \\
ONM & 0.0 & 0.0 & 0.0 & 0.1 & -0.5 & -0.7 & -0.3 & -0.5 & -1.1 & -2.2 \\
ISM & 0.0 & 0.0 & -0.1 & -0.1 & 1.0 & 3.2 & 4.1 & 4.5 & 3.1 & 3.6 \\
ISP & 0.0 & 0.0 & -0.1 & -0.1 & 0.0 & 0.5 & 1.0 & 1.1 & 0.3 & 0.5 \\
ALU & 0.0 & 0.0 & -0.6 & -0.7 & 2.7 & 3.1 & 3.4 & 1.1 & -4.9 & -5.4 \\
ONF & 0.0 & 0.0 & -0.6 & -0.7 & 2.9 & 3.1 & 3.6 & 1.6 & -4.2 & -5.0 \\
ELE & 0.0 & 0.0 & -4.0 & -5.3 & 16.1 & 15.5 & 19.5 & 13.4 & -8.0 & 14.7 \\
COL & 0.0 & 0.0 & -0.7 & -2.0 & 3.7 & 17.7 & 65.2 & 125.4 & 92.8 & -42.1 \\
CRU & 0.0 & 0.0 & 0.1 & 0.1 & -2.0 & -8.2 & -9.8 & -13.0 & -18.4 & -28.8 \\
MCH & 0.0 & 0.0 & 0.3 & 0.4 & -1.5 & -2.6 & -2.8 & -3.6 & -5.0 & -8.3 \\
FAW & 0.0 & 0.0 & 0.1 & 0.1 & -0.4 & -1.4 & -2.1 & -3.5 & -5.2 & -7.4 \\
TWL & 0.0 & 0.0 & 0.3 & 0.4 & -1.2 & -2.2 & -2.1 & -1.9 & -2.1 & -3.3 \\
TRN & 0.0 & 0.0 & -1.7 & -2.6 & 12.2 & 16.2 & 14.7 & 13.9 & 13.9 & 17.1 \\
SER & 0.0 & 0.0 & 0.3 & 0.5 & -1.9 & -3.2 & -3.9 & -5.2 & -6.7 & -10.2 \\
\hline
\end{tabular}

Table C7: Competitiveness changes between the Global Action International scenario and the Reference scenario in each year in EU-27 sectors in $\%^{45}$

\footnotetext{
${ }^{45}$ The $\mathrm{COL}$ in late periods are an obvious outlier to be taken with caution. See the caveats below the previous tables.
} 